\title{
PETROLEUM BIOREFINING FOR POLLUTION PREVENTION
}

FINAL REPORT

(April 1999- March 2002)

Principal Investigator: John J. Kilbane II

847-768-0723, john.kilbane@ gastechnology.org

Report Issue Date: March, 2002

DOE Contract \#: DE-AC26-99BC15219

Submitted by

\section{GAS TECHNOLOGY INSTITUTE}

1700 South Mount Prospect Road

Des Plaines, Illinois 60018

GTI Project No. 61119

Submitted to

FETC AAD Document Control

U.S. Department of Energy

Federal Energy Technology Center

P.O. Box 10940, MS 921-143

Pittsburgh, PA 15236-0940

DOE Technical Project Manager: Kathy Stirling 


\section{DISCLAIMER}

This report was prepared as an account of work sponsored by an agency of the United States Government. Neither the United States Government nor any agency thereof, nor any of their employees, makes any warranty, express or implied, or assumes any legal liability or responsibility for the accuracy, completeness, or usefulness of any information, apparatus, product, or process disclosed, or represents that its use would not infringe privately owned rights. Reference herein to any specific commercial product, process, or service by trade name, trademark, manufacturer, or otherwise does not necessarily constitute or imply its endorsement, recommendation, or favoring by, the United States Government or any agency thereof. The views and opinions of authors expressed herein do not necessarily state or reflect those of the United States Government or any agency thereof. 


\section{ABSTRACT}

The objective of this project was to isolate and characterize thermophilic bacterial cultures that can be used for the selective removal of nitrogen, sulfur, and/or metals in the biorefining of petroleum.

The project was completed on schedule and no major difficulties were encountered. Significant progress was made on multiple topics relevant to the development of a petroleum biorefining process capable of operating at thermophilic temperatures. New cultures capable of selectively cleaving C-N or C-S bonds in molecules relevant to petroleum were obtained, and the genes encoding the enzymes for these unique biochemical reactions were cloned and sequenced. Genetic tools were developed that enable the use of Thermus thermophilus as a host to express any gene of interest, and information was obtained regarding the optimum conditions for the growth of T. thermophilus. The development of a practical biorefining process still requires further research and the future research needs identified in this project include the development of new enzymes and pathways for the selective cleavage of $\mathrm{C}-\mathrm{N}$ or $\mathrm{C}-\mathrm{S}$ bonds that have higher specific activities, increased substrate range, and are capable of functioning at thermophilic temperatures. Additionally, there is a need for process engineering research to determine the maximum yield of biomass and cloned gene products that can be obtained in fed-batch cultures using T. thermophilus, and to determine the best configuration for a process employing biocatalysts to treat petroleum. 


\section{TABLE OF CONTENTS}

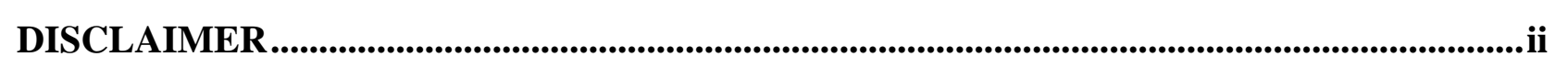

ABSTRACT ..............................................................................................................................................iii

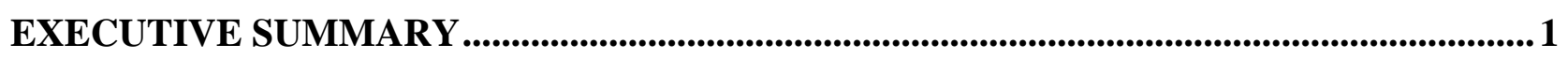

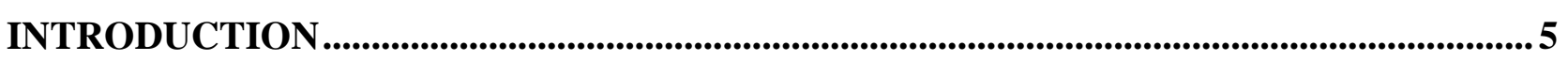

MATERIALS AND METHODS ..........................................................................................10

Bacterial Cultures and Growth Conditions.......................................................................... 10

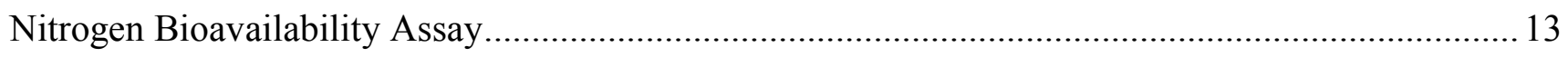

Species Identification................................................................................................... 14

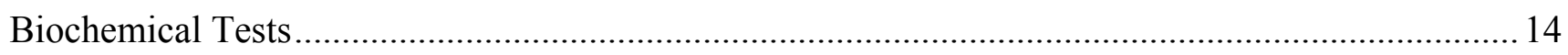

Thin Layer Chromatography for Identification of Metabolites ....................................................... 16

Gas Chromatography-Mass Spectrometry ......................................................................... 17

High Performance Liquid Chromatography ……………........................................................ 17

Reactor Studies: Growth of T. thermophilus (HB27) in a CSTR ……............................................. 18

Minimal Media Experiments with T. thermophilus and T.flavus: ................................................. 19

Genetic Techniques.................................................................................................... 19

Desulfurization Gene Cloning .......................................................................................... 19

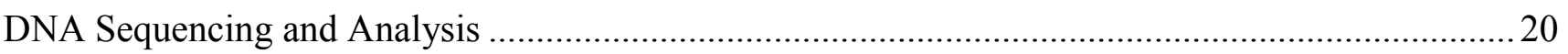

Purification of Desulfurization Enzymes............................................................................20

Biochemical Assays and Analytical Techniques for Desulfurization Enzymes...................................2

Petroleum Experiments...................................................................................................22

RESULTS AND DISCUSSION................................................................................................24

Characterization of a Pyridine-Degrading Culture Anuerinibacillus sp. IGTN4T .............................25

Characterization of a Quinoline-Degrading Culture Gordona sp. IGTN5T.......................................26

Characterization of a Pyridine-Degrading Culture Amycolaptosis sp. IGTN6T ...............................26

Characterization of a Quinazoline-Degrading Thermophilic Culture Bacillus thermoglucosidasius

IGTN7T .......................................................................................................... 27

Characterization of a Quinoline-Degrading Culture Pseudomonas ayucida IGTN9m ......................2

Characterization of a Piperidine-Degrading Culture (Pseudomonas citronellolis IGTN10) ................37

Isolation of Triazine-Utilizing Microorganisms (GTIN8T and GTIN9T) ............................................. 38

Isolation of Carbazole-Utilizing Microorganisms (GTIN11, GTIN12 and GTIN14):.......................... 38 
Culture Isolation and Characterization.

Growth and Characterization of Carbazole Degradation .................................................. 41

Carbazole Degradation Pathway Intermediates Identification............................................. 45

Substrate Range ..................................................................................................... 45

Cloning and characterization of genes involved in carbazole degradation ............................ 48

Nitrogen removal from petroleum................................................................................... 51

Characterization of the Dibenzothiophene-Degrading Thermophile Mycobacterium phlei GTIS10...53

Metabolites of DBT Produced by M. phlei GTIS10 Versus R. erythropolis IGTS8 ..............60

Characterization of the desulfurization genes from M. phlei GTIS10 ............................... 61

Thermotolerance of the desulfurization enzymes. ............................................................ 63

Genetic Expression in Thermus thermophilus ......................................................................... 67

Construction of the promoter probe vectors.................................................................... 68

Isolation of Thermus Promoters.................................................................................... 71

Expression vector Construction ...................................................................................... 72

Construction of Temperature Inducible Expression Vector.................................................. 74

Assay of pTEX-1 and pTEX2-dnak Expression Vectors............................................... 75

Construction of T. thermophilus HB27 and T. flavus Hosts Containing Deletions of the $m d h$

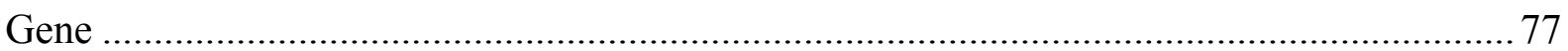

Construction of Thermus vectors containing $m d h$ as a reporter gene. ............................... 78

Malate dehydrogenase activity of Thermus constructs ................................................... 80

Expression of dszC in Thermus thermophilus ...................................................................... 85

Growth Studies with Thermus thermophilus ............................................................................. 92

Growth on Minimal Medium ........................................................................................ 92

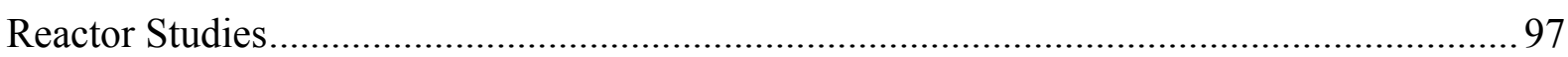

CONCLUSIONS ...........................................................................................................106

REFERENCES ...............................................................................................................109 


\section{LIST OF FIGURES}

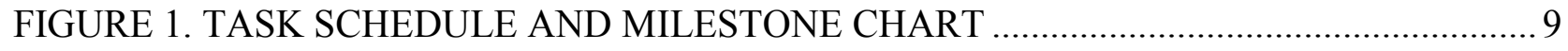

FIGURE 2. COMPARISON OF MS DATA OF A METABOLITE OF QUINOLINE

PRODUCED BY PSEUDOMONAS AYUCIDA IGTN9M WITH 2-QUINOLINONE. ......... 31

FIGURE 3. COMPARISON OF MS DATA OF A METABOLITE OF QUINOLINE PRODUCED

BY PSEUDOMONAS AYUCIDA. IGTN9M WITH 7-HYDROXY-2H-1-BENZOPYRAN-2-

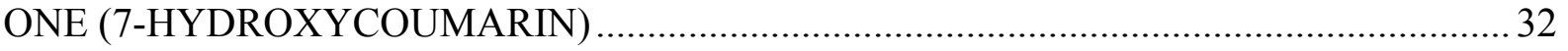

FIGURE 4. SUGGESTED PARTIAL PATHWAY FOR THE DEGRADATION OF QUINOLINE

BY PSEUDOMONAS AYUCIDA IGTN9M. ............................................................. 33

FIGURE 5. BIODEGRADATION PATHWAY FOR PIPERIDINE ..................................... 37

FIGURE 6. BIODEGRADATION PATHWAY FOR CARBAZOLE ......................................40

FIGURE 7. GROWTH OF SPHINGOMONAS SP. GTIN11 IN TT MEDIA AND CARBAZOLE

DEGRADATION.

FIGURE 8. CARBAZOLE METABOLISM BY SPHINGOMONAS SP. GTIN11 AND

PSEUDOMONAS SP. CA10 IN RICH MEDIUM. ................................................ 43

FIGURE 9. EXPONENTIAL PHASE GROWTH OF SPHINGOMONAS SP. GTIN11 (OD A600

NM) AND 2,3-DIHYDROXYBIPHENYL ACTIVITY (OD A434 NM) VS. TIME

(HOURS).

FIGURE 10. GROWTH OF $M$. PHLEI GTIS10 AT 50 C USING DBT AS THE SOLE SULFUR

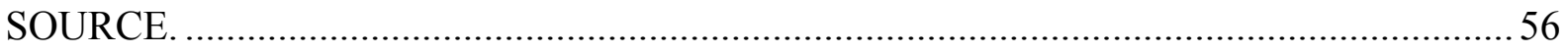

FIGURE 11. RESTING CELLS OF MYCOBACTERIUM PHLEI IGTS10 EXHIBIT

DESULFURIZATION ACTIVITY AT SIGNIFICANTLY HIGHER TEMPERATURES

THAN RESTING CELLS OF RHODOCOCCUS ERYTHROPOLIS IGTS8. ....................64

FIGURE 12. THE CONSTRUCTION OF PLASMID PROMOTER PROBE VECTORS

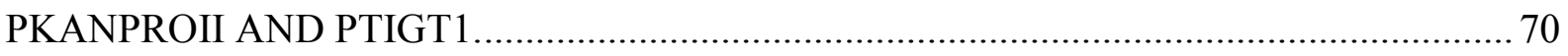

FIGURE 13. CONSTRUCTION OF THE PTEX EXPRESSION VECTORS...........................73

FIGURE 14. EXPRESSION VECTOR PTEX2 DNAK.................................................... 75

FIGURE 15. CONSTRUCTION OF THERMUS THERMOPHILUS $\triangle M D H K^{\mathrm{R}}$ MM8-5 ........82

FIGURE 16. CONSTRUCTION OF THERMUS EXPRESSION VECTORS............................84

FIGURE 17. DBT DESULFURIZATION REACTION CATALYZED BY MYCOBACTERIUM

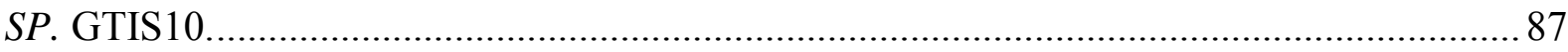

FIGURE 18. CLONING OF THE DSZC GENE OF MYCOBACTERIUM SP. GTIS10 INTO

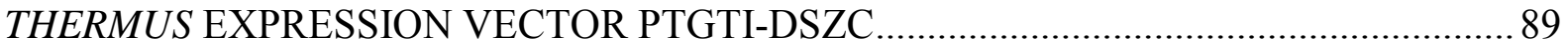

FIGURE 19. HPLC ANALYSES DEMONSTRATING THE CONVERSION OF DBT TO DBT-

SULFONE BY T. THERMOPHILUS HB27/PTGTI-DSZC ...................................... 90

FIGURE 20. MALATE DEHYDROGENASE LEVELS OF VARIOUS T. THERMOPHHUS

STRAINS. 
FIGURE 21. DISSOLVED OXYGEN LEVELS OF T. THERMOPHILUS HB27 CULTURES AT

VARIOUS AERATION AND AGITATION RATES ..................................................... 103

FIGURE 22. GROWTH RATE OF T. THERMOPHILUS HB27 IN RICH MEDIUM AT

VARIOUS AGITATION-AERATION RATES ................................................................104 


\section{LIST OF TABLES}

TABLE 1: SUMMARY OF PURE CULTURES USING ORGANONITROGEN/SULFUR AS THE

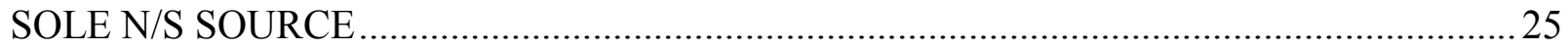

TABLE 2. TIME COURSE OF ACCUMULATION OF QUINOLINE METABOLITES

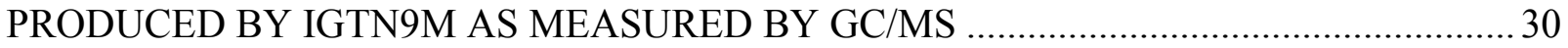

TABLE 3. BIOTREATMENT OF SHALE OIL WITH PSEUDOMONAS AYUCIDA IGTN9M ......36 TABLE 4. METABOLITES OF VARIOUS PRODUCED BY RESTING CELL CULTURES OF SPHINGOMONAS SP. GTIN11 AS DETECTED BY THIN LAYER CHROMATOGRAPHY

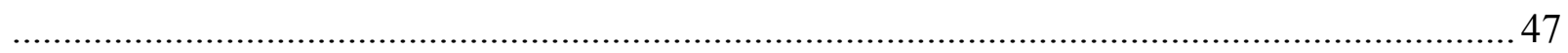

TABLE 5. DEDUCED AMINO ACID SEQUENCE OF SPHINGOMONAS SP. GTIN11 CARBAZOLE OPERON AND PERCENT SIMILARITY TO OTHER GENE PRODUCTS.49

TABLE 6. AS MUCH AS 95\% OF THE CARBAZOLE PRESENT IN SHALE OIL WAS REMOVED AS A CONSEQUENCE OF BIOTREATMENT WITH SPHINGOMONAS SP. GTIN11.

TABLE 7. RANGE OF ORGANOSULFUR SUBSTRATES UTILIZED AS A SOLE SOURCE OF

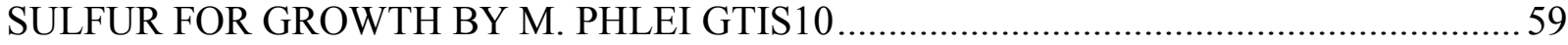

TABLE 8. THE RELATIVE ABUNDANCE OF METABOLITES OF DIBENZOTHIOPHENE PRODUCED BY M. PHLEI GTIS10 DIFFERS FROM R. ERYTHROPOLIS IGTS8 .......... 61

TABLE 9. AMOUNT OF MALATE DEHYDROGENASE ACTIVITY OF THERMUS EXPRESSION VECTOR CONSTRUCTS

TABLE 10. MALATE DEHYDROGENASE ACTIVITY OF THERMUS VECTOR CONSTRUCTS.

TABLE 11: GRAECO LATIN SQUARE MATRIX FOR T. FLAVUS GROWTH IN MINIMAL

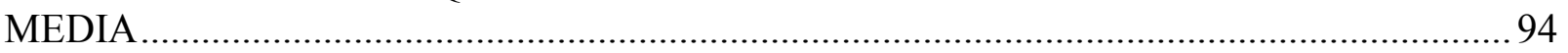

TABLE 12: GRAECO LATIN SQUARE MATRIX FOR T. THERMOPHILUS GROWTH IN

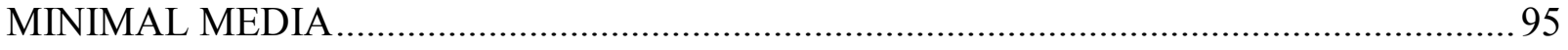

TABLE 13: GROWTH OF PROTOTROPH HB28 IN MINIMAL MEDIA.................................97

TABLE14. THE OXYGEN TRANSFER RATE, MAXIMUM GROWTH RATE, DOUBLING TIME, AND MAXIMUM CELL YIELDS OF T. THERMOPHILUS HB27 AT DIFFERENT AERATION AND AGITATION RATES 


\section{EXECUTIVE SUMMARY}

The objective of this project was to isolate and characterize bacterial cultures, particularly thermophilic cultures, that can be used for the selective removal of nitrogen, sulfur, and/or metals in the biorefining of petroleum. In order to accomplish this objective bacterial cultures capable of selectively cleaving carbon-nitrogen and carbon-sulfur bonds were isolated, and these cultures were characterized microbiologically, biochemically, and genetically. Additionally, $T$. thermophilus was developed to serve as an efficient host for the expression of cloned genes and to be grown efficiently using simple low cost ingredients.

Enrichment culture experiments were performed to isolate bacterial cultures capable of utilizing model compounds or petroleum as sole sources of nitrogen or sulfur. The model compounds employed in enrichment culture experiments were chosen to be representative of chemical structures of organonitrogen or organosulfur compounds present in petroleum and these chemicals included: carbazole, dibenzothiophene, isoquinoline, morpholine, piperidine, porphyrin, pyridine, pyrrolidine, triazine, quinoline, and quinazoline. While numerous cultures were obtained that could utilize organonitrogen or organosulfur compounds as sole sources of nitrogen or sulfur for growth it proved difficult to isolate bacterial cultures that could selectively cleave carbon-nitrogen or carbon-sulfur bonds, or to isolate cultures that could metabolize a broad range of substrates. Most cultures obtained nitrogen or sulfur from the overall degradation of compounds, but culture characterization and screening activities focused on the identification of cultures that selectively cleaved $\mathrm{C}-\mathrm{N}$ or $\mathrm{C}-\mathrm{S}$ bonds. The most interesting cultures obtained and characterized were Pseudomonas ayucida IGTN9m, Sphingomonas sp. GTIN11, and Mycobacterium phlei GTIS10.

Pseudomonas ayucida IGTN9m was shown to be capable of selectively cleaving C-N bonds in quinoline. Examination of metabolites using thin-layer chromatography and gas chromatography-mass spectrometry indicated that Pseudomonas ayucida IGTN9m converts quinoline to 2-quinolinone and subsequently to 8-hydroxycoumarin. Resting cells of Pseudomonas ayucida IGTN9m could selectively remove $68 \%$ of quinoline from petroleum in a 16-hour treatment time. However, there was no significant decrease in the total nitrogen content of the oil. A description of the characterization of Pseudomonas ayucida IGTN9m was published in Applied \& Environmental Microbiology 66: 688-693 (2000). The substrate range for the 
cleavage of C-N bonds by Pseudomonas ayucida IGTN9m was limited to quinoline so the search for more versatile bacterial cultures continued.

Sphingomonas sp. GTIN11 was shown to be capable of utilizing carbazole, and chemically related compounds, as a sole source of nitrogen. Moreover, Sphingomonas sp. GTIN11 removed up to $95 \%$ of carbazole from petroleum. However, there was no significant decrease in the total nitrogen content of the oil. Biochemical investigations revealed that Sphingomonas sp. GTIN11 selectively cleaved one of the two C-N bonds in carbazole, but subsequently degraded the carbazole molecule in the course of liberating nitrogen. A manuscript describing the characterization of Sphingomonas sp. GTIN11 has been submitted for publication to Applied \& Environmental Microbiology.

It was determined that it was unlikely that naturally occurring bacteria would be isolated that could selectively cleave $\mathrm{C}-\mathrm{N}$ bonds in a wide range of organonitrogen substrates so that genetic engineering may be a more productive approach to obtain bacterial cultures with desired properties. Accordingly, the genes encoding the carbazole degradation pathway of Sphingomonas sp. GTIN11 were cloned and sequenced. The genes from Sphingomonas sp. GTIN11 that are responsible for the selective cleavage of the first C-N bond in carbazole were identified and can be used in future studies to construct a new pathway that will encode for enzymes that allow the selective cleavage of both $\mathrm{C}-\mathrm{N}$ bonds in carbazole. Then these genes can be the target of future directed evolution experiments to obtain cultures capable of metabolizing a wider range of organonitrogen compounds.

An organism, identified as Mycobacterium phlei GTIS10, was isolated based on its ability to use dibenzothiophene (DBT) as a sole source of sulfur for growth at $30^{\circ} \mathrm{C}-52^{\circ} \mathrm{C}$. Similar to other biodesulfurization competent organisms $M$. phlei GTIS10 converts DBT to 2-hydroxybiphenyl (2-HBP). The specific desulfurization activity of the $50^{\circ} \mathrm{C} \mathrm{M}$. phlei GTIS10 culture was determined to be $1.1 \pm 0.07 \mu$ mole 2-HBP/min g-dry cell. $M$. phlei GTIS10 can also utilize benzothiophene and thiophene as sulfur sources for growth. The $d s z A B C$ operon of M. phlei GTIS10 was cloned and sequenced and was found to be identical to that of Rhodococcus erythropolis IGTS8. The presence of the R. erythropolis IGTS8 120-kb plasmid pSOX, which encodes the $d s z A B C$ operon, has been demonstrated in M. phlei GTIS10. Even though identical $d s z$ genes are contained in both cultures the temperature at which resting cells of $R$. erythropolis IGTS8 reach the highest rate of DBT metabolism is near $30^{\circ} \mathrm{C}$ whereas the temperature that 
shows the highest activity of resting cell cultures of $M$. phlei GTIS10 is near $50^{\circ} \mathrm{C}$, and activity is detectable at temperatures as high as $57^{\circ} \mathrm{C}$. In $M$. phlei GTIS10 the rate limiting step in vivo appears to be the conversion of DBT to dibenzothiophene sulfone $\left(\mathrm{DBTSO}_{2}\right)$ catalyzed by the product of the $d s z C$ gene, dibenzothiophene monooxygenase. The thermostability of individual desulfurization enzymes was determined and 2-hydroxybiphenyl-2-sulfinate sulfinolyase, encoded by $d s z B$, was found to be the most thermolabile. These results demonstrate that the thermostability of individual enzymes determined in vitro are not necessarily good predictors of the functional temperature range of enzymes in vivo. A manuscript characterizing $M$. phlei GTIS10 was submitted for publication to Applied Microbiology and Biotechnology and is currently In Press.

If genetic engineering is to be used to develop bioprocesses capable of operating at high temperatures, then it will be necessary to use a thermophile as the bacterial host in genetic experiments. While many genes from thermophiles have been cloned and expressed in mesophilic hosts, genetic tools and techniques for the expression of cloned genes in thermophiles are lacking. To address this issue shuttle vectors, promoter probe vectors, and expression vectors were constructed for use in the extreme thermophile Thermus thermophilus. T. thermophilus is a gram-negative microorganism that grows aerobically at temperatures between $50^{\circ}$ and $82^{\circ} \mathrm{C}$. Both integrative and plasmid vectors were constructed that allow the convenient cloning and expression of genes in T. thermophilus. Promoters that allow inducible expression of genes in $T$. thermophilus, and reporter genes that allow accurate and convenient quantification of gene expression in T. thermophilus were constructed. Descriptions of these genetic tools have been published (Journal of Bacteriology 183: 1792-1795 (2001), and Letters in Applied Microbiology 32: 412-418 (2001)) and these tools were used for the expression of desulfurization genes from M. phlei GTIS10 in T. thermophilus. Future studies can further use these tools to develop high temperature bioprocesses for a variety of applications.

The final topic addressed in this project was the growth of T. thermophilus. Most bioprocesses currently employ the mesophilic microorganism Escherichia coli because genetic tools and fermentation technology are well developed for this microorganism. The application of thermophilic bacteria in bioprocesses has several advantages such as high metabolic activity, decreased viscosity of substrates, increased solubility of nongaseous substrates, little to no cooling required, low contamination risk, and improved process stability and ability to tolerate 
excursions of $\mathrm{pH}$ and exposure to solvents. However, information on the growth and fermentation of $T$. thermophilus is highly limited, and before viable bioprocesses can be designed using a thermophilic host such as T. thermophilus more data is needed. To address this need, batch fermentations were performed using T. thermophilus in rich medium to study the effects of aeration and agitation rates on oxygen transfer, growth rates and biomass yield. The cell yields obtained in this study, $3 \mathrm{~g} / \mathrm{L}$, were higher than any previously published reports for growth of Thermus cultures, including studies that employed pressurized bioreactors. A publication summarizing these data was submitted to the Journal of Biosciences \& Bioengineering and is currently In Press.

In summary, significant progress was made on multiple topics relevant to the development of a petroleum biorefining process capable of operating at thermophilic temperatures. New cultures capable of selectively cleaving C-N or C-S bonds in molecules relevant to petroleum were obtained, and the genes encoding the enzymes for these unique biochemical reactions were cloned and sequenced. Genetic tools were developed that enable the use of $T$. thermophilus as a host to express any gene of interest, and information was obtained regarding the optimum conditions for the growth of $T$. thermophilus. The development of a practical biorefining process still requires further research and the future research needs identified in this project include the development of new enzymes and pathways for the selective cleavage of C-N or C-S bonds that have higher specific activities, increased substrate range, and are capable of functioning at thermophilic temperatures. Additionally, there is a need for process engineering research to determine the maximum yield of biomass and cloned gene products that can be obtained in fed-batch cultures using $T$. thermophilus, and to determine the best configuration for a process employing biocatalysts to treat petroleum. 


\section{INTRODUCTION}

With the decline in the production of light and medium weight crude oils, refineries will increasingly be forced to process heavier and sour crudes. These crude oils are high in sulfur, nitrogen and metals. Sulfur fouls catalysts and corrodes surfaces in contact during crude oil processing. In automobiles, it poisons the catalytic converters responsible for the removal of pollutants (nitrogen oxides) from the exhaust of automobiles. The combustion of sour fuels is also a source of environmental pollution since the sulfur oxides combine with atmospheric water to form sulfuric acid. The U.S. Environmental Protection Agency (EPA) has proposed new regulations to reduce the sulfur level in gasoline from $300 \mathrm{ppm}$ to $30 \mathrm{ppm}$. Meeting these standards will require huge expenditures by the petroleum industry in the form of capital and operating costs. The existing hydrodesulfurization technology uses an energy and capital-intensive packed bed system, which employs chemical catalysts at very high temperatures and pressures.

Similarly nitrogen in petroleum can foul catalysts decreasing the efficiency of hydrotreating and catalytic cracking processes. The heavier gas oils and residua contain both basic and non-basic nitrogen compounds. The basic nitrogen compounds include pyridine, quinoline, acridine, phenanthridine, and their derivatives. These are responsible for poisoning of FCC catalysts by the reaction of the basic compounds with the acidic sites of the catalyst. The non-basics are predominantly mixed alkyl derivatives of carbazole and account for $70-75 \%$ of the total nitrogen content of crude oil $(0.3 \% \mathrm{~N})$. The neutralization of the active acid sites results in deactivation of the catalyst. Nitrogen poisoning also affects the selectivity of the reaction. Carbazole, a major constituent of the non-basic portion (and hence of the total nitrogen present), gets converted into basic derivatives during the cracking process and adsorbs and poisons the catalyst. Nitrogen compounds in petroleum foul catalysts and thus decrease the efficiency of the existing hydrotreating and catalytic cracking processes. In addition to catalyst fouling, nitrogen compounds also promote corrosion of the equipment. Also, the combustion of nitrogen compounds leads to formation of nitrogen oxides (NOx) which, in the presence of other hydrocarbons (VOCs:volatile organic compounds) and sunlight lead to ozone formation. Both ozone and NOx are hazardous to human health. Removal of these organonitrogen 
compounds will not only significantly improve the efficiency of the catalytic cracking process and result in cost savings for the refinery but also decrease atmospheric pollution.

There is then a need to develop alternate cost-effective and energy-efficient technologies for the removal of sulfur, nitrogen and metals. Existing thermochemical processes, such as hydrodesulfurization, can efficiently remove much of the sulfur and nitrogen from petroleum but the selective removal of all organically bound sulfur and nitrogen, and the removal of metals cannot be efficiently accomplished using currently available technologies. The specificity of biochemical reactions far exceeds that of chemical reactions. Moreover biorefining can be performed at comparatively low temperatures and pressures and does not require hydrogen thus avoiding a significant amount of operating costs associated with the conventional hydrodesulfurization process. The selective removal of sulfur from dibenzothiophene by biochemical reactions performed by a mesophilic microorganism has been demonstrated and this technology is now being commercialized for the biorefining of petroleum. Biorefining can also potentially be used to remove nitrogen and metals from petroleum, but so far this area of research has received very little attention.

The objectives of this project were to use enrichment culture and directed evolution techniques to identify and/or develop thermophilic microbial cultures that can be used in the biorefining of petroleum with an emphasis on the removal of nitrogen from petroleum.

Since petroleum is often produced, transported, and processed at elevated temperatures thermophilic microorganisms/enzymes that can function at temperatures ranging from 60 to $100^{\circ} \mathrm{C}$ may be the most appropriate microorganisms to examine for biorefining applications. Performing biorefining processes at higher temperatures is compatible with existing industry practices and may also result in higher catalytic rates. The reduced viscosity of petroleum at higher temperatures will allow lower processing costs. Microorganisms which function at thermophilic temperatures can often also function at mesophilic/ambient temperatures; whereas, mesophilic microorganisms almost never function at thermophilic temperatures. Therefore, the isolation of thermophilic cultures capable of selectively removing organic nitrogen from petroleum should result in a highly flexible biorefining process that can be used at a wide range of 
temperatures. Thermophilic microorganisms have not been well studied and no systematic examination of thermophilic cultures for possible use in biorefining has been reported. Moreover studies seeking to identify or develop cultures, thermophilic or otherwise, for the removal of nitrogen or metals from petroleum are rare.

The approach that was taken in this project was to use screening and enrichment culture selection techniques to examine established collections of thermophiles, as well as thermophiles that may be isolated from environmental samples, for use in biorefining specifically for the removal of nitrogen or sulfur. Screening of cultures assessed their ability to metabolize organonitrogen or organosulfur compounds. Screening was performed using growth assays and chemical analyses. The ability to metabolize quinoline, carbazole, pyridine, and/or porphyrin is important as these compounds are notorious for catalyst fouling in cracking operations and are representative of organonitrogen compounds in petroleum that are not easily removed by existing technology. Because metals are often chelated by nitrogen-containing compounds, by metabolizing nitrogen-containing compounds it may be possible to simultaneously allow the selective removal of nitrogen and metals, chiefly nickel and vanadium, from petroleum. Likewise dibenzothiophene serves as a model organosulfur compound typical of molecules present in petroleum. Any cultures that were found to metabolize quinoline, quinazoline, carbazole, pyridine, porphyrin and/or dibenzothiophene, as detected by growth, spectrophotometric or chromatographic assays, were examined to determine if selective cleavage of carbon-nitrogen (or carbon-sulfur) bonds or if generalized degradation of these substrates occurred. Microorganisms capable of selective bond cleavage are preferred, if not requisite, for use in biorefining. Any culture that showed promise for use in biorefining was characterized to more thoroughly determine/document the ability of the cultures to metabolize model compounds. Then cultures with superior abilities were tested for the removal of organonitrogen, organosulfur and/or metals from crude oil and/or petroleum products.

Thus far naturally occurring microorganisms have not been found that produce $\mathrm{C}$ $\mathrm{N}$ or C-S bond-cleaving enzymes in sufficient abundance to support a viable commercial process. A successful biorefining process may then require the use of genetic techniques to achieve high levels of expression of $\mathrm{C}-\mathrm{N}$ or $\mathrm{C}-\mathrm{S}$ bond-cleaving enzymes and the ability 
to inexpensively grow large quantities of biocatalyst. Accordingly, additional goals of this project were to develop and demonstrate the use of genetic techniques for the expression of cloned genes in the extreme thermophile Thermus thermophilus, and to determine the optimum conditions for the growth of $T$. thermophilus using inexpensive ingredients. 
FIGURE 1. TASK SCHEDULE AND MILESTONE CHART

\begin{tabular}{|c|c|c|c|c|c|c|c|c|c|c|c|c|c|}
\hline $\begin{array}{l}\text { Task } \\
\text { No. }\end{array}$ & Task description & $\begin{array}{c}\mathbf{Q 1} \\
4-99 \\
\text { to } \\
6-99\end{array}$ & $\begin{array}{c}\mathbf{Q 2} \\
7-99 \\
\text { to } \\
9-99\end{array}$ & $\begin{array}{c}\mathbf{Q 3} \\
10-99 \\
\text { to } \\
12-99 \\
\end{array}$ & $\begin{array}{c}\mathbf{Q 4} \\
1-00 \\
\text { to } \\
3-00\end{array}$ & $\begin{array}{c}\text { Q5 } \\
4-00 \\
\text { to } \\
6-00\end{array}$ & $\begin{array}{c}\text { Q6 } \\
7-00 \\
\text { to } \\
9-00\end{array}$ & $\begin{array}{c}\mathbf{Q 7} \\
10-00 \\
\text { to } \\
12-00\end{array}$ & $\begin{array}{c}\text { Q8 } \\
1-01 \\
\text { to } \\
3-01\end{array}$ & $\begin{array}{c}\text { Q9 } \\
4-01 \\
\text { to } \\
6-01 \\
\end{array}$ & $\begin{array}{c}\mathbf{Q 1 0} \\
7-01 \\
\text { to } \\
9-01 \\
\end{array}$ & $\begin{array}{c}\text { Q11 } \\
10-01 \\
\text { to } \\
12-01 \\
\end{array}$ & $\begin{array}{c}\text { Q12 } \\
1-02 \\
\text { to } \\
3-02\end{array}$ \\
\hline 1 & $\begin{array}{l}\text { Substrate Range of Existing } \\
\text { Cultures }\end{array}$ & $\mathrm{X}$ & $\mathrm{X}$ & X M1 & & & & & & & & & \\
\hline 2 & $\begin{array}{l}\text { Petroleum Testing of Existing } \\
\text { Cultures }\end{array}$ & & $\mathrm{X}$ & $\mathrm{X}$ & $\mathrm{X}$ & $\begin{array}{l}\mathrm{X} \\
\mathrm{M} 2\end{array}$ & & & & & & & \\
\hline 3 & Isolation of New Cultures & $\mathrm{X}$ & $\mathrm{X} \mathrm{M} 3$ & $\mathrm{X}$ & $\mathrm{X}$ & $\mathrm{X}$ & $\mathrm{X}$ & $\mathrm{X}$ & $\mathrm{X}$ & $\mathrm{X}$ & $\mathrm{X}$ & $\mathrm{X}$ & \\
\hline 4 & $\begin{array}{l}\text { Culture Identification and } \\
\text { Microbiological Characterization }\end{array}$ & & $\mathrm{X}$ & $\mathrm{X}$ & $\begin{array}{l}\mathrm{X} \\
\mathrm{M} 4\end{array}$ & $\mathrm{X}$ & $\mathrm{X}$ & $\mathrm{X}$ & $\mathrm{X}$ & $\mathrm{X}$ & $\mathrm{X}$ & $\mathrm{X}$ & $\bar{X}$ \\
\hline 5 & Substrate Range of New Cultures & & & & & $\mathrm{X}$ & $\mathrm{X}$ & $\mathrm{X}$ & $\mathrm{X}$ & $\begin{array}{ll}\mathrm{X} \\
\mathrm{M} 5 \\
\end{array}$ & $\mathrm{X}$ & $\mathrm{X}$ & $\mathrm{X}$ \\
\hline 6 & Petroleum Testing of New Cultures & & & & & & & $\mathrm{X}$ & $\mathrm{X}$ & $\mathrm{X}$ & X M6 & & \\
\hline 7 & $\begin{array}{l}\text { Genetic Characterization of } \\
\text { Carbazole Degraders }\end{array}$ & & & & & & & & & $\mathrm{X}$ & X M7 & $\mathrm{X}$ & \\
\hline 8 & $\begin{array}{l}\text { Optimization of } T \text {. thermophilus } \\
\text { Fermentation }\end{array}$ & & & & & & & & & $\mathrm{X}$ & $\mathrm{X}$ & $\mathrm{X}$ & X M8 \\
\hline 9 & Management and Reporting & $\mathrm{X}$ & $\mathrm{X}$ & $\mathrm{X}$ & $\mathrm{X}$ & $\mathrm{X}$ & $\mathrm{X}$ & $\mathrm{X}$ & $\bar{X}$ & $\mathrm{X}$ & $\mathrm{X}$ & $\mathrm{X}$ & $\mathrm{X}$ \\
\hline
\end{tabular}

$\mathrm{M} 1=$ The ability of existing cultures to selectively cleave $\mathrm{C}-\mathrm{N}$ bonds is determined.

M2 = The ability of existing cultures to remove nitrogen/metals from petroleum is determined.

M3 = Enrichment culture and chemostat experiments are initiated.

M4 = A culture with demonstrated ability to cleave $\mathrm{C}-\mathrm{N}$ bonds will be available.

M5 = The substrate range of $\mathrm{C}-\mathrm{N}$ bond cleaving cultures will be determined.

M6 = The ability of the best cultures to remove nitrogen/metals from petroleum will be determined.

M7 $=$ Genes involved in carbazole degradation will be identified and cloned .

M8 = The maximum cell and cloned product yield from fermentations employing T. thermophilus will be determined. 


\section{MATERIALS AND METHODS}

\section{Bacterial Cultures and Growth Conditions}

Environmental samples of soil and/or water were obtained from volcanic vent sites, petroleum and coal processing sites, compost, Wisconsin Dells tannic-acid-contaminated site, and other sites where conditions conducive to the growth of thermophiles prevail. Pseudomonas sp. CA10 was a gracious gift from Dr. Hideaki Nojiri, The University of Tokyo. E. coli DH5 $\alpha$ was obtained from Gibco BRL Life Technologies (Gaithersburg, MD).

The environmental samples were used to inoculate nutristat and shake flask directed evolution/enrichment culture experiments to obtain cultures that may be suitable for the metabolism of organonitrogen compounds. Multiple nutristats were set up employing a defined mineral salts medium $(\operatorname{Mod} A)$ :

$\begin{array}{ll}\mathrm{KH}_{2} \mathrm{PO}_{4} & 0.37 \mathrm{~g} / \mathrm{L} \\ \mathrm{MgSO}_{4} \cdot 7 \mathrm{H}_{2} \mathrm{O} & 0.25 \mathrm{~g} / \mathrm{L} \\ \mathrm{CaCl}_{2} \cdot 2 \mathrm{H}_{2} \mathrm{O} & 0.07 \mathrm{~g} / \mathrm{L} \\ \mathrm{FeCl}_{3} & 0.02 \mathrm{~g} / \mathrm{L} \\ \text { Glucose/glycerol/succinate } & 20.0 \mathrm{~g} / \mathrm{L}\end{array}$

This medium was adjusted to $\mathrm{pH} 6.5$ to 7 and nitrogen was supplied in the form of an organonitrogen test compound in the $3-20 \mathrm{mM}$ concentration range. For the positive nitrogen control, $10 \mathrm{mM} \mathrm{NH}_{4} \mathrm{Cl}(0.535 \mathrm{~g} / \mathrm{L})$ was used.

When sulfur-free medium was needed the ingredients used were:

$\begin{array}{lc}\mathrm{KH}_{2} \mathrm{PO}_{4} & 2.44 \mathrm{~g} / \mathrm{L} \\ \mathrm{Na}_{2} \mathrm{HPO}_{4} & 5.57 \mathrm{~g} / \mathrm{L} \\ \mathrm{NH}_{4} \mathrm{Cl} & 2.0 \mathrm{~g} / \mathrm{L} \\ \mathrm{MgCl}_{2} . & 0.20 \mathrm{~g} / \mathrm{L} \\ \mathrm{CaCl}_{2} .2 \mathrm{H}_{2} \mathrm{O} & 0.001 \mathrm{~g} / \mathrm{L} \\ \mathrm{FeCl}_{3} & 0.001 \mathrm{~g} / \mathrm{L} \\ \mathrm{Glucose}_{\text {glycerol} / \text { succinate }} & 20.0 \mathrm{~g} / \mathrm{L}\end{array}$


The rich media used for the growth of Thermus thermophilus cultures is TT medium (ATCC medium 697) which has the following composition.

$\begin{array}{ll}\text { TT medium: } & \\ \text { Yeast Extract } & 4 \mathrm{~g} / \mathrm{L} \\ \text { Polypeptone } & 8 \mathrm{~g} / \mathrm{L} \\ \mathrm{NaCl} & 2 \mathrm{~g} / \mathrm{L}\end{array}$

Nitrogen-free medium A2 is composed of $5.0 \mathrm{~g}$ glucose, $6.3 \mathrm{~g} \mathrm{KH}_{2} \mathrm{PO}_{4}, 8.0 \mathrm{~g} \mathrm{~K}_{2} \mathrm{HPO}_{4}$, $0.2 \mathrm{~g} \mathrm{MgSO}_{4}, 1.0 \mathrm{ml}$ vitamin solution and $2.0 \mathrm{ml}$ metal solution per liter. The vitamin solution contains $400 \mathrm{mg}$ Ca-pantothenate, $400 \mathrm{mg}$ niacin, $400 \mathrm{mg}$ pyridoxine-HCL, $200 \mathrm{mg}$ inositol, 200 $\mathrm{mg}$ p-aminobenzoate, $200 \mathrm{mg}$ D-biotin, $50 \mathrm{mg}$ riboflavin, $50 \mathrm{mg}$ folic acid, $15 \mathrm{mg}$ thiamine $\mathrm{HCL}$ and $50 \mathrm{mg}$ cyanocobalamin per liter of distilled water. The metal solution contains $100 \mathrm{mg}$ $\mathrm{MnSO}_{4}, 31.7 \mathrm{mg} \mathrm{CuCl} 2,25 \mathrm{mg}\left(\mathrm{NH}_{4}\right)_{6} \mathrm{Mo}_{7} \mathrm{O}_{24}, 20 \mathrm{mg} \mathrm{H} \mathrm{BO}_{3}, 25 \mathrm{mg} \mathrm{Co}\left(\mathrm{NO}_{3}\right)_{2}, 25 \mathrm{mg} \mathrm{ZnCl}_{2}$ and $10 \mathrm{mg} \mathrm{NH}_{4} \mathrm{VO}_{3}$ per liter of distilled water. Nitrogen, either an ammonium salt or an organic compound, was added at concentrations ranging from 0 to $1 \mathrm{mM}$. Cultures were grown at $37^{\circ} \mathrm{C}$.

Nutristats and shake flasks were operated at temperatures of 25 (room temperature), 37, $45,50,55,59$, and $65^{\circ} \mathrm{C}$. The working volume of nutristats is one liter and shake flask experiments generally utilize 25 to $100 \mathrm{~mL}$ of liquid medium. The organonitrogen test compound is routinely varied during the course of operation of the nutristats/shake flask experiments. Nutristats are operated in series so that the effluent of one nutristat serves as the influent for the next. Quinoline, pyridine, quinazoline, quinoxaline, piperidine, pyrolidine, triazine or other test compounds are added to the fresh media influent at concentrations of 3 $20 \mathrm{mM}$. Flow rates of the nutristats are adjusted to achieve hydraulic retention times ranging from 35 hours to 60 hours. The flow rates and the organonitrogen test compound are altered as needed to ensure that the nutristats create an environment suitable for the selection of cultures with improved abilities to selectively cleave C-N bonds. This means that the bacterial cell density in the nutristats/shake flasks ranges from $10^{2}$ to $10^{8}$ cells $/ \mathrm{mL}$, but generally cell densities of $10^{4}$ to $10^{5}$ cells $/ \mathrm{mL}$ are maintained. The bacteria isolated from the effluent of nutristats and/or from shake flasks or nitrogen bioavailability assays are subjected to short wave ultraviolet (UV) irradiation. Cell populations are mutagenized under conditions that result in the death of about $99 \%$ of the population. The mutagenized cells are then used to reinoculate nutristats, start 
additional shake flask experiments, and to streak onto agar plates containing organonitrogen test compounds. Care is taken to ensure that the amount of biomass that is added back to nutristats in the form of inocula is insufficient to provide a significant amount of nitrogen in the form of dead biomass. Hence significant bacterial growth in the nutristat experiments should be due to the utilization of nitrogen from the organonitrogen test compounds and not from readily available sources such as dead biomass. The effluent of nutristats and cells from shake flasks and from agar plates are routinely tested using the nitrogen bioavailability assay.

Land treatment has been successfully used to treat hydrocarbon-contaminated soils. Composting of petroleum-contaminated soil was hence initiated in the laboratory to create an environment where thermophiles can thrive in the presence of petroleum. This serves as a potential source of microorganisms that use crude oil or shale oil as the sole carbon, nitrogen or sulfur source.

The composting was done in a bucket using the following:

$\begin{array}{ll}\text { Sand } & 20 \mathrm{lbs} \\ \text { Twigs/Straw } & 2 \mathrm{dm}^{3} \\ \text { Mod A medium } & 800 \mathrm{~mL} \\ \text { DBC Plus } & 1 \mathrm{gm} \\ \text { Crude Oil } & 100 \mathrm{~mL} \\ \text { Volcanic Mud from Dominica } & 1 \mathrm{gm} \\ \text { Potatoes, cauliflower leaves } & 835 \mathrm{gm} \\ \text { Carbon Mix (glucose+glycerol+succinate) } & 50 \mathrm{~mL}\end{array}$

Aerobic conditions were maintained by regularly opening the lid and exposing to air and thorough mixing of bucket contents to provide sufficient aeration. Bulking agents like twigs/straw were added to facilitate mixing of soil clumps resulting in better soil aeration. Temperature was maintained at about $60^{\circ} \mathrm{C}$ and monitored on a daily basis. Sampling was done every week and nitrogen and sulfur bioavailability assays were set up with the samples obtained to test the ability of these cultures to use organo nitrogen/sulfur compounds as the sole carbon/nitrogen/sulfur source. At each sampling event additional carbon mixture $(50 \mathrm{~mL})$ and crude oil $(50 \mathrm{~mL})$ was added to the compost and mixed completely. 


\section{Nitrogen Bioavailability Assay}

The nitrogen bioavailability assay utilizes defined mineral salts medium in growth tests in which organonitrogen model compounds such as quinoline, pyridine, carbazole, quinazoline, and piperidine, pyrolidine, and triazine serve as sources of carbon and/or nitrogen. For selective cleavage of carbon-nitrogen bonds, a culture should be capable of utilizing an organonitrogen compound as a nitrogen source but not as a carbon source. Accordingly, growth tests are performed using the following eight conditions:

1. Test compound as sole source of carbon and nitrogen.

2. Test compound as sole source of carbon (alternative nitrogen source, ammonia, is available).

3. Test compound as sole source of nitrogen (alternative carbon source, glucose/glycerol/succinate, is available).

4. Test compound present as well as alternative sources of carbon and nitrogen.

5. Only alternative nitrogen (ammonia) and carbon (glucose/glycerol/succinate) sources are available. The test compound is not present.

6. No carbon or nitrogen compounds of any kind are present.

7. Only alternative nitrogen (ammonia) is present. No carbon or test compound is present.

8. Only carbon (glucose/glycerol/succinate) sources are available. No nitrogen compounds (ammonia or test compound) are present.

These eight growth conditions constitute a bioassay for the ability of a culture to metabolize organonitrogen compounds. The basis of the nitrogen bioavailability assay is that all microorganisms require nitrogen for growth. When carbon and nitrogen sources other than the test compounds are needed, they will be supplied in the form of glucose/glycerol/succinate, and as ammonia respectively.

The nitrogen bioavailability assay described above can be performed with any organonitrogen test compound and is ordinarily used at a concentration of from 1 to $20 \mathrm{mM}$. The various cultures to be tested are inoculated into test tubes or shake flasks containing medium components appropriate for the eight test conditions. The cultures are then incubated either aerobically or anaerobically for 2 to 5 days, at $37,45,50,55,59$, and $65^{\circ} \mathrm{C}$. The growth of the 
cultures is monitored easily by measuring the turbidity/optical density of the cultures in the various test conditions, or by determining colony-forming units. The unamended sample (test condition No. 6) serves as a negative control while the samples amended with both a carbon and nitrogen source (test conditions No. 4 and 5) serves as positive controls and should produce healthy microbial growth unless the test compound is toxic to the culture being tested. In this only condition No. 5 should result in healthy growth. The amount of bacterial growth observed in test conditions 1, 2, and 3 in comparison with the amount of growth observed in test conditions 4, 5 and 6 , indicate the ability of cultures to use the organonitrogen test compound as a source of carbon and/or nitrogen. Those cultures which show better growth in test condition No. 3 than conditions in Nos. 1 or 2 may be preferentially utilizing the organonitrogen compound as a nitrogen source only, and should be examined more thoroughly and included in further experiments. Conditions 7 and 8 serve as controls for conditions 2 and 3.

This same experimental approach can also be adapted to examine the metabolism of organosulfur compounds in a sulfur bioavailability assay.

\section{Species Identification}

The identification of the species of the bacterial isolate obtained was done by microscopic observation, measuring various biochemical parameters using the API 20E bacterial identification system (bioMerieux, Hazelwood MO), and by determining the DNA sequence of a $500 \mathrm{bp}$ portion of the 16S-rRNA gene (MIDI Labs, Newark NJ) and comparison with a library of known DNA sequences in the ribosomal database project.

\section{Biochemical Tests}

The Gibbs assay was used to quantify 2-hydroxybiphenyl according to published procedures (Kayser et al., 1993, J. Gen. Microbiol. 139: 3123-3129).

The conversion of 2,3 dihydroxybiphenyl to a yellow metabolite, 2-hydroxy-6-oxo-6phenylhexa-2,4-dienoic acid (HOPDA). HOPDA was quantified spectrophotometrically at A434 $\mathrm{nm}$ using cell suspensions adjusted to a cell concentration of 0.5 optical density (OD) units at 600 nm (Furukawa and Miyazaki, 1986, J. Bacteriol. 166: 392-398). 
The malate dehydrogenase ( $m d h)$ activity encoded by the $m d h$ gene can be accurately quantified spectrophotometrically and was chosen as the reporter gene for use in quantitative assays of promoter strength/gene expression.

$$
\mathrm{NADH}+\text { oxaloacetate }+\mathrm{H}^{+} \leftrightarrow \text { L-malate }+\mathrm{NAD}^{+}
$$

This gene catalyzes the interconversion of L-malate and oxaloacetate using NAD as the coenzyme and can hence be easily quantified by measuring the decrease in absorbance at $340 \mathrm{~nm}$ resulting from the oxidation of NADH.

Activity of $m d h$ is calculated using the formula:

Activity (units $/ \mathrm{mg})=\left(\Delta \mathrm{Abs}_{340 \mathrm{~mm}} / \mathrm{min}\right) /(6.22 \times \mathrm{mg} / \mathrm{mL}$ protein $)$

The ability to accurately quantify malate dehydrogenase activities in extracts of $T$. thermophilus cells could allow the $m d h$ gene to be used as a reporter gene in experiments to quantify promoter strength/gene expression in T. thermophilus. Bacterial cultures were evaluated on the basis of $m d h$ activity using the following procedure. (I) Sample preparation: Thermus cultures were grown in a TT rich medium at $59-65^{\circ} \mathrm{C}$ until mid-late log phase. A 1-mL sample is taken during the late log phase. Each sample is harvested by centrifugation at $14000 \mathrm{rpm}$ for $2 \mathrm{~min}$, washed with $500 \mu \mathrm{L}$ TES buffer, re-centrifuged at 14000 for $2 \mathrm{~min}$ and then suspended in $200 \mu \mathrm{L} 0.1 \mathrm{M}$ phosphate buffer. This $200 \mu \mathrm{L}$ sample was sonicated for 5 pulses using a Branson 350 sonicator (at $70 \%$ duty cycle and 7 microtip output speed). The enzyme extract was the supernatant obtained after centrifugation at $9000 \mathrm{rpm}$ for $5 \mathrm{~min}$. (II) Microtiter assay: Malate dehydrogenase activity encoded by the $m d h$ gene was quantified spectrophotometrically. The assay was carried out initially using a microtiter plate reader as follows: $10 \mu \mathrm{L}$ of the enzyme extract is pipetted into the microtiter plate in replicate (5-8). The reagent mixture $\left(33 \mathrm{mM} \mathrm{KPO}_{4} \mathrm{pH} 7.0,0.15 \mathrm{mM}\right.$ NADH and $0.17 \mathrm{mM}$ oxaloacetate) was pre-warmed to $50{ }^{\circ} \mathrm{C}(200 \mu \mathrm{L}$ for $2-3 \mathrm{~min}$ in the microtiter plate or $10 \mathrm{~mL}$ for $10 \mathrm{~min}$ in a water bath). Activity at $50^{\circ} \mathrm{C}$ was higher than at $25^{\circ} \mathrm{C}$ and was chosen as the assay temperature. A program to note the OD at $340 \mathrm{~nm}$ every 10 seconds was set up using the software, Revelation, which calculates the $\mathrm{OD} / \mathrm{min}$. $200 \mu \mathrm{L}$ reaction mixture is added to $10 \mu \mathrm{L}$ enzyme extract and the reaction $\left(\Delta \mathrm{Abs}_{340 \mathrm{~mm}} / \mathrm{min}\right)$ was observed for 1 min. The total protein concentration was determined using the BCA protein kit from Pierce Biochemical, Rockford, IL. The activity was calculated using equation 2. 
(III) Spectrophotometer assay: The malate dehydrogenase assay was conducted at 25 and $50{ }^{\circ} \mathrm{C}$ in a Beckman DU-65 spectrophotometer using the following procedure: $10 \mu 1$ of the Thermus cell free extract (obtained using procedure given in (I) ) was placed into a $4.5 \mathrm{ml}, 1-\mathrm{cm}$ pathlength cuvette. The reaction was started by the addition of $3 \mathrm{ml}$ assay reagent $\left(33 \mathrm{mM} \mathrm{KPO}_{4}\right.$ $\mathrm{pH}$ 7.0, $0.15 \mathrm{mM}$ NADH and $0.17 \mathrm{mM}$ oxaloacetate) equilibrated or preheated in a water bath maintained at $25^{\circ} \mathrm{C}$ or $50^{\circ} \mathrm{C}$. Change in absorbance was monitored at $340 \mathrm{~nm}$ for 3 to 5 minutes. Rate of change in absorbance at $340 \mathrm{~nm}\left(\Delta \mathrm{A}_{340 \mathrm{~nm}} / \mathrm{min}\right)$ was calculated from the initial linear portion of the curve. The total protein concentration in cell free extracts was determined using the BCA protein kit from Pierce Biochemical, Rockford, IL. At the assay temperature of $50{ }^{\circ} \mathrm{C}$, for some cultures, the cell-free extracts were serially diluted to observe a linear rate of decrease in absorbance at $340 \mathrm{~nm}$.

\section{Thin Layer Chromatography for Identification of Metabolites}

Thin layer chromatography (TLC) was performed on Whatman Silica C-18 plates by the method described by Watson and Cain (Biochem. J. 146: 157-172, 1975). Running phase solvents used were chloroform-toluene (1:3), and hexane-acetic acid-xylene (5:1:2). Supernatants from bacterial cultures grown with an organonitrogen test compound as the sole source of nitrogen were obtained after centrifugation at $10,000 \mathrm{x} g$ for 15 minutes. These supernatants were used at neutral or alkaline $\mathrm{pH}$. Typically $10 \mathrm{ml}$ of aqueous supernatant was acidified to $\mathrm{pH} 1$ to 2 with $\mathrm{HCl}$ and extracted with ethyl acetate $(1: 1$ or 1:0.5 v/v). The organic phase was separated from the aqueous phase by centrifugation or by using a separatory funnel. The ethyl acetate extract was then evaporated in a hood resulting in the concentration of the sample from 20 to 1000 -fold prior to the analysis of the extracts by TLC. 10 to $50 \mu \mathrm{L}$ of ethyl acetate sample that had been concentrated 100-fold relative to the volume of aqueous supernatant extracted was spotted onto TLC plates. Typical running times of the TLC plates were about 20 minutes. These plates were later observed under normal lighting, short (245 nm), and long wave (366 nm) UV light.

Some experiments also utilized resting cells that were prepared by centrifuging from 500 $\mathrm{ml}$ of log phase cultures grown with either an organonitrogen compound or ammonia as nitrogen sources. Then the washed cell pellets were resuspended in 5 to $50 \mathrm{ml}$ of mineral salts medium achieving final cell densities of from $10^{10}$ to $10^{11}$ cells $/ \mathrm{ml}$. These cell suspensions were 
incubated with from 1 to $20 \mathrm{mM}$ test compound (organonitrogen compound) for periods ranging from 15 minutes to 24 hours. The incubator was agitated at about $200 \mathrm{rpm}$ and maintained at the microorganism's optimum temperature. The ethyl acetate extract was stored in amber vials at $4^{\circ} \mathrm{C}$ until they were analyzed by TLC, HPLC and/or GC-MS.

\section{Gas Chromatography-Mass Spectrometry}

GC-MS analysis was performed on extracts derived from growing and resting cell cultures exposed to organonitrogen test compounds, and on compounds eluted from spots observed on thin layer chromatography plates.

Extraction of the supernatants from resting cells as well as growing cells were carried out either by ethyl acetate solvent extraction or with $\mathrm{C}-18$ solid phase extraction cartridges as described above for the preparation of samples for TLC analysis. Additionally, TLC spots of possible metabolites were scraped from the TLC plates and eluted with ethyl acetate and concentrated for analysis by GC-MS.

For analysis of the extracts a Hewlett Packard 5971 mass selective detector and 5890 series II GC with HP 7673 auto sampler tower and a 30 meter Rezteck XTI-5 column was used. The final oven temperature was maintained at $300^{\circ} \mathrm{C}$. The detection limit was $1 \mathrm{ng}$ or $1 \mu \mathrm{g} / \mathrm{ml}$ with a $1 \mu$ l injection. Mass spectrographs were compared with various libraries of mass spectrograph data prepared from known standard compounds. Several chromatograph libraries were consulted to determine the identity of metabolites of organonitrogen compounds. The presence or absence of nitrogen in various compounds was also determined by GC-AED using the nitrogen-specific wavelength of $174.2 \mathrm{~nm}$ for detection.

\section{High Performance Liquid Chromatography}

The extracts derived from growing and resting cell experiments were analyzed by HPLC. Extraction was carried out with ethyl acetate as described in the TLC section. The ethyl acetate was then evaporated completely and the residue (nonvolatile organics) was suspended in acetonitrile before injecting into the HPLC system. A Waters system equipped with a Symmetry $\mathrm{C}_{18}(3.5 \mu \mathrm{m}, 4.6 \times 100 \mathrm{~mm})$ column and a 600 controller was used for this purpose. Detection of compounds was carried out using a 996 photodiode array detector coupled to the HPLC system. 
An isocratic mobile phase of acetonitrile:water at the flowrate of $1.5 \mathrm{ml} / \mathrm{min}$ was used as the running solvent.

\section{Reactor Studies: Growth of T. thermophilus (HB27) in a CSTR}

Two continuously stirred tank reactors (CSTRs) were used for our study - a 2-L working volume Virtis reactor and a $2.75 \mathrm{~L}$ working volume Applicon reactor. Each reactor was filled with TT rich medium, sterilized, and aerated at $65^{\circ} \mathrm{C}$ overnight before inoculation. The tubing, filters and other autoclavable accessories were sterilized separately in a gravity cycle. The reactor was inoculated with $T$. thermophilus $\mathrm{HB} 27$ grown overnight at $59-65^{\circ} \mathrm{C}$. Samples were withdrawn every hour and were monitored for optical density (Absorbance at 600nm), $\mathrm{pH}$ and dry weight $(\mathrm{g} / \mathrm{L})$. The dry weight was calculated by filtering a known volume of microbial suspension using a vacuum device through a preweighed (W1) paper, drying the filter paper at $105^{\circ} \mathrm{C}$ overnight, putting it in a desiccator for at least $1 / 2$ an hour before weighing the filter paper again (W2).

Dry weight $(\mathrm{g} / \mathrm{L})=(\mathrm{W} 1-\mathrm{W} 2) /($ volume of microbial suspension filtered $)$

In the Virtis fermentor the $\mathrm{pH}$ was monitored using a bench-top $\mathrm{pH}$ meter and the OD was noted using a Beckmann DU-65 spectrophotomter. Air was supplied at 0.5-1.5L/min using a 300W air pump. The Applicon reactor has its own autoclavable $\mathrm{pH}$ and dissolved oxygen (DO) probe and real time data was obtained using a data acquisition system. This reactor was connected to a biocontroller (ADI 1030) which has the capability of controlling 4 variables. In this system, $\mathrm{pH}$ was the controlled variable and temperature, DO were measured variables. For aeration, house air was passed into the system $(0.5-2.5 \mathrm{~L} / \mathrm{min})$ through a calibrated rotameter. In both the systems, filters were used at the inlet of the air line to the reactor to avoid contamination. Temperature was maintained at $65^{\circ} \mathrm{C}$ using a waterbath. The Applicon reactor minimized evaporative losses due to its feature of condensing volatiles using cooling water through a heat exchanger in the outlet stream. The measured and controlled variables were used to calculate maximum specific growth rate $\left(\mu_{\max }\right)$ and mass transfer coefficient (kla). 


\section{Minimal Media Experiments with T. thermophilus and T.flavus:}

Media composition can significantly affect product/biomass yield and productivity. Designing the perfect medium is a time-consuming and open-ended process. We carried out the media optimization experiments in our laboratory for Thermus thermophilus (HB27) and Thermus flavus. We initiated medium development with the closed strategy and then continued medium design using open strategy. In the closed strategy a fixed number of components are chosen and the best combination is developed. In the open strategy one can experiment with any component of any composition. We had adopted the component swapping strategy in our medium development work. In this open strategy effect of various carbon and nitrogen sources on HB27 growth was compared. The concentrations of the carbon and nitrogen sources added to the medium were calculated based on the carbon and nitrogen levels in the cell. Graeco-Latin Square experiments were set for optimization of growth medium. The design and interpretation of Graeco-Latin Square experiments are described in the Results and Discussion section. Graeco-Latin Square is based on the open strategy and the effect of a component can be studied with less number of experiments than if it were done on a one-by-one basis. The base medium used in all experiments was Mod A.

\section{Genetic Techniques}

Methods used in genetic experiments are described in detail in the recent publications from GTI's biotechnology laboratory:

"New Host Vector System for Thermus spp. Based on the Malate Dehydrogenase Gene", K. J. Kayser and J. J. Kilbane II, Journal of Bacteriology 183: 1792-1795. (2001)

"Inducible and Constitutive Expression Using New Plasmid and Integrative Expression Vectors for Thermus sp.” K. J. Kayser, J.-H. Kwak, H.-S. Park, and J. J. Kilbane II. Letters in Applied Microbiology 32: 412-418 (2001).

\section{Desulfurization Gene Cloning}

Genomic DNA from M. phlei GTIS10 was used as the template for the amplification of the $d s z A, d s z B$ and $d s z C$ genes using PCR. The PCR primers correspond to the first $25 \mathrm{bp}$ and the last $25 \mathrm{bp}$ of each of the individual $d s z$ genes, GenBank accession number L37363. Restriction sites were added to both $5^{\prime}$ and $3^{\prime}$ ends on each amplified product to facilitate 
subsequent in-phase cloning into the pFLAG-CTC expression vector. The PCR primers used were:

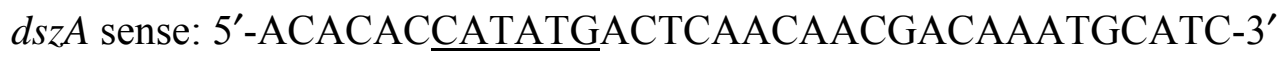

$d s z A$ antisense: 5'-ACACACAGATCTTCATGAAGGTTGTCCTTGCAGTTGT-3'

$d s z B$ sense: $5^{\prime}$-ACACACCATATGACAAGCCGCGTCGACCCCGCAAAC-3'

$d s z B$ antisense: $5^{\prime}$-ACACACAGATCTGTGGCGATTGAGGCTGTTGTTCAGA-3'

$d s z C$ sense:5'-ACACACCATATGACACTGTCACCTGAAAAGCAGC-3'

$d s z C$ antisense: 5'-ACACACAGATCTTCAGGAGGTGAAGCCGGGAATCGGG-3'

$d s z D$ sense: $5^{\prime}$-ACACACCATATGTCTGACAAGCCGAATGCCGTTT-3'

$d s z D$ antisense: 5'-ACACACAGATCTCTATTGACCTAACGGAGTCGGGCGG-3'

The underlined sequences indicate 5' $N d e I$ and 3' $B g l I I$ restriction enzyme recognition sites. The DNA sequences of the pSOX replication genes used to design PCR primers were from GenBank accession number AF059700. The PCR primers used to isolate the pSOX replication genes were:

pSOX sense: $5^{\prime}$ - CGCTCAGCACTGGGTGGAAA-3' and pSOX antisense 5'-TCCGCCGCGTTAGAGATGGA-3'

\section{DNA Sequencing and Analysis}

PCR-generated and restriction enzyme generated DNA fragments were cloned into pFLAG-CTC and sequences were determined on both strands by primer walking by the University of Iowa DNA facility (Iowa City, Iowa). Sequence analysis was performed with the BLAST programs of the National Center for Biotechnology Information (Bethesda, Md.).

\section{Purification of Desulfurization Enzymes}

Each indiviual desulfurization gene was cloned into pQE80 (Qiagen, Hilden, Germany) to produce recombinant proteins appended at the $\mathrm{N}$-terminus with a polyhistidine (His) domain to facilitate the binding of recombinant molecules to a Ni-NTA resin. Preparations of cell lysates were prepared following the manufacturer's recommendations. Briefly, E. coli DH5 $\alpha$ strains containing desulfurization genes cloned into pQE80 were grown at $37^{\circ} \mathrm{C}$ to mid-log phase, and expression of the cloned genes was induced by addition of IPTG $(1 \mathrm{mM})$. After $4 \mathrm{~h}$ of growth at 
$37^{\circ} \mathrm{C} 100 \mathrm{ml}$ of cell suspension were harvested by centrifugation at $12000 \mathrm{xg}$, and the bacterial pellets were suspended in $30 \mathrm{ml}$ of lysis buffer $(20 \mathrm{mM}$ Tris-Cl [ $\mathrm{pH} 8.0$ ], $100 \mathrm{mM} \mathrm{NaCl}, 8 \mathrm{M}$ urea). $1 \mathrm{ml}$ of lysozyme $(10 \mathrm{mg} / \mathrm{ml})$ was added and incubated on ice for $30 \mathrm{~min} .40 \mathrm{mg}$ of deoxycholic acid was added and samples were incubated at $37^{\circ} \mathrm{C}$ until the lysates became sticky, then $200 \mu \mathrm{l}$ of DNaseI $(1 \mathrm{mg} / \mathrm{ml})$ was added and incubated at room temperature until the lysates were no longer sticky. Cell lysates were clarified by centrifugation at $10,000 \mathrm{x} \mathrm{g}$ for $30 \mathrm{~min}$ at $4^{\circ} \mathrm{C}$. The clarified supernatants were filtered using a $0.45 \mu$ filter. 5-ml Ni-NTA Superflow resin was added into cleared lysate samples and allowed to settle. 6X HIS binding columns (Qiagen, Hilden, Germany) were equilibrated with 5 column volumes of lysis buffer. Filtered lysates were applied to the 6X HIS binding columns and washed twice with lysis buffer, followed by four column bed volumes of $20 \mathrm{mM}$ Tris-Cl, $\mathrm{pH} 8.0$, containing $100 \mathrm{mM} \mathrm{NaCl}$. The bound protein was eluted from the resin with $100 \mathrm{mM}$ EDTA and dialyzed overnight against $10 \mathrm{mM}$ Tris-Cl, pH8.0. Eluted protein was assayed for purity by SDS-PAGE.

\section{Biochemical Assays and Analytical Techniques for Desulfurization Enzymes}

M. phlei GTIS10 resting cells were prepared by growing the culture on DBT or $\mathrm{DBTSO}_{2}$ as the sole sulfur source until cells were in mid logarithmic phase (approximately OD 600nm of 0.5). Cells were harvested by centrifugation, washed twice with 50mM HEPES $\mathrm{pH} 7.5$, and resuspended in the same buffer. Dry cell weight was determined and recorded. These resting cell suspensions were then incubated at temperatures ranging from $25^{\circ}$ to $75^{\circ} \mathrm{C}$ with $200 \mu \mathrm{M}$ DBT or DBTSO2 introduced from a $40 \mathrm{mM}$ stock solution in acetone. Samples were removed at various intervals over a 24-hour period and desulfurization specific activity was determined based on the quantity of 2-HBP produced per minute per gram dry cell weight ( $\mu$ mole 2-HBP/ min g-dry cell) as quantified by HPLC. When purified Dsz enzymes were used, the protein preparations were divided into portions and pre-incubated at temperatures ranging between $30^{\circ}$ to $72^{\circ} \mathrm{C}$ for 30,60 , and 120 minutes. At each time interval, $750 \mu \mathrm{l}$ of sample was removed and residual activity of the Dsz enzymes was determined by the addition of $10 \mu \mathrm{M}$ of appropriate organosulfur substrates, $4 \mathrm{mM} \mathrm{NADH}$, and $10 \mu \mathrm{M} F M N H$. The samples were incubated at $30^{\circ} \mathrm{C}$ for 60 minutes and terminated by the addition of $750 \mu 1$ of acetonitrile and thorough mixing. DBT, $\mathrm{DBTSO}_{2}$, HBPSi and 2-HBP were quantified using HPLC according to published procedures (Oldfield, Pogrebinsky et al. 1997). Briefly, a Waters liquid chromatograph equipped with a 
photodiode array detector and fitted with a Waters Symmetry ${ }^{\mathrm{TM}}$ C18 column was used. The mobile phase was acetonitrile and phosphate buffer $(\mathrm{pH} 6.0$ 10mM) mixed 1:1. FMN oxidoreductase (DszD) activity was measured by the oxidation of NADH monitored at $340 \mathrm{~nm}$ (Gray, Pogrebinsky et al. 1996). In GC-MS analysis of DBT and desulfurization pathway intermediates acidified ethyl acetate extracts(Konishi, Y. Ishii et al. 1997) were injected into a Hewlett Packard 5971 mass selective detector and 5890 series II GC with HP 7673 auto sampler tower and a 30 meter Rezteck XTI-5 column was used. The carrier gas was helium and the run conditions were a starting temperature of $40^{\circ} \mathrm{C}$ held for 2 minutes, followed by $10^{\circ} \mathrm{C}$ per minute ramp to a final oven temperature of $300^{\circ} \mathrm{C}$, which was maintained for an additional 10 minutes. Mass spectrographs were compared with various libraries of mass spectrograph data prepared from known standard compounds. Several chromatograph libraries were consulted to determine the identity of metabolites. Thin layer chromatography (TLC) analyses were performed on ethyl acetate extracts(Konishi, Y. Ishii et al. 1997; Konishi, Onaka et al. 2000) derived from growing cell cultures, resting cell cultures, and cell free extracts exposed to various organosulfur model compounds. TLC was performed by spotting $30 \mu \mathrm{l}$ of an ethyl acetate extract sample on Whatman Silica PE Sil G/UV plates. The running phase solvents used were chloroform and toluene in the ratio of 1:3. These plates were observed under UV light.

\section{Petroleum Experiments}

Two types of petroleum samples were used in this project. A crude oil obtained from Petrobras and a shale oil obtained from archived samples at GTI. The crude oil was Marlim crude which had $85.85 \%$ carbon, $0.71 \%$ sulfur, and $0.42 \%$ nitrogen. The shale oil had a total nitrogen content of $1.71 \%$, of which about $0.2 \%$ was comprised of carbazole. Petroleum biotreatment experiments employed either Sphingomonas sp. GTIN11 or Pseudomonas sp. CA10 resting cell preparations. Bacterial cultures were grown in $1 \mathrm{~L}$ of TT medium at $37^{\circ} \mathrm{C}$ and harvested by centrifugation when OD 0.7 to $0.9 \mathrm{~A} 600 \mathrm{~nm}$ was achieved. Cells were resuspended in $25 \mathrm{ml}$ of fresh TT media that was pre-warmed to $37^{\circ} \mathrm{C}, 2 \mathrm{ml}$ of crude oil or shale oil was added to each sample which was then incubated for 16 hours at $37^{\circ} \mathrm{C}$ in $250 \mathrm{ml}$ Erlenmeyer flasks shaking at $175 \mathrm{rpm}$. The oil was recovered by transferring the suspensions to $50 \mathrm{ml}$ conical tubes that were then centrifuged at $8,000 \times \mathrm{g}$ for 15 minutes. Each cell suspension was divided into two portions and used to treat duplicate samples. Oil was recovered directly from 
one set of samples, as emulsion formation was not a significant problem and recovery of oil from the upper phase of these samples was achieved using a micropipette. Oil was recovered from the other set of samples by extraction with an equal volume of dichloromethane, which was subsequently evaporated to yield oil samples. The untreated and biotreated samples were submitted for analysis by GC-MS to quantify the amount of carbazole compounds present. 


\section{RESULTS AND DISCUSSION}

The objective of this project was to isolate microbial cultures, particularly thermophilic cultures, which can selectively cleave carbon-nitrogen and carbon-sulfur bonds. As shown in the project task and milestone schedule in Figure 1, the project was completed as planned.

Nutristats and shake flask enrichment culture/directed evolution experiments were operated so that microbial cultures with the ability to selectively cleave carbon-nitrogen or carbon-sulfur bonds could be isolated. Multiple nutristats were operated employing defined mineral salts media that was either nitrogen-free or sulfur-free. Model compounds or crude oil were used to serve as sole sources of nitrogen or sulfur. The effluents of nutristats and cells from

shake flasks and from agar plates were routinely tested using the nitrogen/sulfur bioavailability assay.

Growth was obtained in several nutristats and shake flask enrichment culture experiments suggesting that bacterial cultures were obtained that utilize crude oil or model compounds as sole sources of nitrogen or sulfur for growth. These mixed cultures were subsequently processed to isolate pure bacterial cultures that can utilize organonitrogen or organosulfur compounds as sole nitrogen or sulfur sources. The pure cultures isolated that appear to selectively cleave C-N/S bonds in organonitrogen/sulfur compounds, as indicated from the results of nitrogen and sulfur bioavailability assays, are summarized in Table 1. 
Table 1: Summary Of Pure Cultures Using Organonitrogen/Sulfur As The Sole N/S Source

\begin{tabular}{|l|l|l|}
\hline Microbe & Substrate & $\begin{array}{l}\text { Temperature } \\
\left({ }^{\circ} \mathrm{C}\right)\end{array}$ \\
\hline Anuerinibacillus sp. IGTN4T & Pyridine & 45 to 55 \\
\hline Gordona sp. IGTN5T & Quinoline & 45 \\
\hline Amycolaptosis sp. IGTN6T & Pyridine & 45 to 50 \\
\hline Bacillus thermoglucosidasius IGTN7T & Quinazoline, Triazine & 55 to 65 \\
\hline Pseudomonas ayucida IGTN9m & Quinoline & 30 \\
\hline Pseudomonas citronellolis IGTN10 & $\begin{array}{l}\text { Piperidine, } \\
\text { Pyrrolidine, } \\
\text { Quinazoline, Triazine }\end{array}$ & 30 to 45 \\
\hline Bacillus thermocatenulatus GTIN8T & Quinazoline, Triazine & 55 to 59 \\
\hline Bacillus smithii GTIN9T & Quinazoline, Triazine & 55 to 59 \\
\hline Sphingomas sp. GTIN11, GTIN12, GTIN14 & Carbazole & 30 to 37 \\
\hline Rhodococcus erythropolis IGTS8 & DBT & 30 \\
\hline Mycobacterium phlei GTIS10 & DBT & 52 \\
\hline
\end{tabular}

\section{Characterization of a Pyridine-Degrading Culture Anuerinibacillus sp. IGTN4T}

Enrichment culture experiments operated at $55^{\circ} \mathrm{C}$ with crude oil as the sole nitrogen source subsequently led to the growth of a mixed culture at $45^{\circ}$ to $55^{\circ} \mathrm{C}$ capable of using pyridine as a sole nitrogen source. Streaking of this mixed culture onto various solid media allowed the isolation of pure cultures that were subsequently examined in nitrogen bioavailability assays, resulting in the isolation of a culture designated as IGTN4T. The exponential growth rate for IGTN4T utilizing pyridine as a sole source of nitrogen at $55^{\circ} \mathrm{C}$ was determined as 0.13 hours with a generation time of 7.55 hours. The culture failed to grow at temperatures above $55^{\circ} \mathrm{C}$ but growth could be obtained with temperatures as low as $30^{\circ} \mathrm{C}$. The minimum nitrogen requirement for this culture was $0.5 \mathrm{mM}$ regardless if pyridine or ammonia was used. The maximum amount of growth was obtained using pyridine concentrations ranging from 3 to $5 \mathrm{mM}$, but pyridine is apparently toxic to IGTN4T at concentrations $\geq 10 \mathrm{mM}$. Biochemical tests and sequencing of a 
500 basepair portion of the $16 \mathrm{~S}$ rRNA gene of this culture resulted in an identification as an Anuerinibacillus sp. Preliminary investigations of the metabolites produced from the metabolism of pyridine by Anuerinibacillus sp. IGTN4T were performed using UV/Vis spectrophotometry and thin layer chromatography. The disappearance of pyridine was documented, but no metabolites of pyridine produced by this culture were identified. The substrate range of Anuerinibacillus sp. IGTN4T was investigated using a wide variety of organonitrogen compounds. Growth was obtained using urea, tryptophan, lysine, guanine, pyridine, and nicotinic acid. However, the only organonitrogen compound whose structure is relevant to molecules commonly found in petroleum was pyridine. Moreover, growth of Anuerinibacillus sp. IGTN4T using crude oil as a sole nitrogen source was unsuccessful. The extremely limited substrate range for the utilization of organonitrogen compounds by Anuerinibacillus sp. IGTN4T led us to archive this culture and continue the search for additional cultures with better capabilities.

\section{Characterization of a Quinoline-Degrading Culture Gordona sp. IGTN5T}

Enrichment culture experiments operated at $45^{\circ} \mathrm{C}$ with crude oil as the sole nitrogen source subsequently led to the growth of a mixed culture at $45^{\circ} \mathrm{C}$ capable of using quinoline as a sole nitrogen source. Streaking of this mixed culture onto various solid media allowed the isolation of pure cultures that were subsequently examined in nitrogen bioavailability assays, resulting in the isolation of a culture designated as IGTN5T. Preliminary investigation of the metabolites of quinoline produced by IGTN5T were performed using UV/Vis spectrophotometry and thin layer chromatography. The disappearance of quinoline was documented, but no metabolites of pyridine produced by this culture were identified. Biochemical tests and sequencing of a 500 basepair portion of the 16S rRNA gene of this culture resulted in an identification as Gordona sp. IGTN5T. The substrate range of Gordona sp. IGTN5T was investigated using a wide variety of organonitrogen compounds, but quinoline was the only substrate relevant to petroleum that was utilized by this culture.

\section{Characterization of a Pyridine-Degrading Culture Amycolaptosis sp. IGTN6T}

Enrichment culture experiments operated at $50^{\circ} \mathrm{C}$ with crude oil as the sole nitrogen source subsequently led to the growth of a mixed culture at $45^{\circ}$ to $50^{\circ} \mathrm{C}$ capable of using pyridine as a sole nitrogen source. Streaking of this mixed culture onto various solid media allowed the 
isolation of pure cultures that were subsequently examined in nitrogen bioavailability assays, resulting in the isolation of a culture designated as IGTN6T. Biochemical tests and sequencing of a 500 basepair portion of the 16S rRNA gene of this culture resulted in an identification as Amycolaptosis sp. IGTN6T. The substrate range of Amycolaptosis sp. IGTN6T was investigated using a wide variety of organonitrogen compounds, but pyridine was the only substrate relevant to petroleum that was utilized by this culture.

\section{Characterization of a Quinazoline-Degrading Thermophilic Culture Bacillus thermoglucosidasius IGTN7T}

A thermophilic quinazoline-utilizing culture was isolated that could grow at $55^{\circ}$ to $65^{\circ} \mathrm{C}$, and the pure culture was given the designation IGTN7T. IGTN7T was sent to MIDI Labs, Newark, DE, for partial 16S rRNA sequencing which identified the culture as most closely related (95\% similarity) to Bacillus thermoglucosidasius. The metabolites of quinazoline degradation were investigated using UV-Vis spectrophotometric scans, Thin layer chromatography (TLC), and Gas chromatography-mass spectroscopy (GC-MS). While TLC analyses of supernatants derived from resting cell experiments revealed the presence of possible metabolites of quinazoline, the analysis of samples by GC-MS failed to detect metabolites. Nitrogen availability assays confirmed that IGTN7T can use triazine as well as quinazoline as the sole nitrogen source in the temperature range 55 to $59^{\circ} \mathrm{C}$. There was no metabolism of other organonitrogen compounds.

\section{Characterization of a Quinoline-Degrading Culture Pseudomonas ayucida IGTN9m}

Environmental samples obtained from petroleum-contaminated locations were used to inoculate nutristats and shake flask enrichment culture experiments in which $3 \mathrm{mM}$ to $20 \mathrm{mM}$ quinoline was supplied as the sole source of nitrogen. Quinoline was initially toxic to the nutristat cultures making it difficult to establish and maintain bacterial growth. However, after several weeks bacterial growth was obtained. Initially the flow rates of the nutristats were adjusted to achieve hydraulic retention times of about 30 days. As the ability of the microbial culture to tolerate and utilize quinoline improved the flow rates of the nutristats were increased to be as fast as possible without causing washout of all the cells. Eventually, hydraulic retention times of 48 hours were achieved. Mixed and pure cultures obtained from the quinoline nutristats 
were routinely tested using the Nitrogen Bioavailability Assay to detect cultures capable of using quinoline as a nitrogen source, but not as a carbon source. All of the quinoline-utilizing cultures initially obtained from the nutristats were found to fully degrade quinoline, utilizing it as a carbon as well as a nitrogen source. Subsequently, the flow rates of the nutristats were increased so that hydraulic retention times decreased from 96 hours to 4 hours or less over a period of 4 months. During this time cells were routinely obtained from the nutristat effluent, mutagenized, and returned to the nutristat. Mutagenesis was employed because repeated enrichment culture experiments performed without mutagenesis failed to isolate any cultures that utilized quinoline as a nitrogen source, without also using it as a carbon source. Eventually, a pure culture was obtained that yielded Nitrogen Bioavailability Assay results that indicated that quinoline was used as a nitrogen, but not as a carbon source. A partial sequence (500 bp) of the 16S-rRNA gene of this gram negative, rod-shaped bacteria was determined identifying it as Pseudomonas ayucida. This culture was designated Pseudomonas ayucida IGTN9m. P. monteilii, which shows 99\% homology, and Pseudomonas nitroreducens and $P$. pseudoalcaligenes pseudoalcaligenes, which both show $98.3 \%$ homology, are closely related, but not identical to Pseudomonas ayucida IGTN9m.

Pseudomonas ayucida IGTN9m was determined to have a cell doubling time of 4.25 hours when grown in defined salts medium at $30^{\circ} \mathrm{C}$ with quinoline serving as the sole nitrogen source. Substrate range and specificity tests were also carried out for Pseudomonas ayucida IGTN9m using prolonged incubations of 2 to 3 weeks. These substrate range tests were repeated several times using inocula derived from all of those organonitrogen compounds that did yield growth in a previous Nitrogen Bioavailability Assay. This was done to address the possible need for adaptation to a given compound before growth could be obtained, and to accurately determine the widest range of organonitrogen structures that could be utilized by Pseudomonas ayucida IGTN9m. Agar plates were streaked after growth was observed on any of the test compounds to check culture purity. Repeated substrate range tests confirmed that the results obtained were representative of the abilities of Pseudomonas ayucida IGTN9m and not a mutant derivative of the culture. The full range of compounds used in these tests is listed in the Materials and Methods section. Growth was obtained on urea, tryptophan, lysine, guanine, nicotinic acid, quinoline, 3,4-dihydro-2(1H)-quinolinone, 2,4-quinolinediol, 8-hydroxyquinoline, and quinoxaline. Growth with urea, tryptophan, lysine, guanine, and nicotinic acid as nitrogen 
sources is a common ability possessed by many if not most aerobic bacteria and most likely has no relationship to metabolic pathways relevant to the utilization of quinoline. The culture grew in the presence of all of the test compounds except 1-butylpyrrolidine and 2-methylene-1,3,3trimethyl indoline when quinoline was simultaneously present as an alternate nitrogen source. These results indicate that with the exception of the two compounds mentioned above most of the organonitrogen compounds do not have a toxic effect on the culture so that failure to grow on the other test compounds provides a true reflection of the substrate range of Pseudomonas ayucida IGTN9m for the metabolism of organonitrogen compounds. Further tests are needed to determine if 1-butylpyrrolidine and/or 2-methylene-1,3,3-trimethyl indoline are intrinsically toxic or if they are metabolized by IGTN9m into inhibitory compounds.

Spectrophotometric scans (UV/Vis) were carried out on the supernatants of Pseudomonas ayucida IGTN9m cultures that were grown with quinoline as the sole nitrogen source. This was done to determine if spectrophotometric peaks other than quinoline could be detected that might correspond to the accumulation of metabolites. Control supernatants from the cultures grown with ammonium sulfate were included to rule out artifacts arising from normal metabolism of the culture. Quinoline has an absorption maximum peak at $310 \mathrm{~nm}$. This peak can be observed to decrease with time during the growth of Pseudomonas ayucida IGTN9m at the expense of quinoline; however, no new peak was observed that might correspond to a metabolite of quinoline (data not shown).

TLC was performed on the extracts derived from the culture supernatants of Pseudomonas ayucida IGTN9m grown with quinoline as the sole nitrogen source, as well as with resting cells incubated for various times in the presence of quinoline. Controls consisting of Pseudomonas ayucida IGTN9m grown using ammonium sulfate rather than quinoline as a nitrogen source were included in all experiments. Additionally, pure chemicals that are possible metabolites of quinoline such as protocatechuate, catechol, pyruvic acid and p-hydroxy benzoic acid, formamide, 8-hydroxyquinoline and succinic acid dimethyl ester were included on the TLC plates to determine if any of these compounds were formed during the microbial degradation of quinoline. Two spots which have Retardation factor (Rf) values of 0.73 and 0.88 were identified as possible metabolites of quinoline by Pseudomonas ayucida IGTN9m as these compounds were found only in samples derived from the incubation of Pseudomonas ayucida IGTN9m cells with quinoline. Pseudomonas ayucida IGTN9m cells incubated with ammonia did not produce 
these compounds (data not shown). These two compounds could not be accurately identified by TLC analysis alone so these spots were scraped from TLC plates, eluted with ethyl acetate, and subjected to GC/MS analysis.

Gas Chromatography/Mass Spectroscopy (GC/MS) analysis was not only performed on compounds obtained from TLC spots, but also on extracts of culture supernatants from growing cell as well as resting cells of Pseudomonas ayucida IGTN9m. The GC/MS analysis of extracts of culture supernatants allowed for the possible detection of metabolites that did not yield detectable spots in TLC. The results from the GC/MS analyses provided probable structures for two compounds as metabolites of quinoline produced by Pseudomonas ayucida IGTN9m: 2quinolinone and 8-hydroxycoumarin. MS data comparing these metabolites with authentic 2quinolinone and 7-hydroxy-2H-1-benzopyran-2-one are shown in Figures 2 and 3 respectively. 8-hydroxycoumarin is not commercially available, but 7-hydroxycoumarin (7-hydroxy-2H-1benzopyran-2-one ) is so 7-hydroxycoumarin was used as a standard in these experiments. The metabolite of quinoline produced by Pseudomonas ayucida IGTN9m had a somewhat shorter retention time in GC analysis than 7-hydroxycoumarin, but it yielded a mass spectrum apparently identical to 7-hydroxycoumarin and to published spectra of 8-hydroxycoumarin (18). To further analyze the metabolites of quinoline produced by Pseudomonas ayucida IGTN9m the relative abundance of these two metabolites was quantified with resting cells exposed to quinoline for various times, and the results are shown in Table 2.

Table 2. Time Course of Accumulation of Quinoline Metabolites produced by IGTN9m as Measured by GC/MS

\begin{tabular}{|l|l|l|l|}
\hline Metabolite & 15 minutes & 60 minutes & 4 hours \\
\hline 2-quinolinone & $47.8 \%$ & $37.3 \%$ & $17.2 \%$ \\
\hline 8-hydroxycoumarin & $8.4 \%$ & $17.3 \%$ & $16.7 \%$ \\
\hline
\end{tabular}




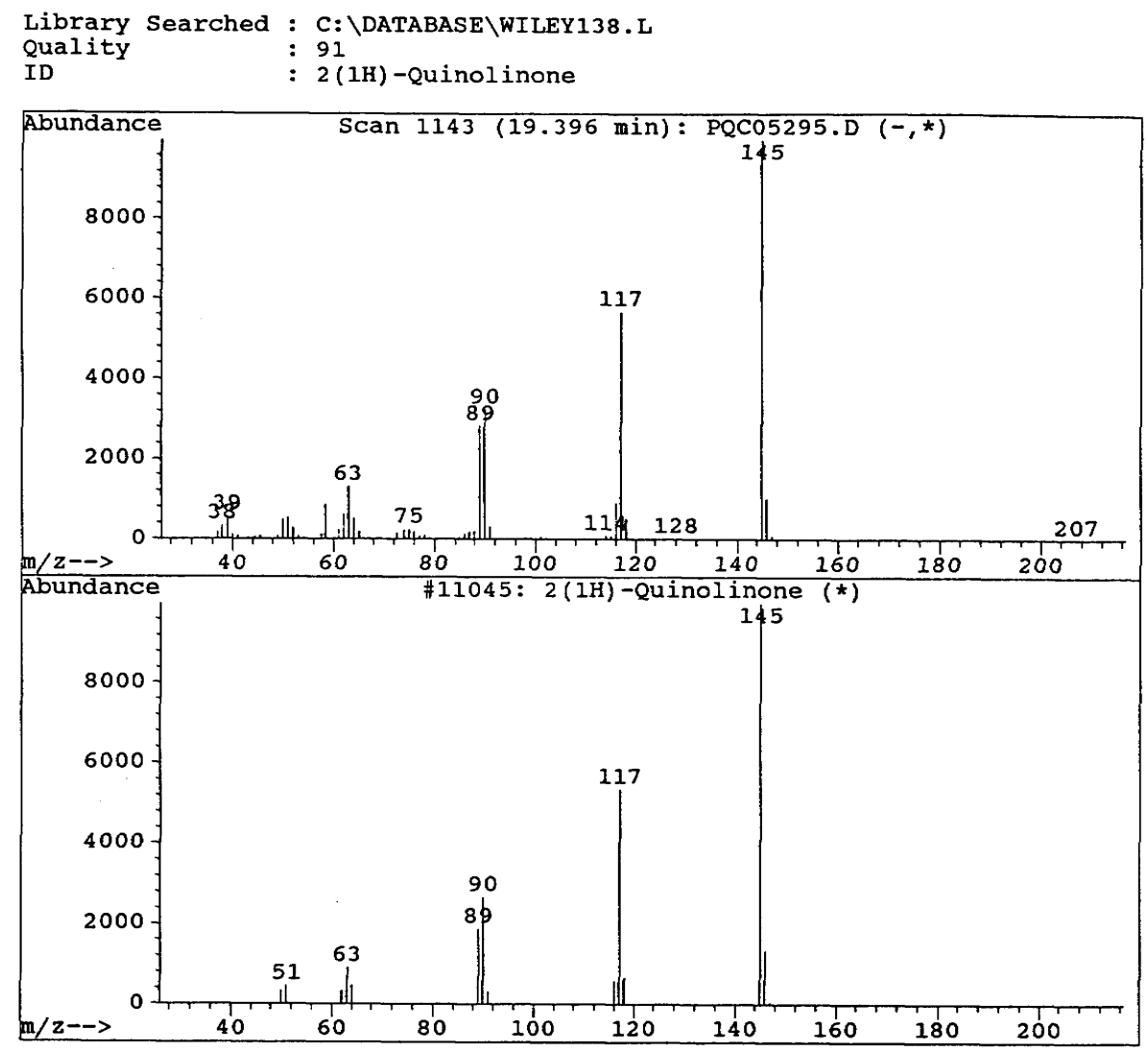

FIGURE 2. COMPARISON OF MS DATA OF A METABOLITE OF QUINOLINE PRODUCED BY PSEUDOMONAS AYUCIDA IGTN9M WITH 2-QUINOLINONE. 


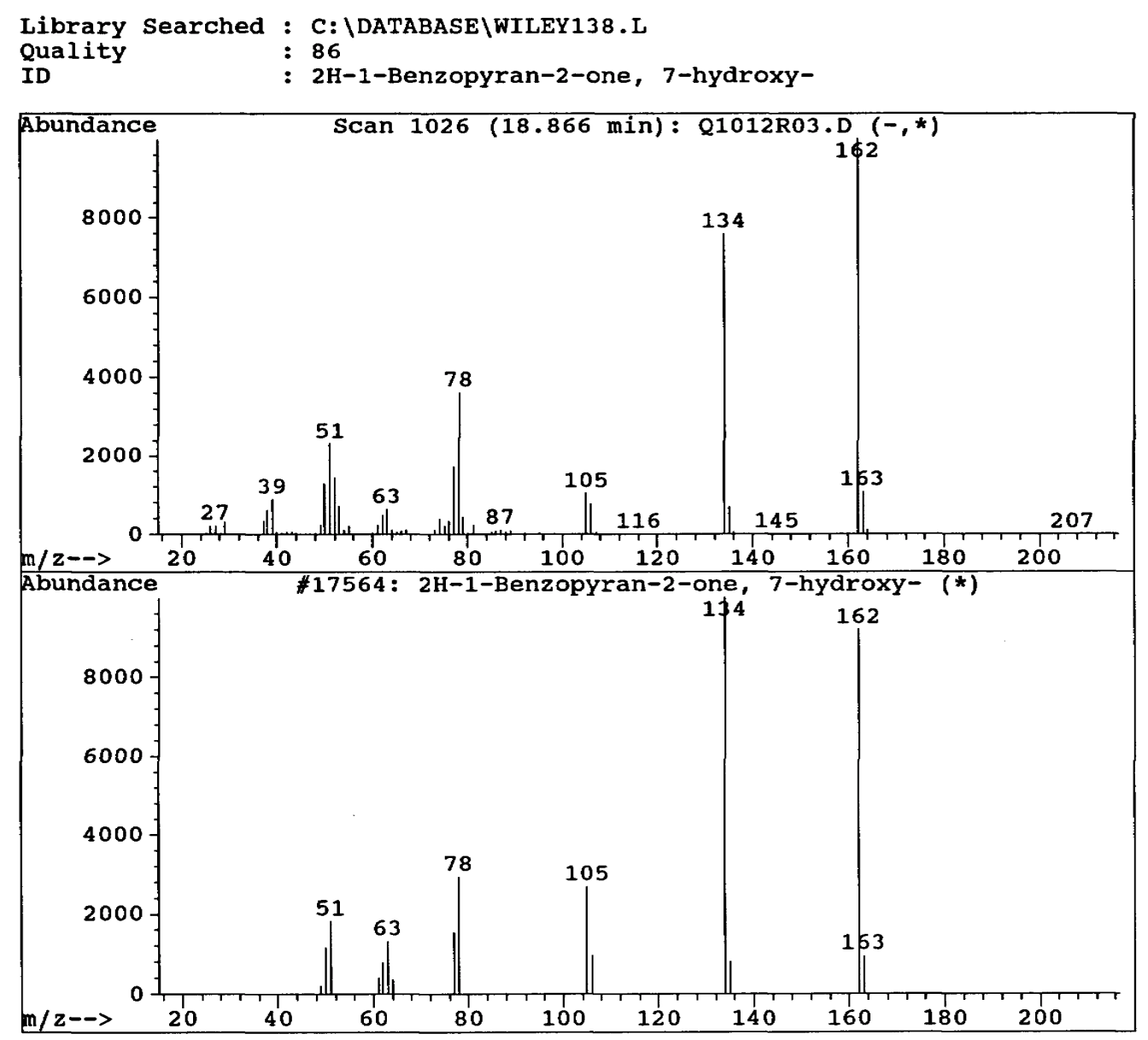

FIGURE 3. COMPARISON OF MS DATA OF A METABOLITE OF QUINOLINE

PRODUCED BY PSEUDOMONAS AYUCIDA. IGTN9M WITH 7-HYDROXY-2H-1BENZOPYRAN-2-ONE (7-HYDROXYCOUMARIN) 


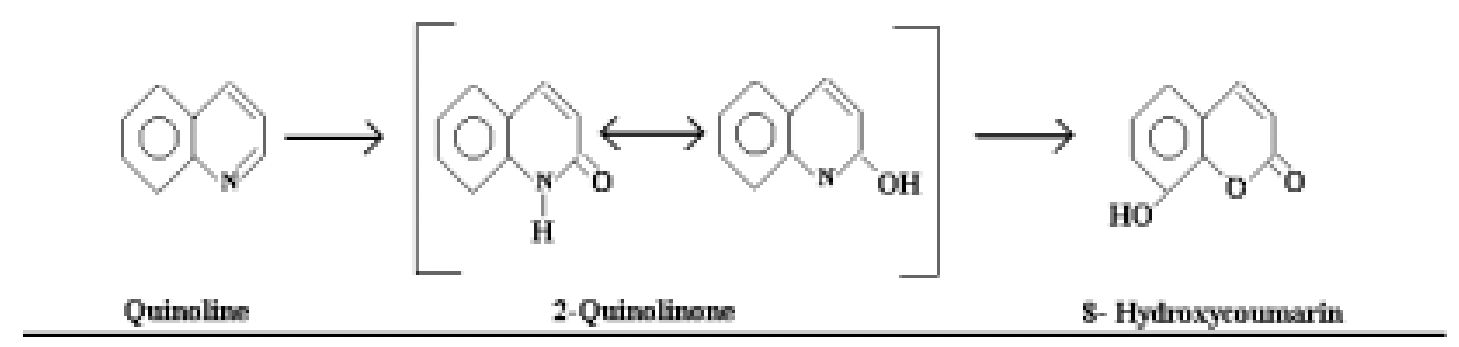

\section{FIGURE 4. SUGGESTED PARTIAL PATHWAY FOR THE DEGRADATION OF QUINOLINE BY PSEUDOMONAS AYUCIDA IGTN9M.}

The data presented in Table 2 are expressed as a percentage of the total area of all peaks present in the chromatograph (with the exception of quinoline). These data strongly indicate that quinoline is first converted to 2-quinolinone and then to 8-hydroxycoumarin. There are undoubtedly other metabolites as the direct conversion of 2-quinolinone to 8-hydroxycoumarin is unlikely. However, no other intermediates relevant to this conversion were observed in these experiments. The structures of 2-quinolinone and 8-hydroxycoumarin are shown in Figure 4 that suggests a partial pathway for the biotransformation of quinoline by Pseudomonas ayucida IGTN9m. The oxygenation of the carbon atom adjacent to the nitrogen atom in quinoline to form 2-quinolinone is consistent with the selective cleavage of $\mathrm{C}-\mathrm{N}$ bonds in quinoline by Pseudomonas ayucida IGTN9m. Moreover, the results of the substrate range tests which indicate that Pseudomonas ayucida IGTN9m can utilize quinoline, 3,4-dihydro-2(1H)quinolinone, 2,4-quinolinediol, 8-hydroxyquinoline, and quinoxaline are also consistent with the partial pathway depicted in Figure 4. The identification of 2-quinolinone and 8hydroxycoumarin as metabolites of quinoline produced by Pseudomonas ayucida IGTN9m is also consistent with published results of other investigations of the bacterial metabolism of quinoline $(9,19)$. Nonetheless, the partial pathway for the metabolism of quinoline by Pseudomonas ayucida IGTN9m pictured in Figure 4 must be considered tentative, as the structures of the metabolites have not been identified with absolute certainty.

Since 8-hydroxycoumarin does not contain nitrogen these data demonstrate that Pseudomonas ayucida IGTN9m is capable of selective removal of nitrogen from quinoline. The 
subsequent decreased abundance of 8-hydroxycoumarin with longer incubation times (see table 2) indicates that this compound is in turn converted to other, as yet unidentified, metabolites. However, it is important to keep in mind that this culture does not use quinoline as a carbon source and is unable to completely degrade it efficiently. Also, many quinoline-degrading microorganisms have been reported to produce pink, green, and brown metabolites, but Pseudomonas ayucida IGTN9m produces no colored metabolites derived from quinoline.

The metabolism of quinoline by microbial cultures is complicated by the use of different chemical nomenclature by various researchers. The initial aerobic metabolites of quinoline are sometimes called 2-quinolinone, 2(1H)-quinolinone, 2-hydroxyquinoline, or 2-oxo-1,2dihydroquinoline. However, these various names refer to the same metabolite, which tautomerizes between different structures as shown in Figure 4 The oxygen involved in the conversion of quinoline to 2-quinolinone/2-hydroxyquinoline/2-oxo-1,2-dihydroquinoline has been shown to be derived from water. Quinoline 2-oxidoreductase has been shown to be responsible for this initial metabolism of quinoline. The subsequent conversion of 2 quinolinone/2-hydroxyquinoline/2-oxo-1,2-dihydroquinoline to 2,6-dihydroxyquinoline or 2,8dihydroxyquinoline has been reported for various microbial cultures. The further metabolism of 2,6-dihydroxyquinoline has been reported to result in the degradation of the benzene ring portion of the molecule, while the further metabolism of 2,8-dihydroxyquinoline has been reported to result in the formation of 8-hydroxycoumarin with concomitant release of nitrogen and the subsequent degradation of the molecule to 2,3-dihydroxyphenyl-propionic acid, cis,cis muconic acid, and catechol. The production of 8-hydroxycoumarin by Pseudomonas ayucida IGTN9m is similar to the metabolism of quinoline reported for an unidentified Pseudomonas culture; however, the inability to use quinoline as a carbon source and the lack of production of colored metabolites make the metabolism of quinoline by Pseudomonas ayucida IGTN9m unique. 


\section{Results with Petroleum}

A test for the removal of organic nitrogen from petroleum was performed to determine the ability of Pseudomonas ayucida IGTN9m to remove nitrogen from shale oil. Duplicate washed, concentrated Pseudomonas ayucida IGTN9m cell suspensions were incubated with shale oil samples for 16 hours at $30^{\circ} \mathrm{C}$. The control sample consisted of shale oil added to sterile mineral salts medium which was incubated for 16 hours at $30^{\circ} \mathrm{C}$. After incubation the petroleum samples were recovered and analyzed. The results are shown in Table 3 which indicate that pregrown Pseudomonas ayucida IGTN9m cells are capable of removing about 5\% of the total organic nitrogen and about $68 \%$ of quinoline from shale oil during an overnight (16 hr) incubation. 
Table 3. Biotreatment of Shale Oil with Pseudomonas ayucida IGTN9m

\begin{tabular}{lrrr} 
Element & Control oil & Biotreated \#1 & \multicolumn{1}{r}{ Biotreated \#2 } \\
\cline { 3 - 4 } Carbon, wt\% & 85.01 & 85.21 & 84.87 \\
Hydrogen, wt\% & 9.69 & 9.81 & 9.85 \\
Nitrogen wt\% & 1.71 & 1.63 & 1.62 \\
Sulfur wt\% & 1.41 & 1.34 & 1.36 \\
& & & \\
Quinoline & 177,495 & 58,502 & 57,415 \\
(GC peak area) & & &
\end{tabular}

\begin{abstract}
Results are reported as a percentage of the neat oil, except for the amount of quinoline which is reported as the area under the peak corresponding to the retention time of quinoline in gas chromatographs.
\end{abstract}

To summarize results obtained with Pseudomonas ayucida IGTN9m, the selective cleavage of carbon-nitrogen bonds by Pseudomonas ayucida IGTN9m was demonstrated by determining that quinoline is metabolized to compounds tentatively identified as 2-quinolinone and 8-hydroxycoumarin. Initial results indicate only a $5 \%$ reduction of total nitrogen from petroleum, but about $68 \%$ of the quinoline present in petroleum was selectively removed as a consequence of biotreatment. These results indicate that biorefining processes for the selective removal of nitrogen from petroleum are technically feasible. However, while these results are encouraging they must be extended with further research and the isolation of cultures which metabolize a broader range of organonitrogen substrates if a practical petroleum biorefining process for the removal of nitrogen is to be developed. 


\section{Characterization of a Piperidine-Degrading Culture (Pseudomonas citronellolis IGTN10)}

Cytochrome $\mathrm{P} 450$ (pipA) is involved in piperidine and pyrolidine utilization in a Mycobacterium species and the gene encoding this P450 enzyme has been isolated, sequenced and characterized(3). IGTN10, a piperidine-and-pyrolidine-utilizing microorganism, was isolated from enrichment culture experiments and can grow at temperatures up to $45^{\circ} \mathrm{C}$. Since the pipA gene has already been identified in a Mycobacterium species, that gene or an analogous gene isolated from IGTN10, may be obtained and expressed in Thermus thermophilus. In this way the production of an extreme thermophile with the ability to selectively cleave C-N bonds may be obtained. The ability to genetically manipulate a gene involved in $\mathrm{C}-\mathrm{N}$ bond cleavage is an important accomplishment because it can lead to high-level expression of this enzyme and the possible expansion of the substrate range of the enzyme.

Piperidine is a non-aromatic organonitrogen cyclic compound. Several mesophilic bacterial cultures, typically Mycobacterium and Arthrobacter species, capable of degrading piperidine and related organonitrogen compounds morpholine and pyrrolidine have been isolated. A schematic outline of the pathway for the biodegradation of piperidine is shown in Figure 5 .

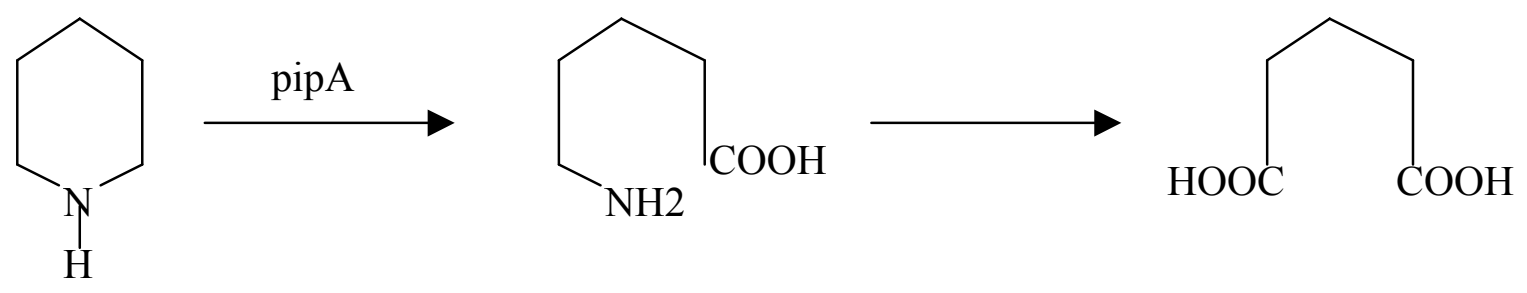

piperidine

5-aminovaleric acid

glutaric acid

\section{FIGURE 5. BIODEGRADATION PATHWAY FOR PIPERIDINE}

While piperidine contains several carbon-carbon bonds the initial enzymatic attack in piperidine biodegradation is the cleavage of a $\mathrm{C}-\mathrm{N}$ bond catalyzed by the cytochrome p450-like oxygenase enzyme encoded by the pipA gene. The piperidine-degrading Mycobacterium strain 105337 was obtained from another laboratory and in this project Pseudomonas citronellolis IGTN10 was isolated that is capable of utilizing piperidine as a sole nitrogen source at $45^{\circ} \mathrm{C}$. 
The fact that the cytochrome oxygenase encoded by pipA is apparently capable of selectively cleaving $\mathrm{C}-\mathrm{N}$ bonds in a range of organonitrogen compounds (piperidine, pyrrolidine, morpholine, and thiomorpholine) make the pipA gene an interesting candidate for possible genetic study.

Sequencing of the 16S rRNA gene from this piperidine-utilizing culture isolated in this project showed that IGTN10m is Pseudomonas citronellolis. IGTN10 was also shown to utilize quinazoline and triazine (in addition to piperidine and pyrolidine) as the sole nitrogen source for growth at $45^{\circ} \mathrm{C}$. Other organonitrogen compounds such as quinoline, quinoxaline, isoquinoline, pyridine and carbazole were not used as sole nitrogen sources by IGTN10m. Nonetheless, IGTN10m possesses a broader substrate range for the utilization of organonitrogen compounds than other cultures isolated in this project. Ultimately it was determined that further characterization of this culture was not appropriate and cultures with broader substrate range for organonitrogen compounds more typically found in petroleum was the focus of research.

\section{Isolation of Triazine-Utilizing Microorganisms (GTIN8T and GTIN9T)}

Triazine is a cyclic alkane consisting of alternating carbon and nitrogen atoms. Thus triazine contains only carbon-nitrogen and carbon-hydrogen bonds. Enrichment culture experiments utilizing triazine as a sole nitrogen source should then result in the isolation of cultures capable of cleaving C-N bonds. Triazine enrichment culture experiments resulted in isolation of two thermophilic cultures that can utilize triazine as a sole nitrogen source in the temperature range 55 to $60^{\circ} \mathrm{C}$. These cultures have been identified as Bacillus thermocatenulatus GTIN8T and Bacillus smithii GTIN9T based on a determination of a portion of the 16S rRNA genes of these cultures. Both cultures were shown to utilize quinazoline as well as triazine as sole nitrogen sources in nitrogen bioavailability assays. No other organonitrogen test compounds were utilized by these cultures.

\section{Isolation of Carbazole-Utilizing Microorganisms (GTIN11, GTIN12 and GTIN14):}

A mixed inoculum was found to grow at $45{ }^{\circ} \mathrm{C}$ using carbazole as a sole nitrogen source. The isolation of pure colonies with ability to selectively cleave $\mathrm{C}-\mathrm{N}$ bonds in carbazole was accomplished through repeated streaking of the mixed culture onto nutrient agar and ModA agar 
plates. Multiple nitrogen bioavailablity assays confirmed that GTIN11, GTIN12, GTIN14 selectively utilize carbazole as the sole nitrogen source at $30-37^{\circ} \mathrm{C}$. A partial sequencing of $16 \mathrm{~S}$ rRNA genes showed that these microorganisms are from the genus Sphingomonas.

A candidate source for genes that encode enzymes involved in the selective cleavage of $\mathrm{C}-\mathrm{N}$ bonds derives from the biodegradation of carbazole. Several mesophilic bacterial strains that can degrade carbazole have been described in the literature. The metabolic pathway for carbazole biodegradation has been determined, as shown in Figure 6, and the genes for this pathway have been cloned from a Pseudomonas culture (CA10) and sequenced. The pathway shown in Figure 3 is somewhat misleading as it suggests that a single enzyme encoded by the carA gene is responsible for the initial oxidative attack on carbazole resulting in the cleavage of a $\mathrm{C}-\mathrm{N}$ bond. However, the carbazole 1,9a-dioxygenase enzyme is actually encoded by four genes: two copies of a dioxygenase gene (both designated carAa), a ferredoxin gene $\operatorname{carAc}$, and a ferredoxin reductase gene carAd. Duplicate copies of the dioxygenase gene are not required for enzymatic activity, and it is not yet known if the ferredoxin and ferredoxin reductase gene products encoded by carAc and carAd are required, or if other ferredoxin genes fond in bacterial cells can be substituted. The downstream portion of the carbazole degradation pathway encoded by the $\operatorname{carB}$ and $\operatorname{carC}$ genes are not involved in $\mathrm{C}-\mathrm{N}$ bond cleavage and therefore are not of interest in this project. The carbazole 1,9a-dioxygenase enzyme encoded by carAa, carAc, and carAd, collectively referred to as CARDO, is of particular interest because it recognizes aromatic organonitrogen compounds as substrates and has a reasonably broad substrate range: dibenzofuran, dioxins, carbazole, dibenzothiophene and other chemically related compounds are all oxidized by CARDO. We isolated three cultures that can selectively degrade utilize the C-N bonds in carbazole at $30-37^{\circ} \mathrm{C}$ and one of these cultures, GTIN11 was selected for further charaterization. 


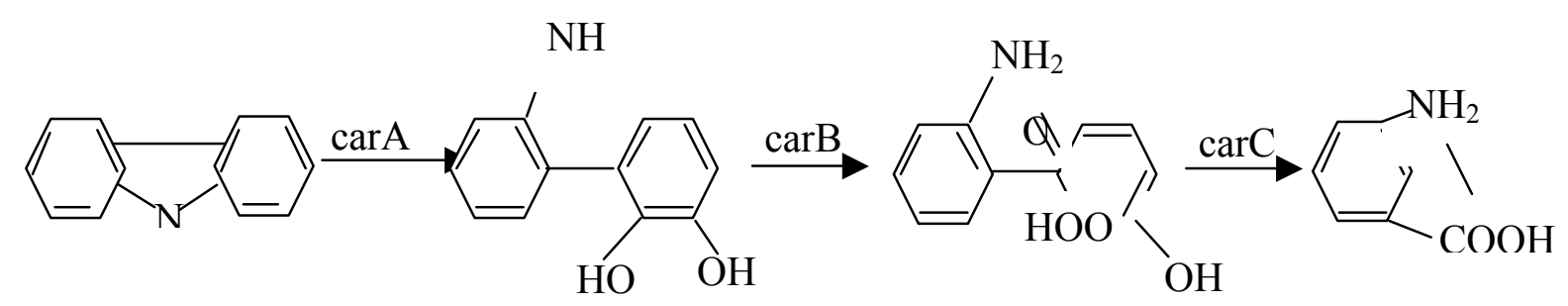

FIGURE 6. BIODEGRADATION PATHWAY FOR CARBAZOLE

\section{Culture Isolation and Characterization}

A turbidostat was operated at $37^{\circ} \mathrm{C}$ using nitrogen-free mineral salts medium (medium A2) and carbazole as the sole source of nitrogen. The turbidostat was inoculated with samples obtained from manufactured gas plant (MGP) soils where chronic hydrocarbon contamination exists. A carbazole degrading strain was obtained by periodic screening of the turbidostat culture supernatant for the ability to grow on carbazole as the sole source of nitrogen. Initially, a mixed culture was obtained, however after streaking the mixed culture onto TT agar and A2-carbazole agar plates individual colonies were isolated and eventually a pure culture capable of growing in nitrogen-free Medium A2 with carbazole as the sole nitrogen source was observed.

The identity of the carbazole-degrading culture was investigated using biochemical tests, microscopic observation, and a determination of the DNA sequence of a 472-bp portion of its 16SrRNA gene. The culture is a facultative Gram-negative rod that forms medium sized, smooth, beige, round colonies with regular and complete margins on TT agar. Positive results indicating that the culture utilizes glucose, rhamnose, melibiose, and arabinose were obtained with the API20E bacterial identification system, while all other tests were negative. The culture is oxidase negative and capable of both oxidizing and fermenting glucose as determined by the API OF test. An alignment of the 472 bp DNA sequence of the 16S rRNA of the culture with DNA sequences available in the MIDI Labs database indicates that it is most closely related to Sphingomonas chlorophenolica (98.51\% homology), and the next most closely related sequence is from Sphingomonas yanoikuyae $(97.24 \%$ homology). These data indicate that this carbazoledegrading bacterium can be identified to the genus level as a Sphingomonas but species identification is not possible at this time. Based on these results the culture was designated as Sphingomonas sp. GTIN11. 


\section{Growth and Characterization of Carbazole Degradation}

Sphingomonas sp. GTIN11 colonies grown on TT agar plates were examined for the presence of meta-cleavage enzymes using a well developed assay that monitors the conversion of 2,3-dihydroxybiphenyl to a yellow metabolite, 2-hydroxy-6-oxo-6-phenylhexa-2,4-dienoic acid (HOPDA). Sphingomonas sp. GTIN11 produced HOPDA on this rich nutrient medium suggesting constitutive expression of the carbazole degradation trait.

Growth of Sphingomonas sp. GTIN11 in TT Media at $37^{\circ} \mathrm{C}$ was observed to be rapid with a generation time of $2.1 \mathrm{hrs}$ as shown in Figure 7. The presence or absence of carbazole does not affect the growth rate of Sphingomonas sp. GTIN11 (data not shown). Moreover, as shown in Figure 7, the culture growing in TT medium is capable of metabolizing carbazole decreasing the concentration from $1,700 \mu \mathrm{M}$ to $300 \mu \mathrm{M}$ (82\% degradation) within 8 hours, but no further degradation of carbazole is observed once the cells enter the stationary phase of growth. The growth of Sphingomonas sp. GTIN11 in medium A2 was observed to be much slower than in TT medium with a generation time of 16 hours using either carbazole or ammonia as sole sources of nitrogen (data not shown). 


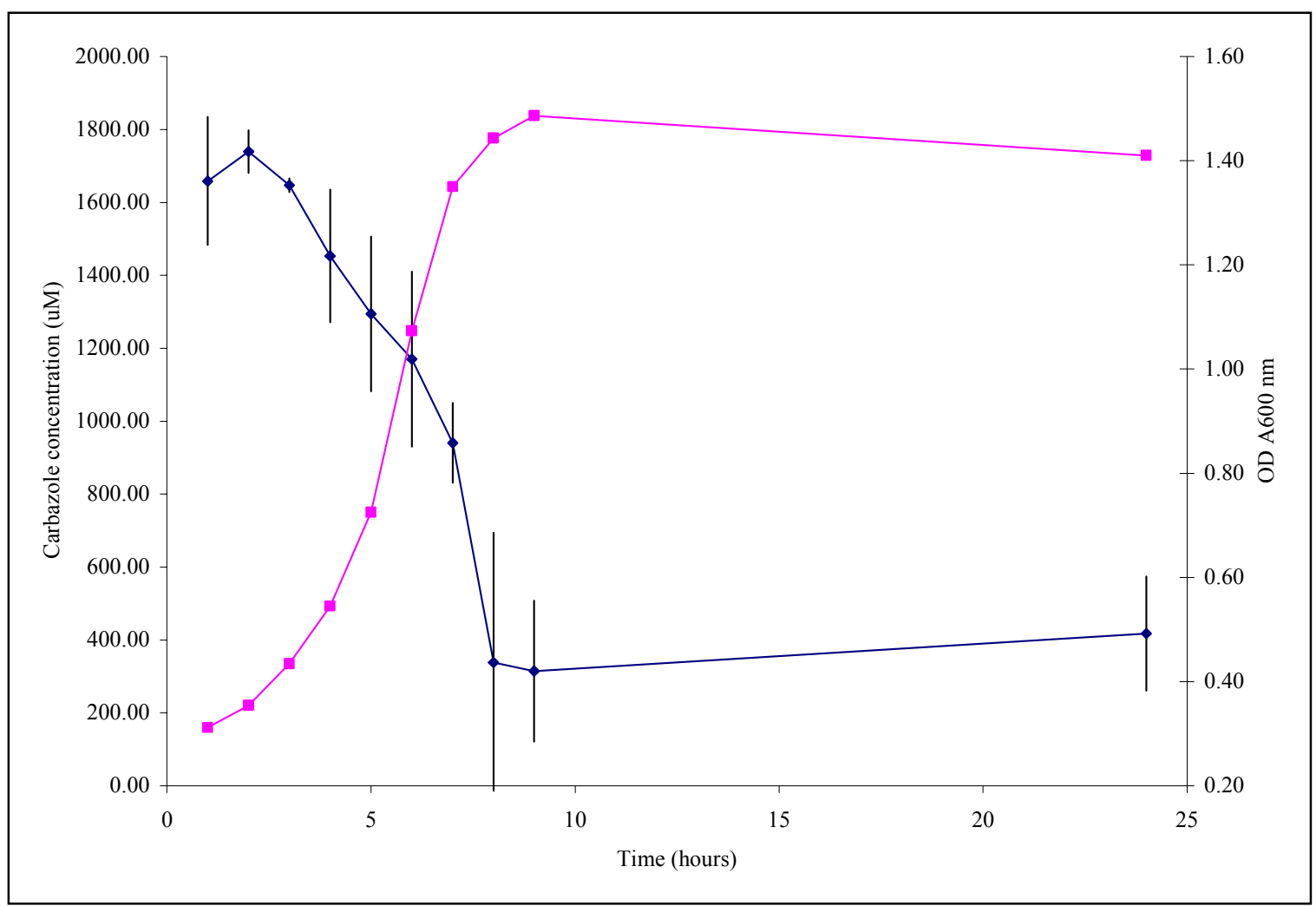

FIGURE 7. GROWTH OF SPHINGOMONAS SP. GTIN11 IN TT MEDIA AND CARBAZOLE DEGRADATION.

Graph of Carbazole degradation (uM) vs. time (hours) ; and Growth Rate in TT Media vs. Time

m. Carbazole concentration values recorded are averages of three replicate samples from three separate experiments for a total of nine data points. Standard deviations are noted in horizontal bars.

To confirm constitutive expression of the carbazole degradation trait of GTIN11 we examined the ability to metabolize carbazole after growth in liquid culture on a rich nutrient medium (TT) using both Sphingomonas sp. GTIN11 and Pseudomonas sp. CA10. Cultures were grown in TT medium until 0.7 to $0.9 \mathrm{OD}$ at A600nm, the cells were washed, $200 \mu \mathrm{M}$ unlabelled carbazole and $1 \times 10^{6}$ DPM of ${ }^{14} \mathrm{C}$ carbazole were added and the cells were incubated for 120minutes at $30^{\circ} \mathrm{C}$. The cultures were extracted and analyzed by HPLC and the results are shown in Figure 8. Sphingomonas sp. GTIN11 metabolizes carbazole in the presence of rich nutrient media where Pseudomonas sp. CA10 does not. The complete degradation (mineralization) of ${ }^{14} \mathrm{C}$ 
carbazole to $\mathrm{CO}_{2}$ and $\mathrm{H}_{2} \mathrm{O}$ was also monitored by measuring $\mathrm{NaOH}$ trapped ${ }^{14} \mathrm{CO}_{2}$ using a scintillation counter. Approximately $4.5 \times 10^{5} \quad \mathrm{DPM}^{14} \mathrm{CO}_{2}$ was recovered from the Sphingomonas sp. GTIN11 flask while no ${ }^{14} \mathrm{CO}_{2}$ was recovered from the Pseudomonas sp. CA10 flask.

To further examine constitutive expression we determined meta-cleavage enzyme activity in nutrient medium throughout the exponential phase of the Sphingomonas sp. GTIN11 growth curve. HOPDA levels were spectrophotometrically monitored and the results are shown in Figure 9. When cell concentrations were normalized HOPDA levels were fairly constant at about $1.1 \mathrm{OD}$ unit at A434nm in log phase cells, however; much reduced values of $0.2 \mathrm{OD}$ at A434nm or less were obtained from stationary phase cells (data not shown). In contrast Pseudomonas sp. CA10 did not show any 2,3-didroxybiphenyl activity when grown using TT medium with or without carbazole (data not shown).

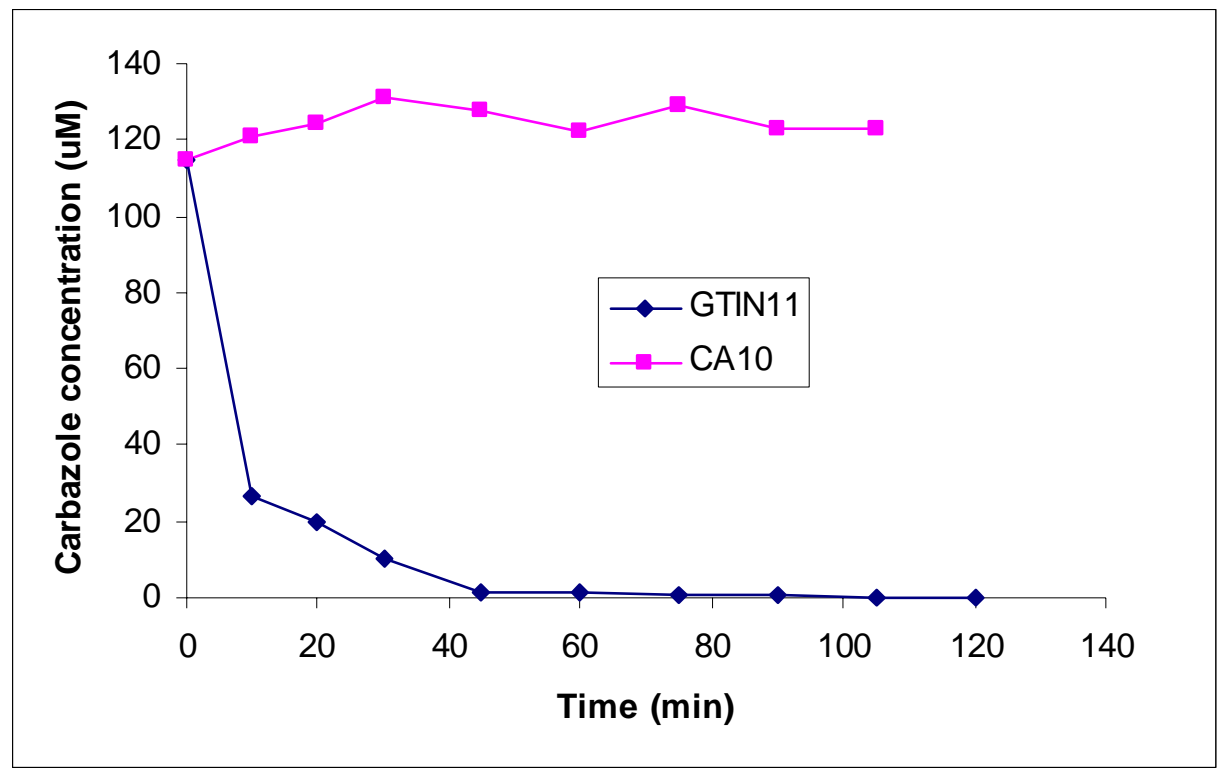

FIGURE 8. CARBAZOLE METABOLISM BY SPHINGOMONAS SP. GTIN11 AND PSEUDOMONAS SP. CA10 IN RICH MEDIUM. 
TT pre-grown cell preparations of Sphingomonas sp. GTIN11 and Pseudomonas sp. CA10 exposed to $120 \mu \mathrm{M}$ carbazole for 120 minutes. Carbazole concentration values (uM) recorded are averages of three replicate samples. Standard deviation is less than $10 \%$.

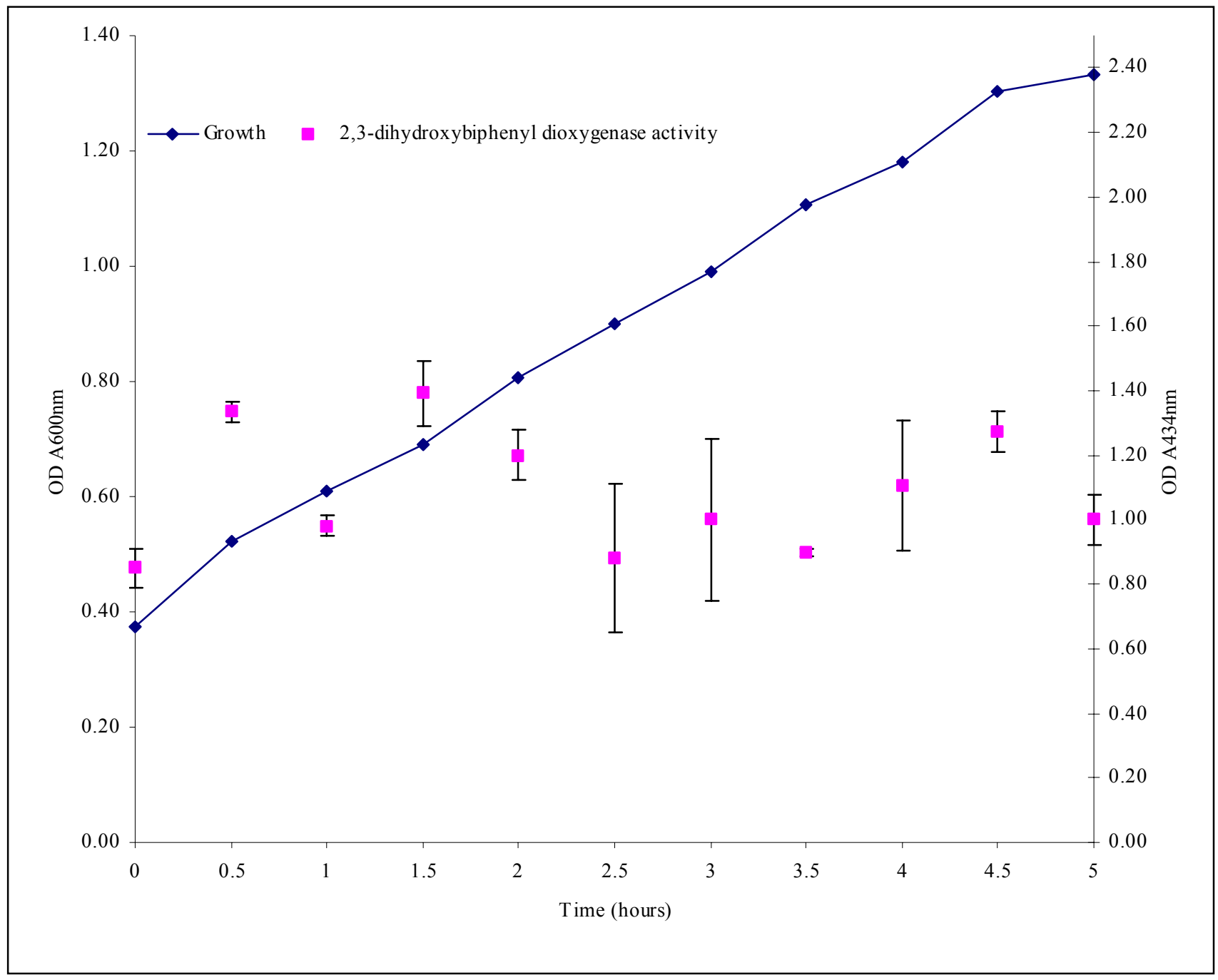

FIGURE 9. EXPONENTIAL PHASE GROWTH OF SPHINGOMONAS SP. GTIN11 (OD A600 NM) AND 2,3-DIHYDROXYBIPHENYL ACTIVITY (OD A434 NM) VS. TIME (HOURS).

2,3-dihydroxybiphenyl activity values recorded are averages of three replicate samples. Standard deviation is noted in horizontal bars. 
Sphingomonas sp. GTIN11 resting cell specific activity (cells pregrown on TT medium) was determined by monitoring the loss of carbazole over time. Resting cell specific activity averaged $8.0 \mu \mathrm{mol} / \mathrm{min}$ g DCW. Sphingomonas sp. GTIN11 was also grown in minimal medium A2 using ammonia as a nitrogen source and a variety of carbon sources (glucose, sucrose, acetate, fumarate, succinate, and lactate). The ability of resting cell preparations to metabolize carbazole was determined, and carbazole degradation was observed under all conditions and specific activity remained the same for TT and minimal media grown Sphingomonas sp. GTIN11 cells (data not shown) Resting cell specific activity is $8.0 \mu \mathrm{mol} / \mathrm{min} \mathrm{g}$ DCW for Sphingomonas sp. GTIN11 compared to an estimated $10 \mu \mathrm{mol} / \mathrm{min} / \mathrm{g}$ DCW for Sphingomonas sp. CDH-7. However, Sphingomonas sp. GTIN11 is unique in expressing the carbazole degradation phenotype constitutively, allowing active cell suspensions to be obtained from rapidly growing cultures in TT medium.

\section{Carbazole Degradation Pathway Intermediates Identification}

In order to identify the metabolic pathway of carbazole degradation by Sphingomonas $s p$. GTIN11 extracts of both growing and resting cells that were exposed to carbazole were analyzed by GC-MS. The results obtained indicated only the presence of metabolites that had undergone substantial biodegradation. Metabolites of carbazole that were detected in Sphingomonas sp. GTIN11 culture supernatants included anthranillic acid, succinic anhydride, succinic acid, and fumaric acid. Anthranillic acid has been detected as a metabolite of carbazole produced by other cultures and it is likely that Sphingomonas sp. GTIN11 follows a similar, if not identical, pathway. However, since metabolites derived from early steps in the pathway were not detected this remains a speculation.

\section{Substrate Range}

Growth tests were performed to determine the range of organonitrogen compounds that can serve as sole sources of nitrogen for Sphingomonas sp. GTIN11. Carbazole was the only organonitrogen compound tested that supported healthy growth of this culture. Sparse growth was obtained with 2-methyl carbazole and the culture supernatant turned from pink to purple to greenish to brown during the course of growth over 5 to 7 days. No growth was obtained using 
N-phenyl carbazole, 9-ethyl carbazole, ellipticine, thiazole, 2-amino biphenyl, or quinoline. Control experiments employing the test organonitrogen compounds plus $\mathrm{NH}_{4} \mathrm{Cl}_{2}$ uniformly yielded growth indicating that these organonitrogen compounds were not toxic to Sphingomonas sp. GTIN11 at the concentration employed in these experiments $(5 \mathrm{mg} / \mathrm{L})$. The supernatant turned light orange in growth experiments containing 9-ethyl carbazole plus $\mathrm{NH}_{4} \mathrm{Cl}_{2}$ indicating that this carbazole derivative can apparently be metabolized by this culture.

The ability of Sphingomonas sp. GTIN11 to metabolize compounds structurally related to carbazole was further investigated by incubating resting cells in the presence of various compounds for 16 hours at $37^{\circ} \mathrm{C}$ and then analyzing the results using thin layer chromatography (TLC). Only those spots observed, using short UV (254 nm) or long UV (365 nm) illumination, in two or more TLC experiments that were unique in comparison with compound-only and cellonly controls were recorded in Table 4. These results indicate that Sphingomonas sp. GTIN11 has activity on a wide range of organic substrates that includes anthracene, biphenyl, dibenzothiophene (DBT), and quinoline. While the TLC results reported in Table 4 using resting cells are similar to results obtained using purified carbazole 1,9a-dioxygenase from the carbazole-degrading culture Pseudomonas sp. strain CA10 the number of metabolites and the relative mobility of the metabolites observed for a given compound are not identical. Since the carbazole-degradation phenotype is constitutively expressed in Sphingomonas sp. GTIN11 it was not possible in these experiments to determine if the enzymes responsible for carbazole degradation in this culture are also responsible for the metabolism of other substrates or if other degradation pathways also contributed to the results. The Gibbs assay was used to further examine the metabolites of DBT produced by Sphingomonas sp. GTIN11 and the results indicated the presence of a compound(s) that contains an aromatic hydroxyl group, which is in agreement with the results obtained with carbazole 1,9-dioxygenase derived from Pseudomonas sp. CA10. 
Table 4. Metabolites of Various Produced by Resting Cell Cultures of Sphingomonas sp. GTIN11 as Detected by Thin Layer Chromatography

\begin{tabular}{|l|l|l|l|l|l|l|l|l|l|}
\hline Substrate & Condition & \multicolumn{6}{|l|}{ Relative Mobility of Spots Observed (254 nm) } \\
\hline Carbazole & control & & & & & & & $.81^{\mathrm{L}}$ & \\
\hline Carbazole & GTIN11 & & & .36 & .43 & & & & \\
\hline DBT & control & & & & & & & & .93 \\
\hline DBT & GTIN11 & & & .33 & $.45^{+}$ & $.59^{+}$ & .75 & & \\
\hline Anthracene & control & & & & & & .71 & & $.92^{\mathrm{L}+}$ \\
\hline Anthracene & GTIN11 & & $.32^{\mathrm{L}}$ & .38 & $.45^{\mathrm{L}+}$ & .64 & $.74^{\mathrm{L}+}$ & & \\
\hline Biphenyl & control & $\mathrm{N}$ & & & & & & & \\
\hline Biphenyl & GTIN11 & & .3 & .34 & & .52 & $.71^{+}$ & .79 & \\
\hline Quinoline & control & & & & & $.62^{\mathrm{L}}$ & & & \\
\hline Quinoline & GTIN11 & $.07^{+}$ & .23 & .37 & & & & & \\
\hline
\end{tabular}

$\mathrm{L}=$ Spot fluoresces under long-wave UV light $(365 \mathrm{~nm})$.

$+=$ Spot was present in greater abundance than other metabolites observed with a given substrate.

$\mathrm{N}=$ No TLC spot was observed. 


\section{Cloning and characterization of genes involved in carbazole degradation}

Colonies of E. coli DH5a containing recombinant pUC18 with a library of cloned fragments from the Sphingomonas sp. GTIN11 chromosome were screened for expression of 2,3-dihydroxybiphenyl dioxygenase. As a result of screening a plasmid containing a $4.2 \mathrm{~kb}$ insert was isolated. The fragment was sequenced, characterized and submitted to GenBank under accession number AF442494. DNA sequence analysis discovered that the fragment contained five open reading frames (ORFs) relevant to carbazole degradation. Each ORF was initiated by either ATG or GTG and was preceded by potential ribosome binding sites (RBS). The deduced amino acid sequence of the ORFs showed homology to other carbazole terminal dioxygenase (ORF1), 2,3-dihydroxybiphenyl dioxygenases (ORF2 and ORF3), meta-cleavage compound hydrolases (ORF4) and ferredoxin component of bacterial multicomponent dioxygenases (ORF5). Immediately preceding the start site of ORF1 nucleotide sequence were two putative prokaryotic promoters at nucleotide positions 426 to 471 (Score $=.85$ ) and at positions 507 to $552($ Score $=.94)$ as determined by promoter prediction by neural network (NNPP) (16) at BCM search launcher http://searchlauncher.bcm.tmc.edu. About $1 \mathrm{~Kb}$ of DNA sequence 5' relative to ORF1 was also determined, but no genes relevant to carbazole degradation were detected.

Table 5 shows the deduced protein feature, nucleotide position, number of amino acids, predicted molecular mass (Kda) and percent similarity to other gene products of the ORFs believed to encode genes from the carbazole operon of GTIN11. Table 5 includes the percent similarity $(>20 \%)$ of the GTIN11 gene products to two other carbazole degrading microorganisms, Pseudomonas sp. CA10 and Sphingomonas sp. CB3, for which sequence information is available. The data in Table 2 indicate that the proteins of the carbazole degradation pathway of Sphingomonas sp. GTIN11 show $\leq 60 \%$ similarity to other known proteins. 
Table 5. Deduced amino acid sequence of Sphingomonas sp. GTIN11 carbazole operon and percent similarity to other gene products.

\begin{tabular}{|c|c|c|c|c|c|}
\hline ORF & $\begin{array}{l}\text { Deduced } \\
\text { Protein } \\
\text { feature }\end{array}$ & $\begin{array}{l}\text { Nucleotide } \\
\text { position }\end{array}$ & $\begin{array}{l}\text { No. of } \\
\text { aa }\end{array}$ & $\begin{array}{l}\text { Predicted } \\
\text { molecular } \\
\text { mass }(\text { Kda })\end{array}$ & $\begin{array}{l}\text { \% similarity to other gene products } \\
\text { (\%similarity, gene name and strain) }\end{array}$ \\
\hline ORF1 & $\begin{array}{l}\text { carbazole } \\
\text { dioxygenase } \\
\text { CARAA }\end{array}$ & $650-1786$ & 378 & 42.6 & $\begin{array}{l}\text { 60: carAa (Pseudomonas CA10); } \\
\text { 41: OXOO (Pseudomonas putida 86); } \\
\text { 22: CAO (Chlamydomonas reinhardtii) } \\
\text { 21: carA (Sphingomonas sp. CB3) }\end{array}$ \\
\hline ORF2 & $\begin{array}{l}\text { meta } \\
\text { cleavage } \\
\text { enzyme } \\
\text { subunit } \\
\text { CARBA }\end{array}$ & $1735-2067$ & 110 & 12 & 36: carBa (Pseudomonas sp. CA10); \\
\hline ORF3 & $\begin{array}{l}\text { meta } \\
\text { cleavage } \\
\text { enzyme } \\
\text { catalytic } \\
\text { subunit } \\
\text { CARBB }\end{array}$ & $2060-2863$ & 267 & 28.9 & $\begin{array}{l}\text { 43: carBb(Pseudomonas sp. CA10); } \\
\text { 31: PHNC(Burkholderia sp. RP007); } \\
\text { 29: FLDU(Sphingomonas sp LB126); }\end{array}$ \\
\hline ORF4 & $\begin{array}{l}\text { meta } \\
\text { cleavage } \\
\text { compound } \\
\text { hydrolase } \\
\text { CARC }\end{array}$ & $2906-3730$ & 274 & 29.6 & $\begin{array}{l}\text { 57: carC(Pseudomonas sp. CA10); } \\
\text { 45 DXNB(Sphingomonas sp. RW1); } \\
\text { 36 NAHN(Pseudomonas sp. AN10 } \\
\text { 32: carD(Sphingomonas sp. CB3); }\end{array}$ \\
\hline ORF5 & $\begin{array}{r}\text { ferredoxin } \\
\text { CARAC }\end{array}$ & $3771-4100$ & 109 & 11.5 & $\begin{array}{l}\text { 50: FDVI(Rhodobacter capsulatus); } \\
\text { 50: FDXE(Rhodobacter capsulatus } \mathrm{B} 10) ; \\
\text { 47: MSL0793(Rhizobium meliloti) }\end{array}$ \\
\hline
\end{tabular}


Legend Table 5.

Bacterial strains and Genbank accession numbers of corresponding genes:

Sphingomonas sp. strain CB3 (AF060489); Pseudomonas sp. strain CA10 (D89064/D89065);

Pseudomonas putida 86 (Y12655); Chlamydomonas reinhardtii (AB0151390); Streptomyces coelicolor A3 (2) (AL021529); Burkholderia sp. RP007 (AF061751); Sphingomonas sp. LB126 (AJ277295); Sphingomonas sp. RW1 (X72850); Pseudomonas sp. AN10 (X52805); Rhodobacter capsulatus ATCC 33303/B10 (Y545612); Rhodobacter capsulatus B10 (Y11304); Rhizobium meliloti MAFF303099 (AP002995);

Gene codes in descending order

carAa $=$ carbazole dioxygenase, $\mathrm{OXOO}=$ 2-oxo-1,2-dihydroquinoline 8-monooxygenase, $\mathrm{CAO}$ $=$ chlorophyll $\mathrm{A}$ oxidase, carA = carbazole dioxygenase, carBa $=$ meta cleavage enzyme, PHNC $=$ extradiol dioxygenase, $\mathrm{FLDU}=$ putative protocatechuate dioxygenase, carC $=$ meta-cleavage compound hydrolase, DXNB = hydrolase ,NAHN = hydroxymuconic semialdehyde hydrolase ,carD = hydrolase ,FDVI $=$ ferredoxin ,FDXE $=$ ferredoxin ,MSL0793 = ferredoxin .

ORF1 encodes for a $42.6 \mathrm{kDa}$ protein that most closely resembles, with $60 \%$ similarity, the CARDO terminal dioxygenase subcomponent (CarAa) from Pseudomonas sp. CA10. This protein was designated CarAa. Similarity was also noted to other multicomponent dioxygenases from aromatic compound degradation pathways. The carbazole terminal dioxygenase protein from Sphingomonas sp. GTIN11 has low (21\%) homology to the terminal dioxygenase component from the carbazole degrader Sphingomonas sp. CB3, and in fact a 2-oxo-1,2dihydroquinoline 8-monooxygenase and a chlorophyll A oxidase have more homology (41\% and $22 \%$ respectively) than the $\mathrm{CB} 3$ carbazole dioxygenase.

ORF2 and ORF3 encode for two proteins that are similar to the meta-cleavage enzyme subunit 2-aminobiphenyl-2,3-diol 1,2-dioxygenase (CarBa) and meta cleavage enzyme catalytic subunit 2-aminobiphenyl-2,3-diol 1,2-dioxygenase (CarBb) from Pseudomonas sp. CA10 respectively. The CarBa protein from GTIN11 showed no significant homology with any other protein in the database except the CarBa enzyme from Pseudomonas sp. CA10 whereas the $\mathrm{CarBb}$ protein of GTIN11 showed similarity to both the CarBb enzyme of Pseudomonas sp. 
CA10 and other protocatechuate dioxygenases. ORF 4 encodes for a meta-cleavage compound hydrolase and was designated as CarC. This enzyme has homology with hydrolases involved in degradation of monocyclic aromatic compounds and is most closely related to the CarC enzyme from Pseudomonas sp. CA10. ORF5 encodes for a ferredoxin enzyme believed to be a subunit (due to gene arrangement similarity to CA10) of carbazole dioxygenase and was designated CarAc. All the carbazole degradation enzymes of GTIN11 except CarAc are the most similar to the carbazole degradation enzymes from Pseudomonas sp. CA10 and proteins involved in degradation of aromatic compounds. However when DNA sequence data is analyzed the carAa and $\operatorname{carC}$ genes of Sphingomonas sp. GTIN11 show $64 \%$ and $65 \%$ homology respectively to the corresponding genes in Pseudomonas sp. CA10. The $c a r B a$ and $c a r B b$ genes of GTIN11 are 58\% homologous to a Pseudomonas paucimobilis protocatechuate 4,5-dioxygenase gene (M34835), while no significant DNA homology was found to any sequences in the GenBank database for the GTIN11 carAc gene.

Sphingomonas sp. GTIN11 resembles Pseudomonas sp. CA10 in that the terminal oxidase component of CARDO is a single subunit rather than the two subunits found in Sphingomonas sp. CB3. Moreover, the arrangement of genes in the carbazole operon of Sphingomonas sp. GTIN11 most closely resembles that of Pseudomonas sp. CA10 except that two copies of the carAa gene are present in Pseudomonas sp. CA10.

\section{Nitrogen removal from petroleum}

While Sphingomonas sp. GTIN11 has shown to metabolize carbazole in experiments employing model compounds it was of interest to determine if similar results could be obtained in experiments using petroleum where a complex mixture of chemicals is present and exposure to petroleum could be potentially damaging to biocatalysts. The results in Table 6 illustrate that Sphingomonas sp. GTIN11 is capable of removing carbazole from shale oil, and that nearly complete removal can be achieved when higher biomass-to-oil ratios are used. The better carbazole removal efficiency seen with samples GTIN11-B in Table 6, versus samples GTIN11A, even though it has slightly lower biomass concentration maybe due to a slight difference in the specific activity of the various cell preparations used in these experiments. GC-MS analyses of biotreated shale oil samples indicated that alkylated derivatives of carbazole were also degraded. Carbazole derivatives containing a single methyl group substitution showed as much 
as $50 \%$ reduction, while no degradation was apparent with more heavily substituted carbazole derivatives (data not shown). Despite the nearly quantitative removal of carbazole, biotreated shale oil samples did not show statistically significant decreases in total nitrogen levels (data not shown).

Table 6. As Much as 95\% of the Carbazole Present in Shale Oil was Removed as a Consequence of Biotreatment with Sphingomonas sp. GTIN11.

\begin{tabular}{|l|c|c|}
\hline SAMPLE & Carbazole $(\mu \mathrm{g} / \mathbf{m l})$ & Carbazole removal (\%) \\
\hline Untreated control & 427 & \\
Untreated control & 416 & \\
P. CA10 (700.8 mg DCW) & 510 & \\
P. CA10 (703.2 mg DCW) & 500 & 87.3 \\
GTIN11-A (732 mg DCW) & 53.5 & 87.9 \\
GTIN11-A (732 mg DCW) & 60.9 & 91.3 \\
GTIN11-B (648 mg DCW) & 36.5 & 91.9 \\
GTIN11-B (648 mg DCW) & 40.7 & 94.1 \\
GTIN11-C (2,560 mg DCW)* & 24.9 & 94.8 \\
GTIN11-C (2,560 mg DCW)* & 26 & \\
\hline
\end{tabular}

$*=$ Biotreatment experiments employed 3 grams of shale oil exposed to an aqueous cell suspension of $50 \mathrm{ml}$, all other biotreatments utilized 2 grams of shale oil and $25 \mathrm{ml}$ of cell suspension containing the indicated dry cell weight (DCW) amounts. 
To summarize results obtained with Sphingomonas sp. GTIN11, enrichment culture experiments employing carbazole as the sole source of nitrogen resulted in the isolation of Sphingomonas sp. GTIN11 that appears to encode a carbazole degradation pathway similar to previously characterized carbazole-degrading cultures. Sphingomonas sp. GTIN11 is unique in expressing the carbazole degradation phenotype constitutively. Protein homology and the organization of genes indicate that the carbazole operon of Sphingomonas sp. GTIN11 is most closely related to Pseudomonas sp. CA10, but differs significantly as proteins are $\leq 60 \%$ similar. The essentially complete removal of carbazole from shale oil was demonstrated using Sphingomonas sp. GTIN11; however, improvements are needed before a practical biorefining process for the removal of nitrogen from petroleum can be developed. The carbazole degradation pathway does not selectively remove nitrogen from carbazole; rather, carbazole is either converted to water-soluble metabolites or degraded completely. It would be preferred if a pathway that selectively removes nitrogen from carbazole while leaving the rest of the molecule intact, analogous to the $d s z$ pathway for the removal of sulfur from DBT by Rhodococcus erythropolis IGTS8, could be isolated or constructed. Cultures with improved substrate ranges are also needed to better address the complex mixture of chemical structures present in petroleum, and thermophilic cultures may be a fruitful source of robust enzymes better suited to the needs of an industrial process.

\section{Characterization of the Dibenzothiophene-Degrading Thermophile Mycobacterium phlei GTIS10}

Turbidostats were operated to enrich for bacterial cultures capable of utilizing DBT as the sole sulfur source for growth at $45^{\circ}, 50^{\circ}, 55^{\circ}, 60^{\circ}$, and $65^{\circ} \mathrm{C}$. The turbidostats were inoculated with samples obtained from various locations where thermophilic conditions and/or chronic hydrocarbon contamination exist. After approximately four months a culture was recovered 
from the $50^{\circ} \mathrm{C}$ turbidostat that could grow well in a sulfur bioavailability assay using DBT at $45^{\circ} \mathrm{C}$. No pure cultures capable of utilizing DBT as a sole sulfur source were isolated from the turbidostats operated at $55^{\circ}, 60^{\circ}$, and $65^{\circ} \mathrm{C}$. Initially a mixed culture was obtained from the $50^{\circ} \mathrm{C}$ turbidostat; however, individual colonies were isolated by streaking the mixed culture onto Nutrient agar plates. These individual colonies were subsequently used to inoculate sulfur bioavailability assays and in this way a pure culture capable of utilizing DBT as a sole source of sulfur was obtained that could grow at temperatures ranging from $20^{\circ} \mathrm{C}$ to $52^{\circ} \mathrm{C}$.

The pure culture was identified as Mycobacterium based on the analysis of biochemical parameters, and on a determination of the DNA sequence of a $500 \mathrm{bp}$ portion of its 16S-RNA gene and was designated as M. phlei GTIS10. M. phlei GTIS10 is a Gram-positive, non-motile rod. Colonies require 2 to 3 days to develop on Nutrient agar at $37^{\circ}$ or $45^{\circ} \mathrm{C}$ and initially are white, small, and round with regular margins. After 5 to 7 days of incubation colonies are light yellow. The culture was positive for arginine dihydrolase, urease, and for the utilization of mannitol and arabinose. The analysis of a 500 bp portion of the 16S-RNA gene derived from this culture (GenBank accession number AY056467) indicated that it has a $99.9 \%$ match to $M$. phlei. The next most closely related species identified in the 16S rRNA DNA sequence database is Mycobacterium confluentis with $97.12 \%$ similarity to GTIS10. The end product of DBT metabolism by $M$. phlei GTIS10 is 2-HBP, which has been reported to be bactericidal, bacteristatic, and to inhibit desulfurization enzymes(Omori, Monna et al. 1992; McFarland 1999; Konishi, Onaka et al. 2000; Reichmuth, H. et al. 2000). Concentrations of $200 \mu \mathrm{M} 2$-HBP are reported to be inhibitory and $400 \mu \mathrm{M} 2$-HBP has been reported to completely prevent growth and desulfurization activity of Corynebacterium (Omori, Monna et al. 1992), Rhodococcus (Reichmuth, H. et al. 2000; Naito 2001), and Gordonia (Chang 2001) cultures. M. phlei GTIS10 is capable of growing well in medium containing concentrations of 2-HBP as high as $750 \mu \mathrm{M}$, and can grow with difficulty in the presence of $1 \mathrm{mM}$ 2-HBP. Viable cells of M. phlei GTIS10 were obtained after exposure to $2 \mathrm{mM} 2$-HBP for 48 hours. It has been stated that bacterial strains with increased tolerance for 2-HBP are needed for a viable petroleum biodesulfurization process(McFarland 1999), and M. phlei GTIS10 appears to be more resistant to 2-HBP than previously reported desulfurization-competent bacterial cultures. 
The growth of $M$. phlei GTIS 10 at $50^{\circ} \mathrm{C}$ using DBT as the sole sulfur source is illustrated in Figure 10. The growth of the culture was monitored spectrophotometrically by recording the change in optical density $\mathrm{A}_{600} \mathrm{~nm}$ over time. M. phlei GTIS10 converted DBT to 2-HBP which accumulated in the culture supernatant and was quantified using HPLC and typical results are included in Figure 10. The generation time of M. phlei GTIS10 growing at $50^{\circ} \mathrm{C}$ in defined salts media with DBT as the sole sulfur source is approximately 5.4 hours when glucose is the carbon source, and 3.7 hours when succinate is used as the carbon source. The generation time of $M$. phlei GTIS10 growing with succinate as the carbon source and dibenzothiophene sulfone as the sole sulfur source is 2.5 hours, which is equivalent to the growth rate of this culture using sulfate under similar conditions (data not shown). The accumulation of 2-HBP closely paralleled the growth of the culture and indicated that stationary phase cells do not continue to metabolize DBT. A modest decrease in 2-HBP concentration was seen in stationary phase cultures that is most probably due to the sorption of 2-HBP to biomass as has been previously observed in studies of DBT metabolism (Oldfield, Pogrebinsky et al. 1997). M. phlei GTIS10 does not utilize DBT or 2-HBP as carbon sources. 


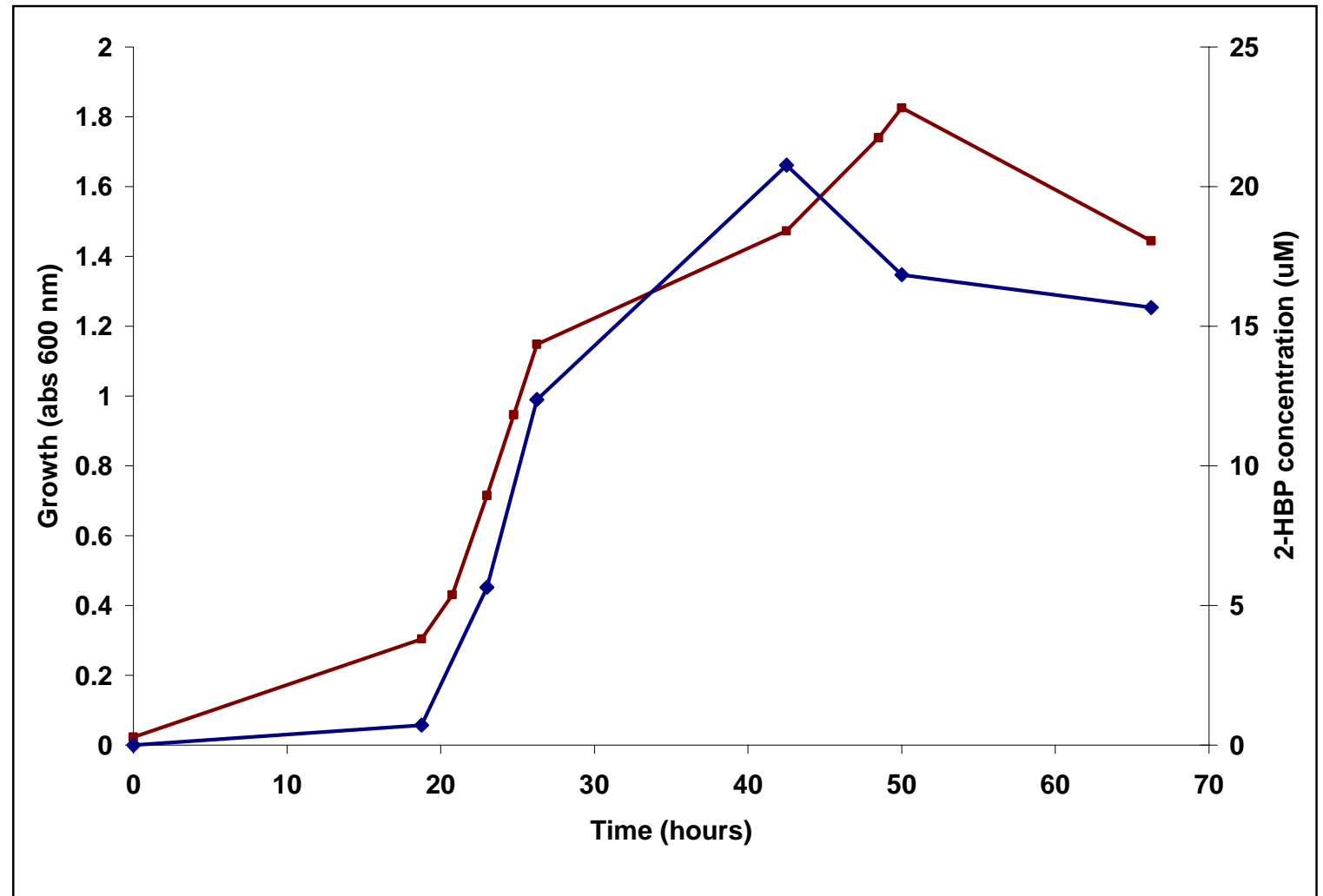

FIGURE 10. GROWTH OF M. PHLEI GTIS10 AT $50^{\circ} \mathrm{C}$ USING DBT AS THE SOLE SULFUR SOURCE.

The accumulation of 2-hydroxybiphenyl (2-HBP) in the supernatant of the growing culture was examined by removing $1.0 \mathrm{ml}$ aliquots at each data point and quantifying 2-HBP using HPLC. Each data point recorded is an average of three replicate samples from three separate experiments for a total of nine data points. Standard deviation is $5 \%$ or less for all data. $\bullet, 2$ HBP; $\mathbf{n}$, growth 
The desulfurization activity of cells harvested at various phases of growth of M. phlei GTIS10 were determined and the best desulfurization activity was observed in resting cells obtained from mid to late log phase cultures (data not shown). The maximum specific desulfurization activity of the $M$. phlei GTIS10 culture converting DBT to 2-HBP was observed at $45^{\circ}$ to $52^{\circ} \mathrm{C}$ and was determined to be $1.1 \pm 0.07 \mu$ mole $2-\mathrm{HBP} / \mathrm{min} / \mathrm{g}$-dry cell. The maximum specific desulfurization activity for $R$. erythropolis IGTS8 was observed at $30^{\circ} \mathrm{C}$ and was $1.2 \pm$ $0.08 \mu$ mole $2-\mathrm{HBP} / \mathrm{min} / \mathrm{g}$-dry cell which is higher than previous studies where other researchers reported specific desulfurization activity values ranging from approximately 0.6 to $.58 \mu$ mole 2 HBP/min/g-dry cell (Konishi, Y. Ishii et al. 1997; Oldfield, Pogrebinsky et al. 1997). The reason why our culture of $R$. erythropolis IGTS8 shows higher desulfurization specific activity than data reported by other researchers may be due to the continuous passage ( $>10$ years) of this culture in our laboratory under conditions where DBT, or other organosulfur compounds, served as sole sulfur source for growth. The highest desulfurization specific activity reported for the thermophilic Paenibacillus sp strain A11-2 was approximately $0.08 \mu$ mole $2-\mathrm{HBP} / \mathrm{min} / \mathrm{g}$-dry cell (Konishi, Y. Ishii et al. 1997). Bacterial cultures containing cloned desulfurization genes from Paenibacillus (tdsABC) have been reported to have a maximum desulfurization specific activity

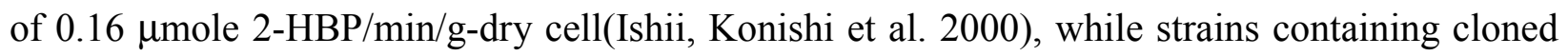
Rhodococcus desulfurization genes $(d s z A B C)$ are reported to have a maximum desulfurization

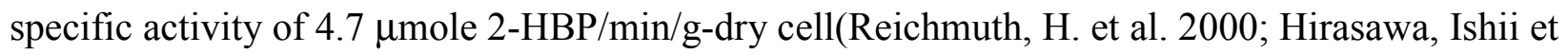
al. 2001). The moderate thermophile Mycobacterium phlei WU-F1 was described as having greater desulfurization activity than Paenibacillus sp. strain A11-2, but no specific activity data was reported.(Furuya, Kirimura et al. 2001)

The range of organosulfur substrates that can be metabolized by $M$. phlei GTIS10 was investigated using various compounds as the sole source of sulfur in growth assays at $45^{\circ} \mathrm{C}$, and the results are shown in Table 7. Test compounds were added at a concentration of $1 \mathrm{mM}$ and the results reported in Table 7 are derived from a minimum of two independent growth tests for each compound. The range of substrates utilized as sulfur sources by $M$. phlei GTIS10 is quite broad and essentially the same as results reported for $R$. erythropolis IGTS8 (Kayser, BielagaJones et al. 1993). It is important to note that M. phlei GTIS10 grew well with thiophene and 
benzothiophene as the sole sulfur source while R. erythropolis IGTS8 has been reported to be unable to utilize thiophene and/or benzothiophene.(Gilbert, Morton et al. 1998; McFarland, Boron et al. 1998; Oldfield, Wood et al. 1998; McFarland 1999) We find that M. phlei GTIS10, as well as $R$. erythropolis IGTS8, grow well with benzothiophene or thiophene as sole sulfur sources, although adaptation by repeated subculturing into medium containing thiophene, benzothiophene, or mixtures of thiophene or benzothiophene plus DBT are required to establish good growth. 
Table 7. Range of Organosulfur Substrates Utilized as a Sole Source of Sulfur for Growth by M. phlei GTIS10

\begin{tabular}{l|c}
\hline Substrate & Used as sole source of sulfur \\
& for growth \\
\hline Dibenzothiophene & + \\
Dibenzothiophene sulfoxide & + \\
Dibenzothiophene sulfone & + \\
4,8-dimethyl dibenzothiophene & + \\
2-methyl dibenzothiophene & + \\
Dibenzothiophene-2,8-dicarbaldehyde & + \\
Benzothiophene & + \\
Thiophene & + \\
2-ethyl thiophene & + \\
2-thiophene carboxylic acid & - \\
2-thiophene carbonitrile & - \\
3-thiophene carboxylic acid & - \\
Trithiane & + \\
Thianthrene & + \\
Thianaphthene & - \\
Trans-1,2-dithiane-4,5-diol & + \\
1,4-dithiane-2,5-diol & + \\
1,3-dithiane & + \\
1,4-dithiane & + \\
Trimethylsilyl-1,3-dithiane & + \\
Thioxanthrene-9-one & + \\
1,4,7-trithiacyclononane & + \\
1,4,7-trithiacyclodecane & + \\
Thiodiglycol & + \\
Thioxanthene & + \\
Phenyl sulfoxide & + \\
Thionin & + \\
Sulfanilamide & + \\
2-nitrophenyl disulfide & + \\
4-nitrophenyl disulfide & - \\
3-nitrophenyl disulfide & + \\
4-aminophenyl disulfide & - \\
Tolyl disulfide & - \\
Benzyl disulfide & + \\
Phenyl disulfide & + \\
Dimethylsulfoxide & + \\
2,2'-thiobis(4,6-dichlorophenol) & + \\
Diphenylthiocarbazone & + \\
5,5'-dithio-bis(2-nitrobenzoic acid) & + \\
2(methylmercapto)benzimidazole & + \\
2-methyl-b-naphthothiazole & + \\
2-phenylbenzothiazole & + \\
Thiazole & + \\
\hline & + \\
\hline
\end{tabular}




\section{Metabolites of DBT Produced by M. phlei GTIS10 Versus $R$. erythropolis IGTS8}

The metabolites of dibenzothiophene produced by $M$. phlei GTIS10 and R. erythropolis IGTS8 were determined by GC-MS analysis of extracts of cultures grown at $45^{\circ} \mathrm{C}$ and $30^{\circ} \mathrm{C}$ respectively with DBT as the sole source of sulfur. Cultures were harvested in mid log phase of growth at an optical density of approximately 1.0 at $\mathrm{A}_{600} \mathrm{~nm}$. The results are listed in Table 8, which shows that both cultures metabolized a similar amount of DBT, but the relative abundance of metabolites produced by each culture showed differences. Of all of the DBT metabolized by R. erythropolis IGTS8 95\% was converted to 2-HBP; whereas, for $M$. phlei GTIS10 only 65\% of the DBT metabolized was converted to 2-HBP. The lack of quantitative conversion of DBT to 2-HBP has been noted in other reports of desulfurization cultures where as little as 54 mole \% of DBT metabolized can be accounted for as 2-HBP (Matsui, Hirasawa et al. 2001). In this study $M$. phlei GTIS10 produced greater levels of dibenzothiophene sulfoxide and dihydroxybiphenyls than did $R$. erythropolis IGTS8. A significant difference between data for $M$. phlei GTIS10 and R. erythropolis IGTS8 illustrated in Table 8 are the results obtained for dihydroxybiphenyls. About $3.3 \%$ of the DBT metabolized by $M$. phlei GTIS10 was converted to dihydroxybiphenyls, while no dihydroxybiphenyls were observed in the metabolites produced by $R$. erythropolis IGTS8. While in the experiment reported in Table 2 no dihydroxybiphenyls were observed as metabolites produced by $R$. erythropolis IGTS8 occasionally trace amounts of dihydroxybiphenyls are observed as metabolites of DBT produced by $R$. erythropolis IGTS8 (Gray, Pogrebinsky et al. 1996; Oldfield, Pogrebinsky et al. 1997). Dihydroxybiphenyls \#1 and \#2 have variations in their hydroxy substitution and have identical molecular formulas but specific structures/isomers could not be identified with the data available due to a lack of dihydroxybiphenyl standards having known structures. 
Table 8. The Relative Abundance of Metabolites of Dibenzothiophene Produced by $M$. phlei GTIS10 Differs from $R$. erythropolis IGTS8

\begin{tabular}{|l|c|c|}
\hline Compound & R. erythropolis IGTS8 & M. phlei GTIS10 \\
\hline dibenzothiophene sulfoxide & $24^{1}$ & \\
\hline dibenzothiophene sulfone & $<1.0$ & 180 \\
\hline hvdroxvbiphenvl sulfine & $<1.0$ & 1.0 \\
\hline 2-hydroxv biphenvl & 481 & 382 \\
\hline dihvdroxv biphenvl \#1 & $<1.0$ & 5.0 \\
\hline dihydroxy biphenyl \#2 & $<1.0$ & 115 \\
\hline Total & 505 & 582 \\
\hline
\end{tabular}

${ }^{1}=$ All concentrations of metabolites are expressed as $\mu \mathrm{g} / \mathrm{ml}$ of the ethyl acetate extract derived from each culture after incubation of resting cells with $200 \mu \mathrm{M}$ DBT. Dihydroxybiphenyl $\# 1$ and \#2 have identical molecular formulas, but could not be assigned specific molecular structures based on data available.

\section{Characterization of the desulfurization genes from M. phlei GTIS10.}

M. phlei GTIS10 appears to be highly similar to R. erythropolis IGTS8 as regards to biodesulfurization capability except that the maximum growth temperature for $R$. erythropolis IGTS8 is about $33^{\circ} \mathrm{C}$ whereas $M$. phlei GTIS10 can grow up to temperatures of $52^{\circ} \mathrm{C}$. DNA hybridization experiments were performed to investigate the relatedness of desulfurization genes from $R$. erythropolis IGTS8 and $M$. phlei GTIS10. Genomic DNA was prepared from both cultures, digested with several restriction enzymes, and used in Southern blotting experiments employing a DNA probe containing the entire $d s z$ operon from $R$. erythropolis IGTS8. Since these two cultures show such different temperature ranges for growth it was anticipated that the sequences of the $d s z$ genes in $M$. phlei GTIS10 versus $R$. erythropolis IGTS8 would be different or contain mutations conferring thermostability, but the results of Southern hybridization experiments showed there were no size differences in restriction enzyme digest patterns of the $d s z$ genes in these two microorganisms (data not shown). The individual $d s z$ genes of M. phlei GTIS10 were amplified by PCR using primers based on the $R$. erythropolis IGTS8 $d s z$ operon, cloned into a pFLAG-CTC expression vector, and sequenced. Surprisingly, all three of the genes in the desulfurization operon ( $d s z A, B$, and $C$ ) appear to be identical in $M$. phlei GTIS10 and $R$. erythropolis IGTS8. The finding that no differences in the DNA sequences of any of the 
desulfurization genes of $M$. phlei GTIS10 versus $R$. erythropolis IGTS8 was unexpected and raised the concern of possible sample contamination during PCR. To address this concern a $M$. phlei GTIS10 DNA phagemid library was constructed. The average M. phlei GTIS10 chromosomal insert in the phagemid library was $15 \mathrm{~kb}$. The library was transferred onto nylon membranes and hybridized to a DNA probe containing the entire $d s z A B C$ operon from $R$. erythropolis IGTS8. Several positive plaques were isolated and submitted for sequencing of the entire $d s z$ operon. Again, we observed $100 \%$ homology of the M. phlei GTIS10 $d s z A B C$ genes to the $R$. erythropolis IGTS8 desulfurization operon. Moreover, this second cloning of desulfurization genes from $M$. phlei GTIS10 was performed in a laboratory that has never worked with $R$. erythropolis IGTS8 or any other desulfurization-competent culture, so sample contamination was not a concern. The phagemid insert, containing the $d s z$ operon derived from M. phlei GTIS10, was sequenced in both the five and three prime directions about $1.5 \mathrm{~kb}$ beyond the boundaries of the $d s z$ genes. Identical sequences were observed in both the three prime $d s z$ promoter region and five prime region of sequences derived from M. phlei GTIS10 in comparison with sequences derived from $R$. erythropolis IGTS8.

Because of the presence of identical $d s z$ operons and flanking regions in both $R$. erythropolis IGTS8 and $M$. phlei GTIS10 we examined $M$. phlei GTIS10 total DNA for the presence of the $120 \mathrm{~kb}$ plasmid pSOX replicon known to encode the $d s z A B C$ operon in $R$. erythropolis IGTS8 (Denise-Larose, C. et al. 1998). M. phlei GTIS10 DNA was examined in PCR experiments using primers targeting an $860 \mathrm{bp}$ sequence of the replication region of the pSOX replicon. The presence of the pSOX plasmid replicon was confirmed (data not shown). The pSOX plasmid replication genes are related to those from Mycobacterium replicons so it is quite reasonable that this plasmid should function in $M$. phlei GTIS10. The $d s z D$ gene of $R$. erythropolis IGTS8 was also used as a probe in hybridization experiments with M. phlei GTIS10 DNA. Mycobacterium sp. GTIS10 contains sequences homologous with $d s z D$ but the location of $d s z D$ in $M$. phlei GTIS10 is unknown other than it is not within $1.5 \mathrm{~kb}$ of the other $d s z$ genes. Downstream from the $d s z A B C$ operon of $R$. erythropolis IGTS8 and $M$. phlei GTIS10 there are two open reading frames (orf's) that have strong homology to a Mycobacterium smegmatis translocase and an IS6120 associated orf (GenBank Accession number M69064).

While there was no attempt to promote the conjugal transfer of the pSOX plasmid from R. erythropolis IGTS8 to other more thermotolerant bacteria, the simplest explanation for the 
presence of $d s z A B C$ operons with identical DNA sequence in both $R$. erythropolis IGTS8 and $M$. phlei GTIS10 is the possible transfer of the pSOX plasmid from $R$. erythropolis IGTS8, which was in use in our laboratory, to M. phlei GTIS10. Rhodococcus erythropolis and Mycobacterium phlei are phylogenetically closely related, both being from the Corynebacteriiaceae suborder. We are in the process of isolating a desulfurization negative $M$. phlei GTIS10 by curing the strain of the desulfurization pSOX plasmid. We intend on confirming this transfer hypothesis once a desulfurization negative mutant has been isolated.

\section{Thermotolerance of the desulfurization enzymes.}

To further investigate the thermotolerance of the desulfurization enzymes contained in $M$. phlei GTIS10 and $R$. erythropolis IGTS8 each culture was grown using DBTSO2 as a sole source of sulfur and logarithmic phase cells of each culture were obtained, washed, resuspended in minimal medium containing DBT, and incubated 24 hours at various temperatures. The quantity of 2-HBP produced by the conversion of DBT by each culture at each temperature was quantified by HPLC over time and the specific activity results are shown in Figure 11. Interestingly, despite the fact that DNA sequence analysis shows that both cultures contain identical $d s z$ operons/enzymes, the specific activity varied with the incubation temperature. Figure 11 illustrates that $R$. erythropolis IGTS8 showed maximal activity at $30^{\circ} \mathrm{C}$ and a progressive loss of activity at $37^{\circ} \mathrm{C}$ and $45^{\circ} \mathrm{C}$, while no activity is observed at temperatures of $52^{\circ} \mathrm{C}$ or above. These results correlate well with the range of temperatures known to support the growth of $R$. erythropolis IGTS8 which grows maximally at about $30^{\circ} \mathrm{C}$ and does not grow at temperatures above $33^{\circ} \mathrm{C}$ (Kayser, Bielaga-Jones et al. 1993). On the other hand, M. phlei GTIS10 exhibits activity over the temperature range of $25^{\circ} \mathrm{C}$ to $57^{\circ} \mathrm{C}$ with maximal activity at $45^{\circ} \mathrm{C}$ to $50^{\circ} \mathrm{C}$, and no activity at $62^{\circ} \mathrm{C}$. These results also correspond well to the range of temperatures known to support the growth of M. phlei GTIS10 which grows maximally at between $45^{\circ} \mathrm{C}$ to $50^{\circ} \mathrm{C}$ and does not grow at temperatures above about $52^{\circ} \mathrm{C}$. 


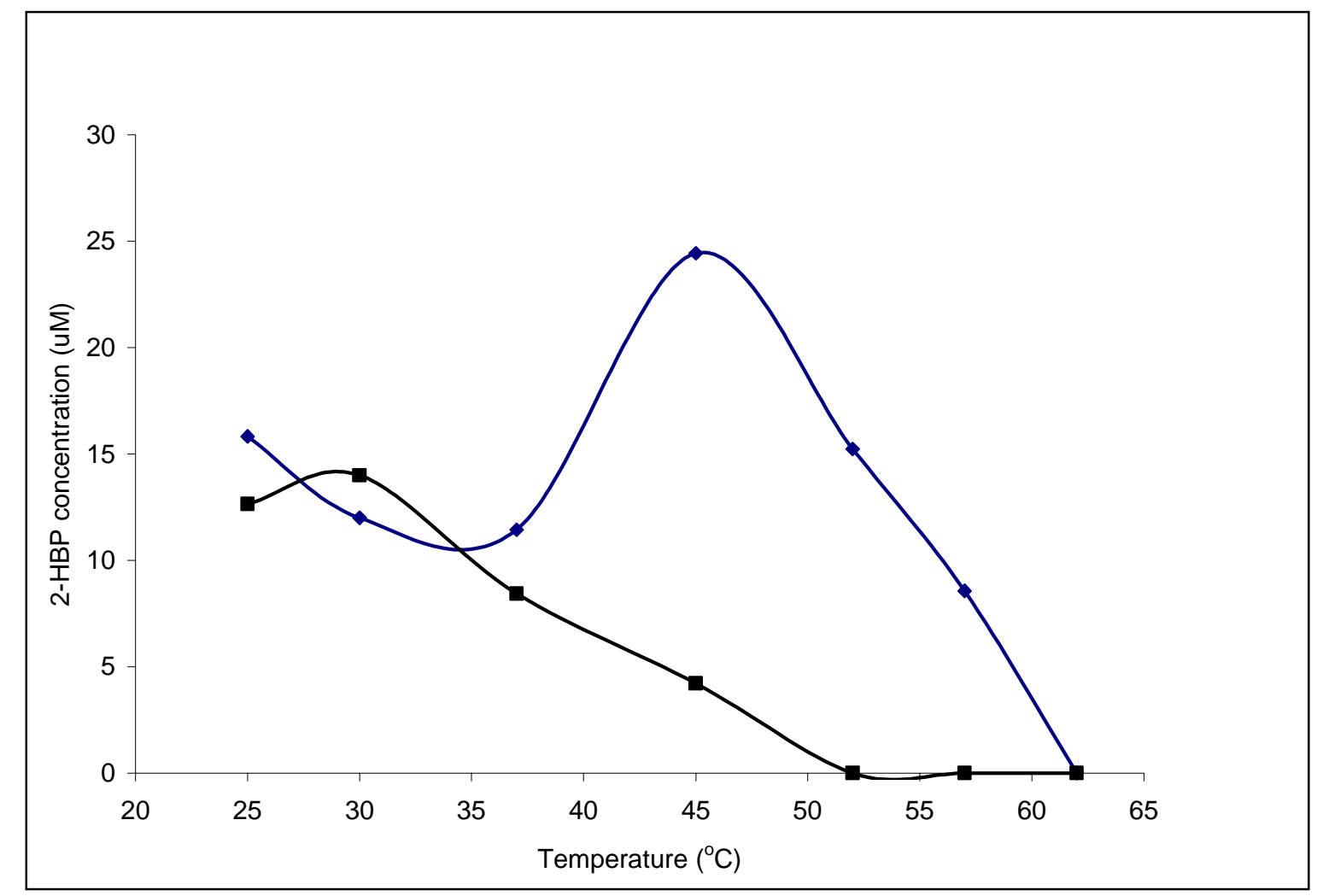

\section{FIGURE 11. RESTING CELLS OF MYCOBACTERIUM PHLEI IGTS10 EXHIBIT DESULFURIZATION ACTIVITY AT SIGNIFICANTLY HIGHER TEMPERATURES THAN RESTING CELLS OF RHODOCOCCUS ERYTHROPOLIS IGTS8.}

The amount of 2-HBP produced by the conversion of DBT by each culture after incubation for 18 hours at various temperatures was quantified by an increase in fluorescence at $414 \mathrm{~nm} \lambda_{\text {ex }}=$ $288 \mathrm{~nm} . \bullet$, Mycobacterium phlei IGTS10; $\mathbf{\square}$, Rhodococcus erythropolis IGTS8.

Taken altogether the results shown in Figure 11, plus the knowledge that DNA sequence analysis shows that both cultures contain identical $d s z$ operons/enzymes, indicate that the ability of the $d s z$ enzymes to function is greatly influenced by the bacterial host strain. Both M. phlei GTIS10 and R. erythropolis IGTS8 exhibit maximal desulfurization activity corresponding to the optimum growth temperature of each culture and then desulfurization activity declines in concert with decreasing cell viability at higher temperatures. The desulfurization pathway requires 
$\mathrm{NADH}, \mathrm{FMNH}_{2}$, and oxygen in order to complete the conversion of DBT to 2-HBP. The host must supply these factors so that the functional temperature range of the desulfurization pathway is seen to be different in two different bacterial hosts possibly reflecting the ability of each bacterial species to provide co-factors and reaction substrates at various temperatures. Transport of substrates and products may also contribute to desulfurization activity. The observation that the $d s z$ operon has two apparent temperature maximums in two different bacterial hosts suggests perhaps that if the $d s z$ operon could be expressed in a thermophilic bacterial host the desulfurization enzymes may function at even higher temperatures.

To further explore the thermostability of the desulfurization enzymes the $R$. erythropolis IGTS8 $d s z A, d s z B$, and $d s z C$ genes were cloned individually and expressed in $E$. coli at high levels so that the thermostability of individual desulfurization enzymes could be determined. Each desulfurization gene was cloned into the E. coli expression vector pQE80 and Dsz A, B, and $\mathrm{C}$ proteins containing polyhistadine residues at their $\mathrm{N}$-termini were obtained and purified by affinity chromatography. Polyacrylamide-SDS gel electrophoresis was performed to confirm that proteins of the correct molecular weight were present in the cell lysates (data not shown).

Samples containing DszA, DszB, and DszC protein were pre-incubated at $30^{\circ}, 37^{\circ}, 45^{\circ}$, $52^{\circ}, 65^{\circ}$, and $72^{\circ} \mathrm{C}$ for 30,60 , and 120 minutes. The enzyme solutions were assayed by adding the appropriate substrate and/or co-factors, incubated at $30^{\circ} \mathrm{C}$ for an hour and then determining the amount of product formed by HPLC analysis. The results of the analyses indicate that DszB activity (conversion of HBPSi to 2-HBP) is not inhibited by pre-incubation at $30^{\circ}$ or $37^{\circ} \mathrm{C}$, but little or no activity is seen when samples are pre-incubated at temperatures of $45^{\circ} \mathrm{C}$ or higher even with exposure times as brief as 30 minutes. The half-life of dibenzothiophene monooxygenase, DszC, was 1 hour at $45^{\circ} \mathrm{C}$ and the half-life of DszA was 1 hour at $60^{\circ} \mathrm{C}$. These data are in agreement with results obtained for the purified desulfurization enzymes isolated from Rhodococcus erythropolis strain D1(Oshiro 1997; Oshiro 1999; Matsubara 2001). The DszC enzyme from $R$. erythropolis D1 was inactivated by pre-incubation at $45^{\circ} \mathrm{C}$ for 30 minutes and DszA purified from $R$. erythropolis D1 was inactivated by pre-incubation at $60^{\circ} \mathrm{C}$ for 30 $\min$.

Since DszB catalyzes the last step in the desulfurization pathway and is responsible for the release of sulfur from DBT it must be functional in order to allow cultures to grow and utilize DBT as a sole sulfur source and it is required to allow the production of 2-HBP in the data 
reported in Figure 11. Therefore it is surprising that the DszB enzyme appears to be thermally inactivated in vitro by exposure to temperatures as low as $45^{\circ} \mathrm{C}$ yet some activity is detected in whole cells at temperatures of $57^{\circ} \mathrm{C}$. While the DszB enzyme may be the most thermolabile enzyme in the desulfurization pathway thermal inactivation is not instantaneous and it apparently has enough residual activity even at $57^{\circ} \mathrm{C}$ to allow the accumulation of 2-HBP to be detected. Table 8 shows that dihydroxybiphenyls were observed in the supernatant of M. phlei GTIS10 cultures grown at $45^{\circ} \mathrm{C}$. Oldfield et al 1997(Oldfield, Pogrebinsky et al. 1997) describes a minor desulfurization pathway in which the dibenzothiophene-5,5-dioxide monooxygenase (DszA product) produces dihydroxybiphenyls from biphenylene sulfone. Biphenylene sulfone can be formed from non-enzymatic oxidation of 2-hydroxybiphenyl-2-sulfinate (HBPSi) . Perhaps at higher temperatures, the DszB enzyme is inactive and the minor desulfurization pathway catalyzed by DszA is active to provide sulfur to the cells.

The dibenzothiophene monooxygenase encoded by $d s z C$ is responsible for the conversion of DBT to dibenzothiophene sulfoxide and then to dibenzothiophene sulfone. The elevated levels of dibenzothiophene sulfoxide seen in $M$. phlei GTIS10, as compared with R. erythropolis IGTS8 (see Table 8), might suggest that the dibenzothiophene monooxygenase is temperature sensitive and works less efficiently at $45^{\circ} \mathrm{C}$ than at $30^{\circ} \mathrm{C}$. Also the faster growth of M. phlei GTIS10 with DBTSO2 versus DBT suggests that DszC activity may be thermolabile. However, the results of in vitro experiments do not support this conclusion, as DszC exhibits activity at $45^{\circ} \mathrm{C}$ while DszB is the most thermolabile desulfurization enzyme. The DszC enzyme requires other cofactors/substrates for proper functioning: $\mathrm{FMNH}_{2}$ and oxygen. The FMN oxidoreductase encoded by $d_{s z} D$ is responsible for providing $\mathrm{FMNH}_{2}$ to enable the reactions catalyzed by DszC to proceed. The accumulation of DBTSO in the supernatant of the M. phlei GTIS10 $45^{\circ} \mathrm{C}$ growing cell experiment might indicate that the FMN oxidoreductase was significantly inactivated in vivo at $45^{\circ} \mathrm{C}$ and the DszC catalyzed reaction did not go to completion due to lack of cofactor. We examined the M. phlei GTIS10 FMN oxidoreductase (DszD) for thermal inactivation and it was found to function with little inactivation up to $45^{\circ} \mathrm{C}$ but was progressively inactivated by exposure to higher temperatures. The half-life of the DszD enzyme from $R$. erythropolis D1 was determined to be about 17 minutes at $50^{\circ} \mathrm{C}$; however, slight activity was detectable even after incubation at $72^{\circ} \mathrm{C}$ for 60 minutes.(Matsubara 2001). 
These data demonstrate that the thermostability of enzymes determined in vitro is not necessarily a good predictor of the functional range of an enzyme in vivo, and that the same operon can yield metabolic pathways with different rate limiting steps and different yields of metabolites in different hosts. M. phlei GTIS10 can be used as a host in higher temperature biorefining applications.

\section{Genetic Expression in Thermus thermophilus}

If we are to be successful in cloning and expressing genes relevant to C-N and/or C-S bonds in thermophiles then it will be necessary to demonstrate proficiency in the genetic manipulation of thermophiles. Thermus thermophilus HB27 has been selected for use in genetic experiments because at the start of this project it was the aerobic extreme thermophile that had the most available information regarding genetic studies. In fact it was almost the only extreme thermophile for which any significant amount of genetic information was available. Nonetheless, the available genetic information primarily concerned the cloning of genes from Thermus and expressing and characterizing them in mesophilic microorganisms such as Escherichia coli. Very little information was available regarding the cloning and expression of genes in Thermus. Therefore a component of this project has been to develop tools and methods to allow genes to be conveniently and reliably expressed in Thermus thermophilus HB27.

From humble beginnings significant progress has been made. Promoter probe vectors were constructed and used to isolate and characterize promoters that function in both Thermus and in E. coli. Some of these promoters are inducible and allow gene expression in Thermus to be regulated. These promoters were then used to construct both plasmid and integrative expression vectors so that cloned genes could be reliably expressed in Thermus. Recent progress in genetic studies with Thermus sp. is summarized in two publications.

"New Host Vector System for Thermus spp. Based on the Malate Dehydrogenase Gene", K. J. Kayser and J. J. Kilbane II, Journal of Bacteriology 183: 1792-1795. (2001)

"Inducible and Constitutive Expression Using New Plasmid and Integrative Expression Vectors for Thermus sp.” K. J. Kayser, J.-H. Kwak, H.-S. Park, and J. J. Kilbane II. Letters in Applied Microbiology 32: 412-418 (2001).

These data are summarized here. 
The construction of promoter probe vectors and expression vectors have been noted for use in Thermus (Raven 1995), derived from the $\operatorname{trpB}$ complementation vector, (Koyama, Arikawa et al. 1990) but are not described in detail. Thermus DNA fragments that encode promoters have been isolated and sequenced using a promoter probe vector based on a heatstable kanamycin resistance gene (Maseda and Hoshino 1995). Comparison between the consensus sequences for Thermus -35 and -10 promoters and the E. coli consensus sequences revealed that Thermus promoters have more than 8 of 12 identical nucleotides in common with E. coli promoters. Moreover, the distances between -35 and - 10 regions in Thermus promoters are 17 or 18 nucleotides just as found in E. coli promoters. Strong Thermus promoters can also contain AT-rich regions upstream -35 promoter sequences.

Although plasmids capable of replication in Thermus species exist and promoters have been characterized, more tools are needed for a thorough genetic characterization of the species. This paper describes the development of genetic tools for the isolation of promoters and the expression of genes in Thermus ssp. These genetic tools will be applicable in a variety of biotechnological applications such as plasmid and integration vectors for the expression of genes in thermophiles or for directed evolution of mesophilic genes to create thermostable derivatives.

\section{Construction of the promoter probe vectors.}

Two plasmid based promoter probe vectors have been constructed for use in Thermus sp. To aid in the ease of genetic manipulations both of the promoter probe vectors are shuttle vectors capable of replicating both in E. coli and Thermus. The plasmid pUC19-EKF-TSP3 expresses kanamycin nucleotidyltransferase $(\mathrm{Km} \mathrm{R})$ via an uncharacterized $T$. aquaticus promoter and is stabily maintained in T. thermophilus. Plasmid pUC19EKF-TSP3 was used to construct the promoter probe vectors. The construction procedures are schematically represented in Figure 12. Both of these constructs are quite similar and contain promoterless kanamycin resistance genes with unique restriction sites located immediately upstream except that pTIGT1 has a more complete multiple cloning site. These vectors pKANPROII and pTIGT1 replicate in both Thermus and E. coli and allow the detection of inserted DNA fragments that encode promoters that allow the expression of the kanamycin resistance in Thermus and E coli transformants. 
An integrative promoter probe vector designated pTPRO1 was constructed to quantify promoter activity and to examine the expression of genes present as a single integrated copy. A transcriptional terminator sequence was inserted to prevent transcriptional read through from the leucine gene. This successfully deleted kanamycin expression in E. coli and Thermus. Unique site upstream of the Km R gene is available for cloning of promoter fragments. 

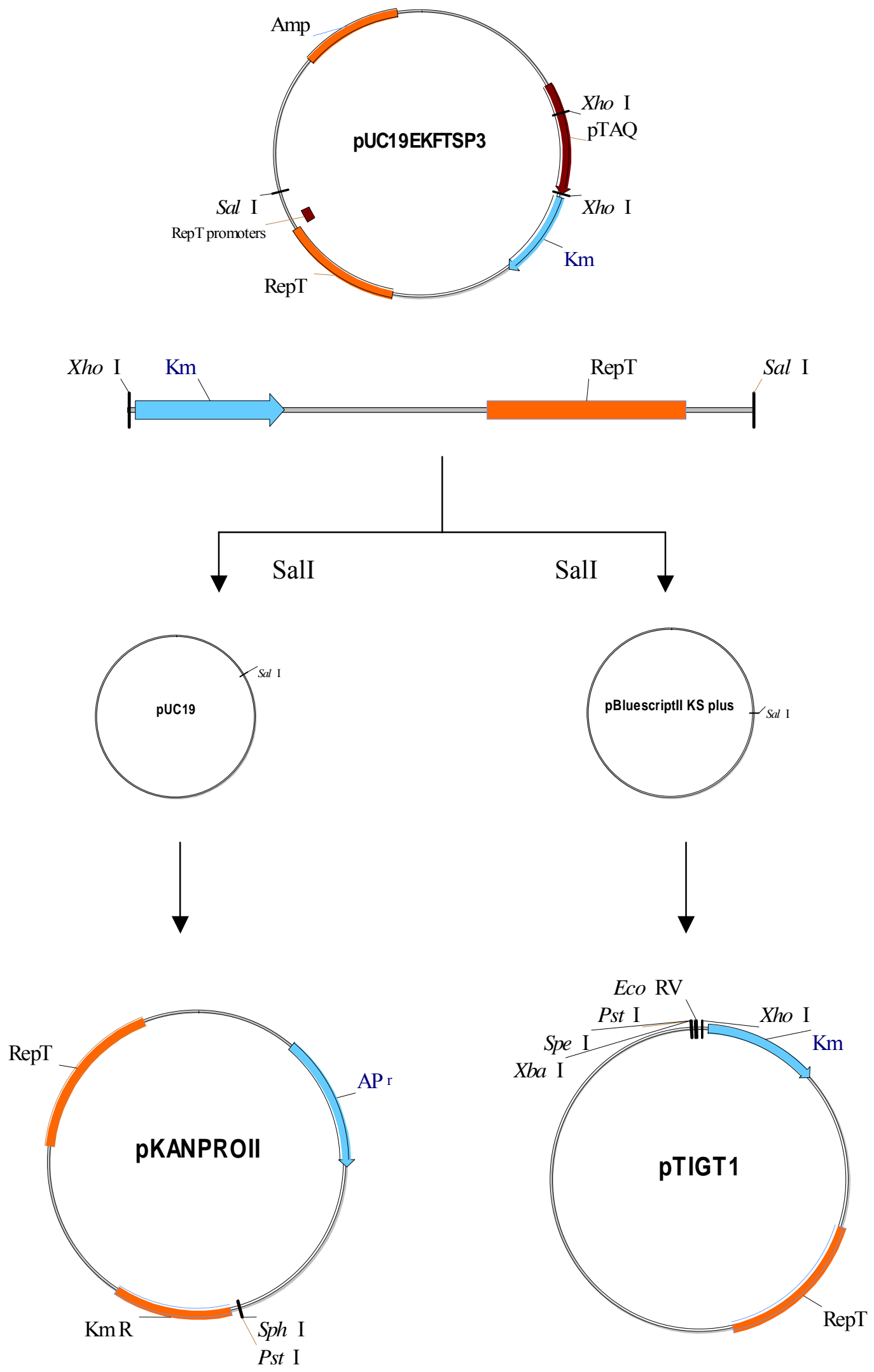

FIGURE 12. THE CONSTRUCTION OF PLASMID PROMOTER PROBE VECTORS PKANPROII AND PTIGT1. 
Plasmid pUC19-EKF-Tsp3 (7.7 kb) was digested with XhoI and SalI to produce $3.8 \mathrm{~kb}$, $3.2 \mathrm{~kb}$ and $0.7 \mathrm{~kb}$ fragments. The $3.2 \mathrm{~kb}$ fragment contains the promoterless $\mathrm{KM} \mathrm{R}$ gene and the Thermus replication origin. It was ligated into SalI-cut pUC19. Plasmids were chosen based on the orientation of the insert that yielded the unique restriction sites PstI and SphI upstream of the promoterless kanamycin nucleotidyltransferase gene. This construct was designated pKANPROII and is $5.9 \mathrm{~kb}$. The same $3.2 \mathrm{~kb}$ fragment was cloned into the XhoI site of pBluescript KS + to create pTIGT1. Constructs were also chosen based on the orientation of the insert that yielded the unique restriction sites XbaI, SpeI, PstI, EcoRV, ClaI, SalI and XhoI upstream of the promoterless kanamycin nucleotidyltransferase gene. Promoter probe vector pTIGT1 is $6.1 \mathrm{~kb}$ in size.

\section{Isolation of Thermus Promoters}

Promoter probe vector pKANProII was digested with unique restriction enzymes upstream from the promoterless kanamycin nucleotidyltransferase gene and random chromosomal fragments from Thermus sp. were ligated into the promoter probe vector. The ligation was transformed into Thermus thermophilus HB27 and transformants were incubated at $55^{\circ} \mathrm{C}$ for 4-5 days on T.T plates containing $40 \mu \mathrm{g} / \mathrm{ml}$ kanamycin $(\mathrm{Km})$. Multiple colonies containing inserts ranging from $100 \mathrm{bp}$ to $1.0 \mathrm{~kb}$ that regulated kanamycin expression (Km 40 $\mathrm{ug} / \mathrm{ml}$ ) in Thermus thermophilus HB27 were isolated. One hundred colonies were randomly chosen and $\mathrm{Km}$ resistance levels were examined. The transformants were replica plated onto TT plates containing $100 \mu \mathrm{g} / \mathrm{ml}, 500 \mu \mathrm{g} / \mathrm{ml}$, and $2000 \mu \mathrm{g} / \mathrm{ml}$ of $\mathrm{Km}$. All transformants grew well on plates containing $100 \mu \mathrm{g} / \mathrm{ml}$ of $\mathrm{Km}$. Thirty-three transformants grew on plates containing 500 $\mu \mathrm{g} / \mathrm{ml}$ of $\mathrm{Km}$ and twenty transformants were found to grow well on $2000 \mu \mathrm{g} / \mathrm{ml}$ of Km. Plasmid DNA was isolated from all of the HB27\pKANProII constructs and transformed into E. coli

DH5 $\alpha$ for kanamycin resistance. Approximately $20 \%$ of the colonies contained promoters that allow expression of Km R in both E. coli and Thermus thermophilus HB27. 


\section{Expression vector Construction}

Vectors were constructed for the expression of foreign genes and the high level expression of native genes in Thermus. A promoter designated P17 was isolated based on its ability to produce high levels $(>3000 \mathrm{ug} / \mathrm{ml} \mathrm{Km})$ of kanamycin resistance in Thermus. This promoter also functions in E. coli and Thermus. Although the expression of the kanamycin nucleotidyltransferase gene under P17 control in Thermus yields high levels of kanamycin resistance, the expression of kanamycin nucleotidyltransferase in E.coli is moderate $(40 \mathrm{ug} / \mathrm{ml}$ $\mathrm{Km}$ ). The promoter P17 was sequenced and found to be about $80 \%$ homologous to the previously published -10 and -35 consensus sequences from Thermus promoters (Maseda and Hoshino 1995). P17 has two regions of high A-T content upstream of the consensus sequences that may, according to Hoshino et al., play a role in strong promoter activity. The promoter P17 also functions at high levels as a single copy when cloned upstream of the KM gene in the promoter probe integrative vector pTPRO1.

Promoter P17 was used to construct two expression vectors. The expression vectors were designated pTEX1-PL and pTEX1-LPL. Both of these vectors have a transcriptional terminator sequence cloned upstream of the P17 promoter to prevent transcriptional read-through from the vector. They also have a multiple cloning site cloned downstream of the P17 promoter. Figure 13 shows the scheme for construction of the pTEX1 LPL vector. The pTEX1 vectors are plasmid expression vectors with that also contain a kanamycin resistance gene under the control of a broad host range promoter (vv12) that allows expression of kanamycin resistance in Thermus and E. coli. pTEX1-LPL has a Thermus ribosomal binding site (RBS) cloned upstream of the MCS with the EcoRI site $6 \mathrm{bp}$ downstream. In the pTEX1-PL the RBS has been deleted. 

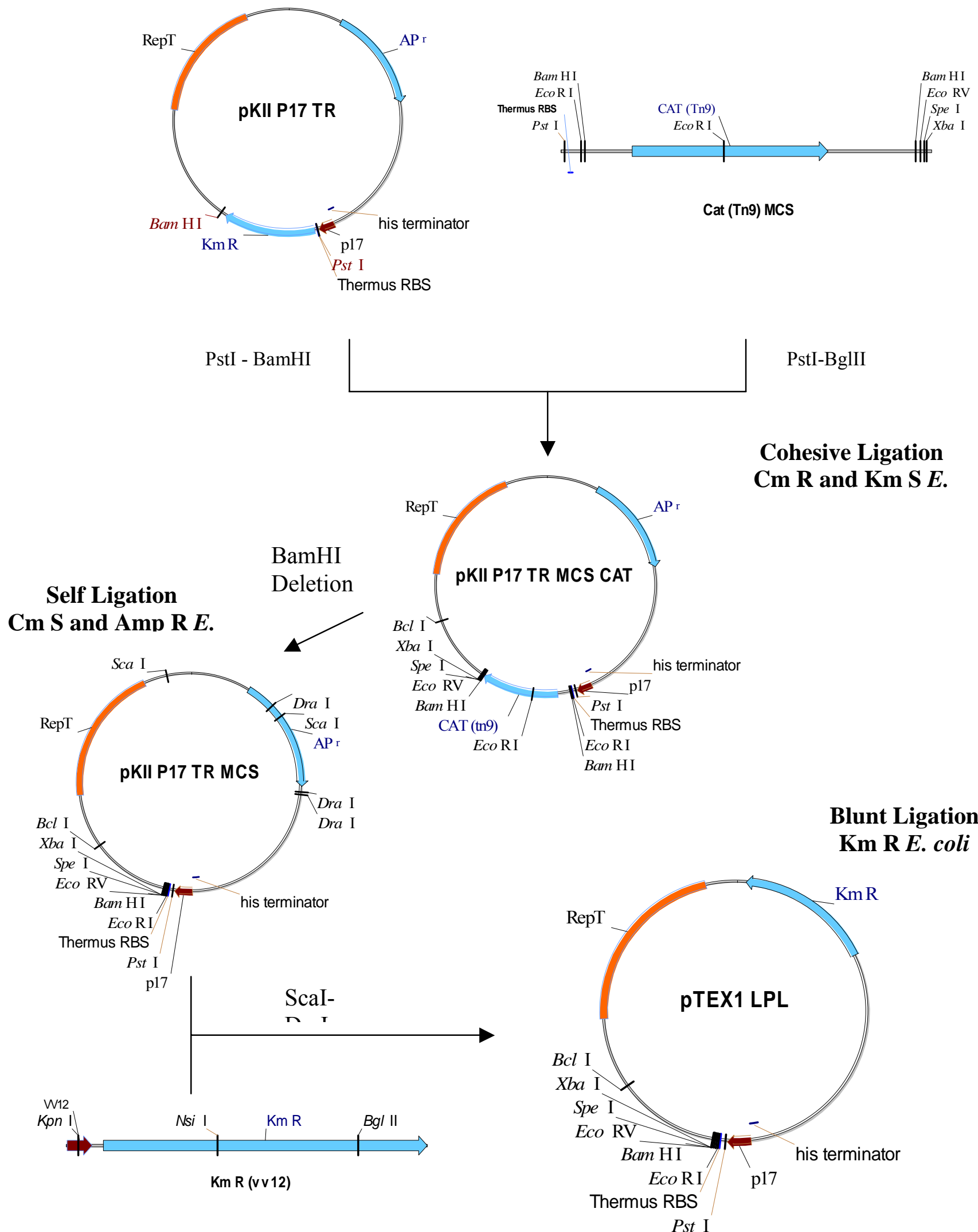

FIGURE 13. CONSTRUCTION OF THE PTEX EXPRESSION VECTORS. 
FIGURE 13. THE CONSTRUCTION OF EXPRESSION VECTORS PTEX1 LPL AND PTEX1 PL.

Plasmid pKII P17 TR (5.86 kb) is a derivative of the vector pKANProII that contains the P17 promoter. Plasmid pKII P17 TR has a $56 \mathrm{bp}$ transcriptional terminator sequence inserted upstream of the P17 promoter. Plasmid pKII P17 TR was digested with PstI and BamHI. A PCR fragment containing the CAT gene from Tn9 flanked by two BamHI sites and multiple unique restriction enzyme sites (MCS) was generated to provide a positive selection mechanism for insertion of the MCS to the vector. The PCR product was digested with PstI and BglII and ligated into the pKII P17 TR PstI-BamHI digest. Transformants were selected on chloramphenicol plates and examined for kanamycin sensitivity. The resulting construct pKII TR MCS CAT was digested with BamHI and ligated back to itself to remove the $\mathrm{Cm}$ gene. Transformants were selected on Amp plates and colonies examined for chloramphenicol sensitivity. The resulting construct pKII TR MCS was digested with ScaI-DraI and a kanamycin gene cassette was blunt end ligated into the vector. The resulting pTEX1 LPL construct was Km resistant and Amp sensitive.

\section{Construction of Temperature Inducible Expression Vector}

An expression vector, designated pTEX2 dnaK, was constructed using the promoter from the dnaK gene of Thermus thermophilus (Osipiuk and Joachimiak 1997). The dnaK operon promoter is regulated by heat shock induction $\left(70^{\circ} \mathrm{C}\right.$ to $\left.85^{\circ} \mathrm{C}\right)$. Figure 14 shows the restriction map of the expression vector pTEX2-dnaK. Like the pTEX1 expression vectors pTEX2-dnaK has a transcriptional terminator upstream of the dnaK promoter, a MCS downstream, and a kanamycin resistance gene under the control of a the broad host range vv12 promoter. 


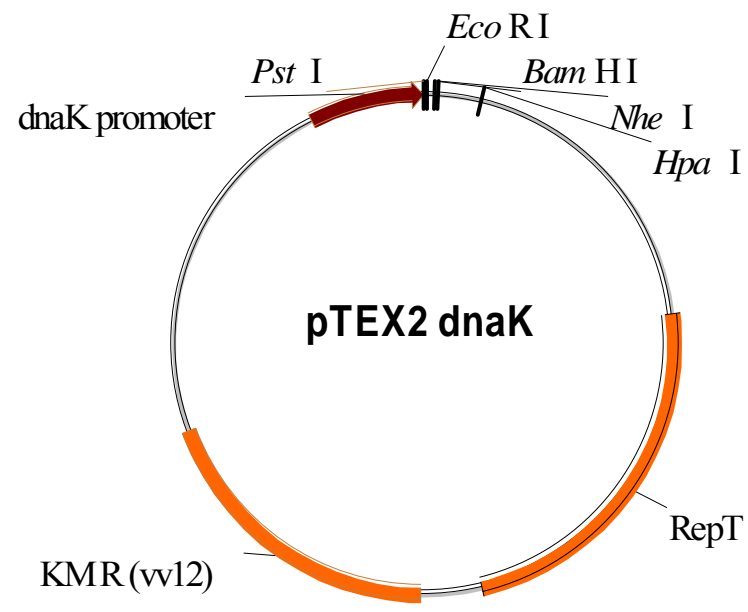

FIGURE 14. EXPRESSION VECTOR PTEX2 DNAK.

\section{Assay of pTEX-1 and pTEX2-dnak Expression Vectors.}

To examine the expression of a gene cloned into the pTEX vectors the malate dehydrogenase gene was cloned into the vectors. The malate dehydrogenase gene from Thermus flavus was isolated from chromosomal DNA by PCR. The gene was cloned into the multiple cloning site of pTEX1-PL and into pTEX2-dnaK. The two promoters used in the pTEX constructs (P17 and dnaK) function in Thermus as well as E. coli. MDH was first assayed in $E$. coli. The Thermus thermophilus $\mathrm{HB} 27 \mathrm{MDH}$ gene is thermostable at $90^{\circ} \mathrm{C}$ and therefore native E. coli MDH activity is easily destroyed and expression of the Thermus MDH gene can be monitored in heat treated cell extracts. In Thermus there is background interference from the native MDH. The pTEX1-MDH constructs were transformed into Thermus thermophilus HB27 for kanamycin resistance. HB27 containing the expression vector pTEX2-dnaK MDH was heat shocked for 10 minutes at $80^{\circ} \mathrm{C}$. Cell-free extracts were prepared and MDH activity was measured. The results are shown in Table 9. HB27 was included to show background levels of MDH. 
TABLE 9. AMOUNT OF MALATE DEHYDROGENASE ACTIVITY OF THERMUS EXPRESSION VECTOR CONSTRUCTS

\begin{tabular}{lc}
\hline \multicolumn{1}{c}{ Culture and condition } & $\begin{array}{c}\text { MDH activity } \\
\text { (Units MDH/mg) }\end{array}$ \\
\hline HB27 & 1.09 \\
HB27/pTEX1-MDH & 1.29 \\
HB27/pTEX2-dnak MDH & 1.25 \\
HB27/pTEX2-dnak MDH Heat Shocked & 1.51 \\
\hline
\end{tabular}

Tools for the isolation and characterization of Thermus DNA involved in the regulation of genetic expression have been developed. The promoter probe vectors pKANPROII and pTIGT1 were constructed using a promoterles kanamycin nucleotidyltransferease gene and genes that allow these plasmids to replicate in both Thermus and E. coli. These promoter probe vectors were used to isolate Thermus promoters. Several strong promoters were isolated and characterized for kanamycin resistance levels. A promoter designated P17 was isolated and shown to allow resistance to $>3000 \mathrm{ug} / \mathrm{ml}$ kanamycin in Thermus. Plasmid pTEX PL and LPL are expression vectors constructed with the P17 promoter upstream of a convenient multiple cloning site. A third plasmid expression vector pTEX2-dnaK was constructed using the heat shock $\left(70^{\circ} \mathrm{C}\right.$ to $85^{\circ} \mathrm{C}$ ) inducible dnaK gene promoter. These vectors are useful for the expression of foreign genes in Thermus cultures. High level expression of cloned genes is often achieved in Escherichia coli, Bacillus subtilis and other well studied microorganisms by the use of high copy number plasmid expression vectors. Besides high copy number, plasmid expression vectors in comparison with integrative vectors can be easily recovered/purified from the host strain so that subsequent genetic modifications can be conveniently performed. However, plasmids are less stable than genes integrated into the chromosome of a host and plasmid instability is thought to be of particular concern in Thermus hosts where growth at temperatures of $55^{\circ} \mathrm{C}$ to $82^{\circ} \mathrm{C}$ is 
routine. Another disadvantage of plasmid vectors for use in Thermus sp. is that plasmid vectors generally have from 10 to 1,000- fold lower transformation efficiencies than integrative vectors. Consequently, integrative vectors are frequently used in genetic studies of Thermus sp. Plasmid vectors that have been used in Thermus have previously been constructed that encode tryptophan, leucine, or pyrimidine synthesis genes to complement auxotrophic/deleted hosts, thus providing for a positive selection of transformants. The host-vector system described here is an improvement on previously reported plasmid vectors for Thermus sp. because not only is the E.coli-Thermus shuttle vector easily selected and maintained in Thermus, but also malate dehydrogenase activity encoded by the $m d h$ gene present in this vector can be readily and accurately quantified.

We describe the construction of a $T$. thermophilus $\Delta m d h$ strain containing a deletion of the entire DNA sequence encoding the $m d h$ gene and its use as a host for Thermus plasmids expressing an intact $m d h$ gene. The use of this host/vector system approach was demonstrated in both T. thermophilus and T. flavus and should be useful in Thermus sp. generally. The TCA cycle in Thermus sp., like most microorganisms, plays a central role in metabolism. Malate dehydrogenase $(\mathrm{MDH})$ catalyses the dehydrogenation of malate to oxaloacetate using $\mathrm{NAD}^{+}$as a cofactor and is a key enzyme in the TCA cycle. The T. thermophilus $\Delta m d h$ host/expression vector system offers a strong positive selection tool for the introduction of plasmid DNA into Thermus sp., aides in stabilization of plasmids and provides a valuable reporter gene that can be used to quantify promoter strength/gene expression in T. thermophilus.

\section{Construction of T. thermophilus HB27 and T. flavus Hosts Containing Deletions of the mdh Gene}

To create the $\Delta m d h$ strain of $T$. thermophilus HB27 we constructed an integration vector designated pUC-S KmA. The construction is detailed in Figure 15. A $2.3 \mathrm{~kb}$ PCR fragment containing a region spanning three separate genes: succinate--CoA ligase $(\operatorname{scs} A)$, malate dehydrogenase $(m d h)$ and purine phosphoribosyltransferase $(g p t)$ gene was PCR amplified from the Thermus flavus chromosome and cloned into pUC 18. The 984 by $m d h$ gene is located near the center of this $2.3 \mathrm{~kb}$ fragment so that the chromosomal regions that flank the $m d h$ are $780 \mathrm{bp}$

five prime and $560 \mathrm{bp}$ three prime. The entire coding sequence of the $m d h$ gene was removed by restriction enzymes and replaced with a thermotolerant kanamycin resistance cassette $\left(K M^{R}\right)$. 
This vector designated pUC-SKmA can replicate in E. coli but not in Thermus. However, homologous recombination between the scsA and gpt gene sequences allows pUC-SkmA to integrate into the chromosome when it was used to transform T. thermophilus HB27. Transformants were screened at $55^{\circ} \mathrm{C}$ on TT rich medium supplemented with kanamycin (40 $\mu \mathrm{g} / \mathrm{ml}$ ). Approximately $1 \times 10^{4}$ kanamycin resistant transformants per $\mu \mathrm{g}$ DNA were observed. Two distinct colony types arose after 5 days incubation. The majority of the colonies were very small even after 5 days. A few colonies, 60 - 100 total per $\mu$ g DNA, were much larger. The two colonies types were sub-cultured and total DNA (plasmid and chromosomal) was dot blotted onto a nylon membrane. The dot blot was probed with a Digoxigenin-11-dUTP (DIG) labeled $T$. flavus $m d h$ gene. DNA prepared from the smaller colonies did not hybridize to the $T$. flavus $m d h$ gene whereas the DNA harvested from the larger colonies hybridized to the $m d h$ probe. The membrane was also probed with a DIG labeled $\mathrm{Km}^{R}$ cassette, both small and large colony types hybridized to the $K m^{R}$ cassette. Because MDH is a key enzyme in the TCA cycle the colonies resulting from double crossover integration events $(\Delta m d h)$, are recognized by this small or "sick" colony phenotype. The larger $K m^{R}$ colonies were single crossover integration events where the chromosomal $m d h$ is intact and the entire plasmid is in the chromosome. The T. thermophilus $\Delta m d h \mathrm{Km}^{R}$ mutant strain was designated MM8-5. The loss of MDH function in MM8-5 results in the accumulation of L-malate in this culture (data not shown). T. thermophilus $\Delta m d h \mathrm{Km}^{R}$ MM8-5 was used as a recipient in further transformation experiments. A derivative of T. flavus containing a deletion of the mdh gene was also constructed using the approach described above. This strain was designated TfMM-1.

\section{Construction of Thermus vectors containing $m d h$ as a reporter gene.}

The malate dehydrogenase $(m d h)$ gene from $T$. flavus was amplified by PCR and cloned into a Thermus and E. coli expression vector pTEXI. The expression vector pTEXI is capable of replication in both Thermus sp. and E. coli, and the promoter (J17) employed in this expression vector functions in both bacterial hosts. The expression vector containing the $m d h$ gene, designated pTEXI-mdh, is diagramed in Figure 16 A.

The J17 promoter from pTEXI-J17 mdh was replaced by two constitutive Thermus promoters (D50-3 and P2-100). These promoters are known to have low and medium levels of 
expression in Thermus relative to $\mathrm{J} 17$. The resulting plasmids were designated pTEX1- D50-3 and pTEX1-P2-100. An integrative vector was constructed to examine the expression of the $m d h$ gene under control of the $\mathrm{J} 17$ promoter present as a single integrated copy. This construct was designated pSJ17mdhA and is shown in Figure 16B. pSJ17mdhA contains pUC19 sequences and can replicate in E. coli. pSJ17mdhA does not replicate in Thermus as a plasmid but integrates into the chromosome by a double crossover event. pSJ17mdhA has the J17 promoter$m d h$ gene cassette flanked by the $s \operatorname{cs} A$ and $g p t$ chromosomal regions. A transcriptional termination sequence from the $T$. flavus phenylalanyl tRNA synthetase operon was cloned upstream of the cassette to prevent transcription read through from the native succinate--CoA ligase/malate dehydrogenase operon promoter.

Several plasmid expression vectors that utilize different promoters to express the $m d h$ gene (pTEX1-mdh, pTEXI-D50-3 and pTEX1-P2_100) and the integrative vector pSJ17mdhA that employs the $\mathrm{J} 17$ promoter to express the mdh gene, were transformed into MM8-5. Transformants of these constructs are easily detected by the restoration of cultures to the "healthy phenotype" or larger and faster growing colonies by the expression of the malate dehydrogenase gene located on these expression vectors. Typically T. thermophilus strain MM85 takes 4 to 5 days to form visible colonies at $55^{\circ} \mathrm{C}$ in $\mathrm{TT}$ supplemented with $40 \mu \mathrm{g} / \mathrm{ml}$ kanamycin. T. thermophilus MM8-5 transformants that received an expression vector encoding the mdh gene yielded colonies in 2 to 3 days. The presence of pTEXI- $m d h$ and the related $m d h$ expression vectors pTEXI-D50-3 and pTEX1-P2-100 in MM8-5 was confirmed by harvesting plasmid DNA from Thermus colonies which was subsequently visualized on an electrophoresis gel and used to transform the plasmid back into E. coli (data not shown). In contrast, and as expected, plasmid DNA could not be detected/recovered from T. thermophilus MM8-5 transformants that received the integrative expression vector $\mathrm{pSJ} 17 \mathrm{mdhA}$.

Expression vector pTEXI-mdh and the alternative promoter pTEX derivatives are very stable in both T. thermophilus MM8-5 and T. flavus TfMM-1 respectively. After greater than 20 generations of growth under non-selective conditions pTEX plasmids were detected in all of the colonies examined (100 for each species). This result is quite expected because those $T$. thermophilus MM8-5 or T. flavus TflVIM-1, cultures that possess expression vectors containing the $m d h$ gene grow more rapidly than plasmid-free strains that lack a functional $m d h$ gene. 


\section{Malate dehydrogenase activity of Thermus constructs}

The levels of malate dehydrogenase (MDH) being produced by plasmid and integrative expression vectors were evaluated in both T. thermophilus HB27 and MM8-5. Crude lysates prepared from each culture were assayed for $\mathrm{MDH}$ activity at two temperatures $\left(25^{\circ} \mathrm{C}\right.$ and $\left.50^{\circ} \mathrm{C}\right)$ and results are shown in Table 10. T. thermophilus MM8-5 had slight to no MDH activity confirming the complete deletion of the $m d h$ gene from the chromosome of this strain. The activity observed in assays performed at $50^{\circ} \mathrm{C}$ reflect a slight amount of background due to the conversion of NADH to NAD by unidentified components of cell lysates rather than the MDHdependent conversion of oxaloacetate and NADH to malate and NAD.

The MDH activity of crude extracts assayed at $50^{\circ} \mathrm{C}$ is on average 9 times higher than the activity levels measured at $25^{\circ} \mathrm{C}$. The data in Table 10 clearly indicate that promoters D50-3, P2- 300, and J17 have different strengths resulting in MDH levels in MM8-5 strains that are $0.28,1.16$, and 1.65 times the MDH level in HB27 respectively. Since each promoter is evaluated here in identical genetic constructs that differ only by virtue of the promoter driving the expression of the $m d h$ gene these MDH levels should serve to accurately quantify the strength of these promoters. Other strains whose MDH activity is listed in Table 10 all use the same promoter, J17, to express the $m d h$ gene in various backgrounds. MM8-5/pS-J17mdh-A contains a single copy of the $m d h$ gene integrated into the chromosome under the control of the J17 promoter. MM8-5/pTEXI-mdh contains the $m d h$ gene under the control of the J17 promoter on a plasmid vector and the HB27/pTEXI-mdh contains two separate sources of the $m d h$ gene, a wild type $m d h$ gene on the chromosome as well as the $m d h$ gene under the control of the J17 promoter on a plasmid vector. Since MM8-5/pTEXI-mdh yields 32.58 units of MDH/mg protein it is unexpected that HB27/pTEXI-mdh that contains two separate copies $m d h$ gene, a wild type $m d h$ gene on the chromosome as well as the $m d h$ gene on a plasmid vector shows less MDH activity (29.62 units/mg). There may be some plasmid instability contributed to homologous recombination between the two $m d h$ gene copies. Although there is no apparent difference in the copy number of the plasmid in these two strains as observed in plasmid DNA samples prepared from equal amounts of cells from both cultures (data not shown). Perhaps there are currently unknown factors that limit the amount of MDH protein that can be made in $T$. thermophilus, but this would require further investigation. 
The addition of a functioning malate dehydrogenase gene to Thermus expression vectors provides a plasmid stabilizing mechanism in $\Delta m d h$ hosts, without the addition of antibiotics. This Thermus malate dehydrogenase based host-vector system should prove to be useful in future genetic studies with Thermus sp. particularly because malate dehydrogenase activity can be conveniently and accurately quantified using a simple spectrophotometric assay and can be used as reporter gene to evaluate promoter strength and gene expression. The results reported here demonstrate the use of this host/vector system to examine constitutive promoters of various strengths. This Thermus host/vector system can also be useful in the investigation of genetic expression in Thermus sp.

Table 10. Malate dehydrogenase activity of Thermus vector constructs.

\begin{tabular}{|c|c|c|}
\hline Culture and Condition & $\begin{array}{c}\text { MDH activity } \\
\text { at } 25^{\circ} \mathrm{C} \\
\text { (Units } \mathrm{MDH} / \mathrm{mg} \text { ) }\end{array}$ & $\begin{array}{c}\text { MDH activity } \\
\text { at } 50^{\circ} \mathrm{C} \\
\text { (Units } \mathrm{MDH} / \mathrm{mg} \text { ) }\end{array}$ \\
\hline HB27 & 2.47 & 19.94 \\
\hline MM8-5/pSJ17mdhA & 0.62 & 5.52 \\
\hline HB27/pTEXl-mdh & 3.71 & 29.62 \\
\hline MM8-5 & 0.00 & 0.46 \\
\hline MM8-5 /pTEXI-mdh & 4.18 & 32.58 \\
\hline MM8-5 /pTEX1-D50-3 & 0.28 & 2.69 \\
\hline MM8-5/pTEX1-P2-300 & 3.02 & 23.16 \\
\hline
\end{tabular}

MDH activity values recorded are averages of three replicate samples from three separate experiments for a total of nine data points. Standard deviation is less than 5\%. MDH activity is reported as units of $M D H$ per $m g$ protein in cell lysates. One unit of $M D H$ activity is defined as the amount of enzyme needed to convert one micromole of NADH to NAD in one minute. 
A

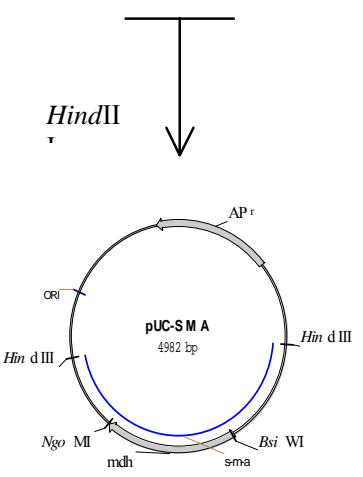

B
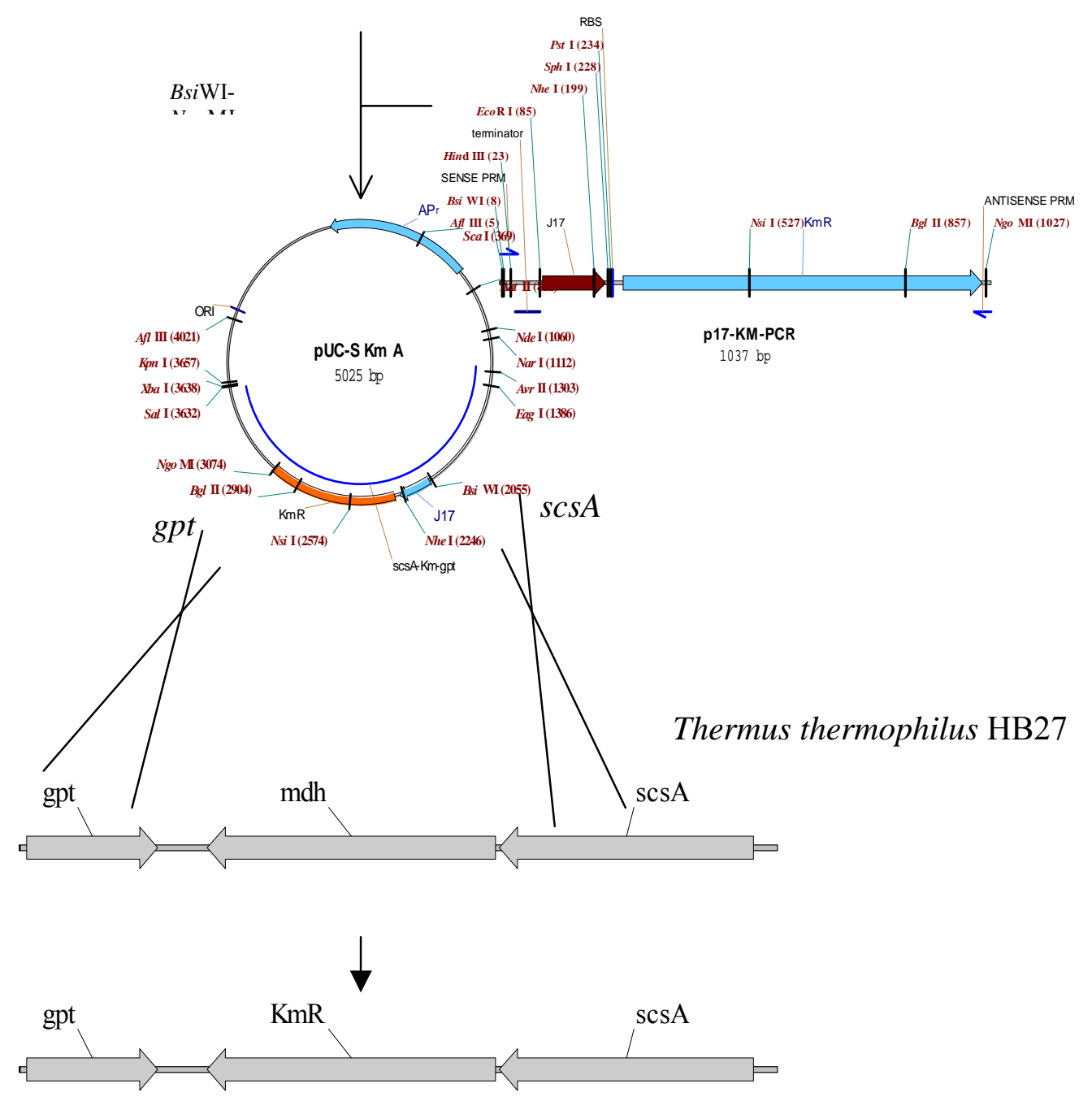
FIGURE 15. CONSTRUCTION OF THERMUS THERMOPHILUS $\triangle M D H K M^{\mathrm{R}}$ MM8-5.
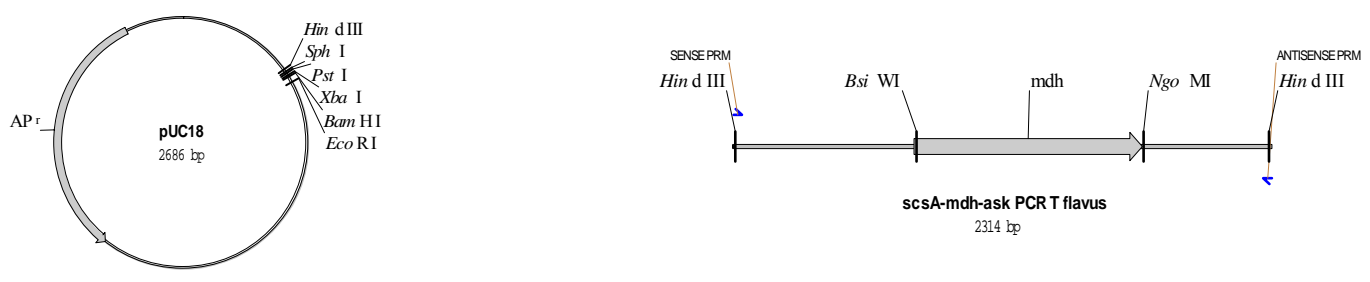

A. The region surrounding the $m d h$ gene from Thermus flavus was amplified from chromosomal DNA using the following PCR primers: forward

5'-ACAACAAAGCTTCGGGCAAAGGGGGAACGGAGGTCCT-3' and reverse 5'-ACAACAAAGCTTGAGCCTTTTGACCTCGTCCTGGGG-3'. These primers were designed to amplify the sequence of the malate dehydrogenase and the regions immediately flanking the malate dehydrogenase gene from Thermus flavus according to published DNA sequences. Restriction sites were added into the PCR primers to give $5^{\prime}$ and $3^{\prime}$ HindIII sites. The $2.3 \mathrm{~Kb}$ PCR product containing the $m d h$ gene and flanking regions was cloned into the HindIII site of pUC18. The resulting plasmid is $4982 \mathrm{bp}$ and was designated pUC S-M-A. B. Plasmid pUC S-M-A was digested with BsiWI and NgoMI removing the all but the first 20 bp of the $m d h$ gene sequence. A kanamycin resistance cassette was amplified using plasmid pTEX J17 as the template and using the following PCR primers: forward.

5'-ACAACACGTACGGATTACGCCAAGCTTCATGGCCTAA-3' and reverse 5'-ACAACAGCCGGCTCGTTCAAAATGGTATGCGTTTTG-3'. Restriction sites were added into the PCR primers to give a $5^{\prime} B s i \mathrm{WI}$ and $3^{\prime}$ NgoMI site. The cassette contains a strong constitutive Thermus promoter (J17) upstream of the themostable kanamycin nucleotidyltransferase cassette $\left(\mathrm{Km}^{\mathrm{R}}\right)$. To prevent transcription read through from the native mdh promoter a transcriptional termination sequence was cloned upstream of the J17 promoter. The kanamycin resistance cassette was digested with $B s i \mathrm{WI}$ and $N g o \mathrm{MI}$ and ligated into the $B s i$ WI-NgoMI digested pUC S-M-A. The $m d h$ gene was replaced with a kanamycin resistance cassette and the resulting plasmid was designated pUC- S Km A. C. After transformation of plasmid pUC- S Km A into Thermus thermophilus HB27 a double crossover homologous 
recombination event replaces $m d h$ with the $\mathrm{Km}^{\mathrm{R}}$ determinant. The $\Delta m d h K m^{\mathrm{R}}$ Thermus thermophilus HB27 strain subsequently isolated was designated MM8-5.

A

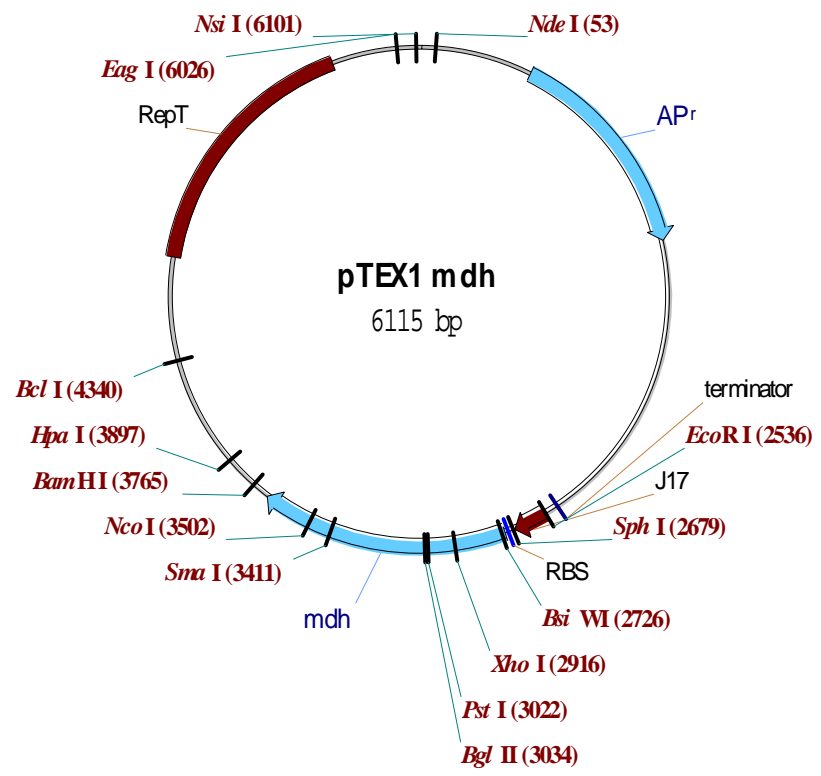

$\mathrm{B}$

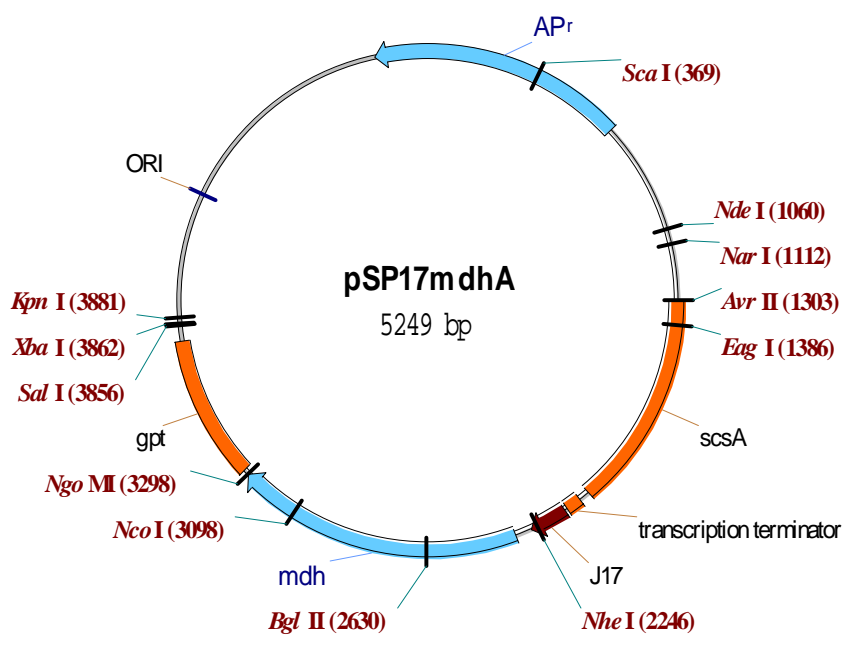

FIGURE 16. CONSTRUCTION OF THERMUS EXPRESSION VECTORS. 
A. Expression vector containing the Thermus flavus malate dehydrogenase downstream of the strong constitutive Thermus promoter J17. The $m d h$ gene from Thermus flavus was amplified from chromosomal DNA using the following PCR primers: forward $m d h$ 5'ACACAGAATTCGCATGCTCAAGAAGGCCCTGGGCTAA-3' and reverse $m d h$ 5'-ACACACGGATCCTGCGCCAGCATGGGGTGGTATAAA-3'. Restriction sites were added into the PCR primers to give 5' EcoRI and 3' BamHI. Plasmid pTEX1 was digested with EcoRI and BamHI and a EcoRI-BamHI digested $m d h$ PCR product was ligated into the vector to create pTEX1-mdh. B. Integrative vector pSJ17mdhA has the J17 promoter- $m d h$ gene cassette flanked by the $\operatorname{scs} A$ and $g p t$ chromosomal regions. A transcriptional termination sequence from the $T$. flavus phenylalanyl tRNA synthetase operon (4) was cloned upstream of the cassette to prevent transcription read through from the native succinate--CoA ligase/malate dehydrogenase operon promoter.

\section{Expression of dszC in Thermus thermophilus}

These genetic tools were used to express the desulfurization genes in Thermus thermophilus HB27. An organism, previously isolated in our laboratory and designated Mycobacterium spp. GTIS10, was isolated based on its ability to use dibenzothiophene (DBT) as a sole source of sulfur for growth at $45-52^{\circ} \mathrm{C}$. Similar to other biodesulfurization competent organisms Mycobacterium sp. GTIS10 converts DBT to 2-hydroxybiphenyl (2-HBP). This bacterial culture contains the desulfurization operon $(d s z)$ on a $120 \mathrm{~kb}$ plasmid (pSOX) (DeniseLarose et al. 1997) and has been shown to be capable of selectively cleaving carbon-sulfur bonds in petroleum, coal, and a wide range of model compounds resulting in the removal of sulfur and the retention of carbon and calorific value(Kayser et al. 2001). The pathway for dibenzothiophene degradation is shown in Figure 17. The $d s z C$ gene encodes dibenzothiophene monooxygenase that catalyzes the conversion of DBT to dibenzothiophene sulfone (DBTS02). The $d s z A$ gene encodes dibenzothiophene-5,5-dioxide monooxygenase that catalyzes the conversion of DBTS02 to 2-hydroxybiphenyl-2-sulfinate (HBPSi). The $d s z B$ gene encodes 2hydroxybiphenyl-2-sulfinate sulfinolyase that catalyzes the conversion of HBPSi to 2hydroxybiphenyl (2HBP) (Denome et al. 1994). A fourth gene the $d s z D$ gene encoding a NADHFMN oxidoreductase is an accessory component of the desulfurization pathway and supplies 
cofactors needed for the monooxygenase reactions catalyzed by the products of $d s z C$ and $d s z A$ (Gray et al. 1996; Reichmuth et al. 2000).

We cloned the $d s z C, d s z A$ and $d s z B$ genes into a Thermus expression vector and obtained the successful expression of the dibenzothiophene monooxygenase (DszC) in Thermus thermophilus HB27. Future research will be required to determine why functional expression of $d s z A$ and $d s z B$ were not obtained in T. thermophilus.

Prior to testing for $d s z C$ expression in Thermus we needed to examine the intrinsic NADH-FMN oxidoreductase or flavin reductase activity of the Thermus cells. NADH-FMN oxidoreductase /flavin reductase $(d s z D)$ is required for activity of the dibenzothiophene desulfurization pathway monooxygenase reactions. The presence of an FMN oxidoreductase is necessary for heterologous $d s z \mathrm{C}$ expression in both Thermus and E. coli. FMN oxidoreductases are common in bacteria and if present in Thermus and/or E. coli the native enzyme should be sufficient in providing cofactors to the DszC enzyme. E. coli FMN oxidoreductase activity has been previously documented in our laboratory and was used as a control for these experiments. We confirmed the presence of the necessary FMN oxidoreductase by conducting a simple spectrophotometric assay that quantifies the conversion $\mathrm{FMN}$ to $\mathrm{FMNH}_{2}$ at the expense of NADH. Crude cell lysates were prepared from both T. thermophilus and from E. coli and FMN oxidoreductase specific activities were quantified spectrophotometrically by monitoring the reduction of NADH at $340 \mathrm{~nm}$. One unit of FMN oxidoreductase enzyme activity is defined as the 


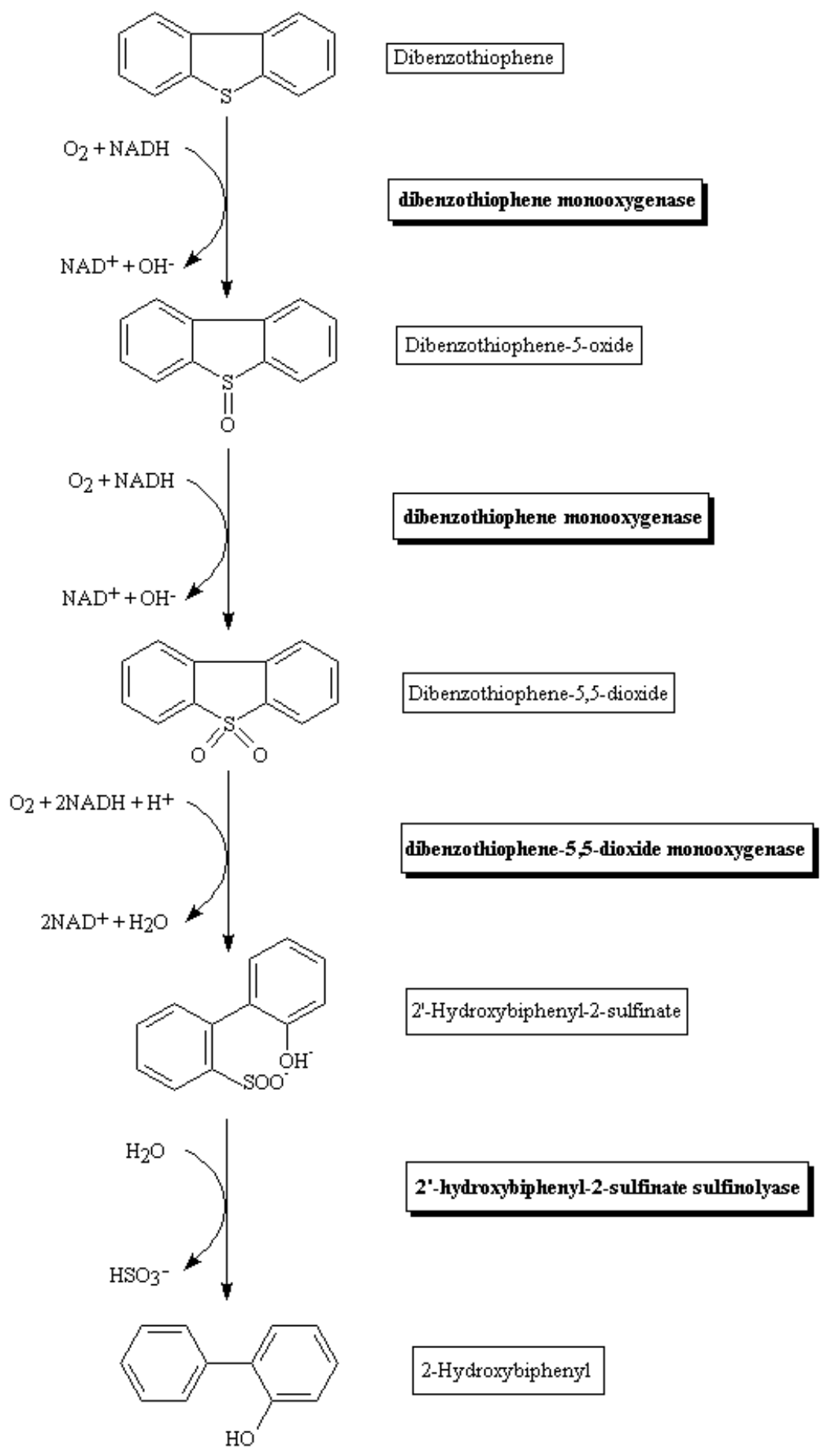
FIGURE 17. DBT DESULFURIZATION REACTION CATALYZED BY MYCOBACTERIUM
SP. GTIS10. 
amount needed to convert one $\mu$ mole of NADH to NAD in one minute. The specific activity of the FMN oxidoreductase in the E. coli extract was 1.26 units/mg protein (comparable with previous results) while the activity in the $T$. thermophilus extract was 0.31 units/mg protein.

A PCR fragment containing the dibenzothiophene monooxidase $(d s z C)$ gene from Mycobacterium sp. GTIS10, was cloned into a Thermus expression vector to create plasmid pTGTI-dszC that allows the $d s z C$ gene to be expressed by a Thermus promoter, and the plasmid is capable of replicating in T. thermophilus. A plasmid map of pTGTI-dszC is illustrated in Figure 18. This plasmid was transformed into T. thermophilus HB27 and grown overnight in TT medium at $55^{\circ} \mathrm{C}$. Cells were washed and concentrated by centrifugation and subsequently incubated at $37^{\circ} \mathrm{C}$ for 1 hour in the presence of $100 \mu$ molar DBT. The cell suspension was subsequently acidified with $\mathrm{HCl}$, extracted with ethyl acetate, and analyzed by thin layer chromatography (TLC) and high-pressure liquid chromatography (HPLC). The expression of the $d s z C$ gene in Thermus was confirmed by both TLC analyses, which indicated the formation of dibenzothiophene sulfone in samples derived fromThermus thermophilus HB27/pTGTI-dszC and by analyses of extracts by HPLC indicated the conversion of dibenzothiothene to dibenzothiophene sulfone as indicated in Figure 19.

T. thermophilus HB27/pTGTI-dszC resting cells incubated at various temperatures for an hour in the presence of DBT indicate DszC activity at 37,45 , and $50^{\circ} \mathrm{C}$, but no activity at $60^{\circ} \mathrm{C}$ and above. The demonstration of a functional DszC enzyme in T. thermophilus HB27 is a major technical accomplishment that validates the strategy of using molecular genetics to produce biocatalysts that can be used in high temperature bioprocesses. Specific activity was determined by HPLC. The specific activity results did not vary between resting cell incubation temperatures. Specific activities were on average near $20 \mu$ mole $\mathrm{DBTSO}_{2}$ produced $/ \mathrm{hr} / \mathrm{g}$ dry cells. The specific activity of the DszC enzyme in the moderate thermophile Paenibacillus sp. strain A11-2 was reported as about $4.8 \mu$ mole $\mathrm{DBTSO}_{2}$ produced $/ \mathrm{hr} / \mathrm{g}$ dry cells (Konishi et al. 2000). Desulfurization activity in Rhodococcus erythropolis IGTS8 has been reported to range from 16.5 to $35 \mu$ mole $\mathrm{DBTSO}_{2}$ produced $/ \mathrm{hr} / \mathrm{g}$ dry cells (Konishi et al 1997; 


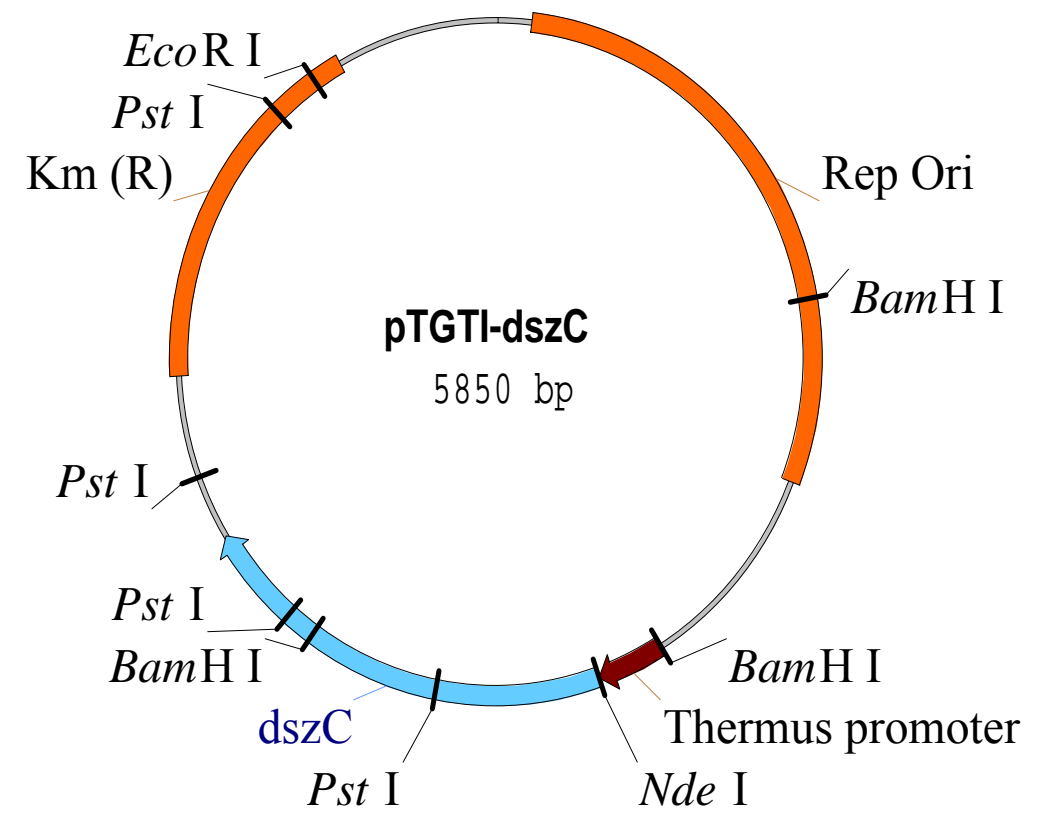

FIGURE 18. CLONING OF THE DSZC GENE OF MYCOBACTERIUM SP. GTIS10 INTO THERMUS EXPRESSION VECTOR PTGTI-DSZC 
FIGURE 19. HPLC ANALYSES DEMONSTRATING THE CONVERSION OF DBT TO DBT-SULFONE BY T. THERMOPHILUS HB27/PTGTI-DSZC

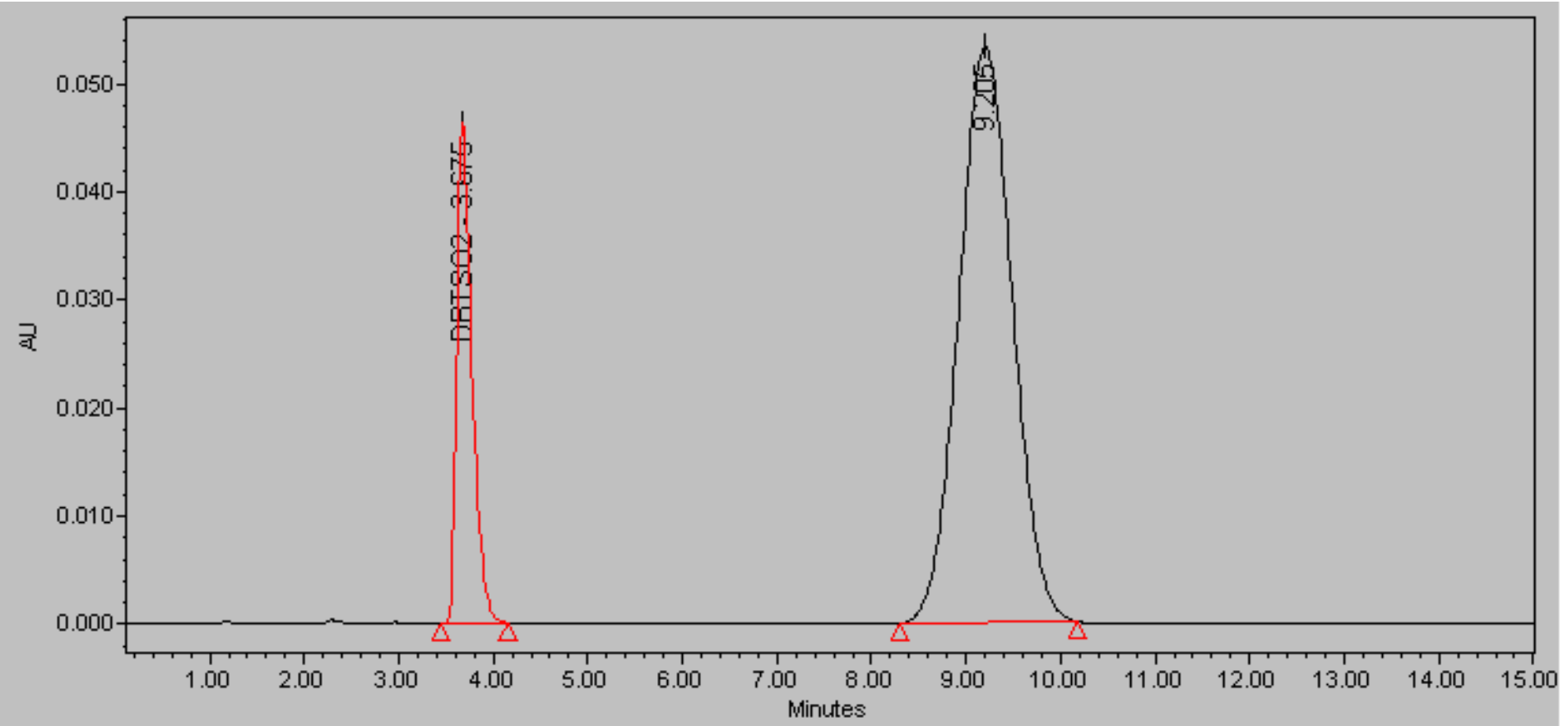


Oldfield et al. 1998) and the specific activity of DszC in Mycobacterium sp. GTIS10 is about 90 $\mu$ mole $\mathrm{DBTSO}_{2}$ produced $/ \mathrm{hr} / \mathrm{g}$ dry cells. Thus the level of DszC activity in Thermus is comparable to other hosts even in these initial experiments. Further improvements in our technology for gene expression in Thermus are anticipated to improve DszC activity levels further. In vitro tests of the thermostability of $\mathrm{DszC}$ indicate that activity is retained after exposure at $50^{\circ} \mathrm{C}$ for a 1 hour period. At this time it is not clear why DszC does not exhibit better activity in T. thermophilus. There are several possible explanations for the low expression levels observed. The FMN oxidoreductase activity in Thermus is quite low (0.31 units/mg protein) and may not provide sufficient amount of cofactor to the DszC enzyme. Future experiments are needed to determine the minimal cofactor requirement necessary for DszC function and if necessary clone alternative FMN oxidoreductases such as dszD into the Thermus strain. In addition we have also observed that the plasmid pTGTI-dszC does not appear to be stable in T. thermophilus and is lost within a few cell generations if the culture is grown without selective pressure (presence of antibiotic) to select for the retention of the plasmid. Attempts to examine crude lysates of $T$. thermophilus HB27/ pTGTI-dszC using protein gels failed to identify a protein band that clearly corresponded to the expected size of DszC, but this is probably due to the presence of multiple native Thermus protein bands in this region of the gel.

These results demonstrating the expression of $\mathrm{DszC}$ in $T$. thermophilus are highly significant as they represent the first example of the functional expression of a cofactorrequiring heterologous gene in $T$. thermophilus. Future research to optimize gene expression in T. thermophilus is clearly needed, but the results obtained in this project have demonstrated that $T$. thermophilus can be genetically manipulated in a convenient fashion and used to express any gene of interest to the biotechnology industry. Results obtained in this project clearly illustrate that $T$. thermophilus can be used as a host for the development of a high temperature biorefining process. 


\section{Growth Studies with Thermus thermophilus}

In order to utilize a thermophilic bacterium as the host in a bioprocess it will be necessary to obtain data concerning the best choice of medium components, and the growth rate and yield of the culture under various process conditions such as aeration and agitation. Information in the literature concerning the growth of aerobic thermophiles is sparse. Since Thermus thermophilus is the aerobic thermophile that can be genetically modified most conveniently it was chosen as the focus of studies in this project to further develop genetic tools and to obtain data concerning the optimum conditions for the growth of this culture.

\section{Growth on Minimal Medium}

Medium composition can significantly affect product concentration, yield, volumetric productivity, ease of downstream processing and overall process economics. Before proceeding to medium improvement experiments, a target variable, growth (absorbance at $600 \mathrm{~nm}$ ) of $T$. thermophilus and T. flavus, was chosen as the performance indicator. T. thermophilus and $T$. flavus were grown in different minimal media in shake flasks. The carbon composition was calculated based on the carbon content of the microorganism and cell mass concentration (biological mimicry). The composition was varied and the medium that shows the maximum growth was zeroed in as the medium of choice. The aim of this experiment was to adapt these cultures to grow in sulfur-free/nitrogen-free minimal medium at a faster rate and ultimately result in the isolation of a Thermus culture that can grow well in the most simple/economical medium composition possible. The long-term goal of these minimal media experiments was to determine the growth conditions for T. thermophilus and T. flavus that can be used to achieve the highest levels of expression of genes encoding carbon-nitrogen or carbon-sulfur bond-cleaving enzymes. ModA was the base medium used. Rich medium components like yeast /Tryptone were added in cases when no growth was observed with minimal media. The carbon sources studied were glucose, sodium $(\mathrm{Na})$ glutamate, $\mathrm{Na}$ succinate, $\mathrm{Na}$ citrate, $\mathrm{Na}$ fumarate, and $\mathrm{Na}$ acetate. Malate dehydrogenase $(\mathrm{MDH})$ catalyses the dehydrogenation of malate to oxaloacetate using $\mathrm{NAD}^{+}$as a cofactor and is a key enzyme in the TCA cycle. All the carbon sources used are a part of the TCA cycle. The effect of each component on growth of $T$. flavus was studied by the one-at-atime method and component swapping method to optimize the media composition. The effect of

each media component was studied by setting up Graeco-Latin Square experiments, which 
involved setting up a minimum number of experiments to get optimum information. A matrix of media components was varied and the effect of individual components and combinations of components can be quantified in growth experiments. It was found that Thermus (both $T$. thermophilus and T. flavus ) grows well in minimal medium supplemented with rich components like yeast and polypeptone $(0.6-2.5 \mathrm{~g} / \mathrm{L})$. The carbon sources in which positive results were obtained are succinate, fumarate, acetate and glutamate. The addition of rich components was reduced in further experiments.

Results from the Graeco-Latin Square experiments_(refer Tables 11 and 12):

- Based on growth (OD - absorbance at $600 \mathrm{~nm}$ ), glutamate is the best carbon source as compared to succinate and acetate.

- Growth with peptone+yeast is comaparable in HB27 \& T.flavus and growth with no peptone or yeast is higher in T.flavus when the other nutrients like biotin+thiamine+casamino acids are added.

- There is a 2 -3 fold increase in OD in the presence of biotin+thiamine and casamino acids in both HB27 and T.flavus.

- No effect of addition of Proline is apparent in T.flavus whereas the OD increases 3 fold in case of HB27. Peptone+yeast and TES were added in this experiment.

- In case of HB27, at the same carbon and nitrogen concentration (glutamate and peptone+yeast), biotin+thiamine and casamino acids give better growth than proline and TES $(\mathrm{OD}=1.813 \mathrm{v} / \mathrm{s} 1.187)$.

- In case of T.flavus, at the same carbon and nitrogen concentration (glutamate and peptone+yeast), biotin+thiamine and casamino acids give better growth than proline and TES $(\mathrm{OD}=1.753 \mathrm{v} / \mathrm{s} 0.695)$. 
Table 11: Graeco Latin Square Matrix for T. flavus Growth in Minimal Media

\begin{tabular}{|c|c|c|c|c|c|c|c|c|c|c|c|c|}
\hline \multicolumn{2}{|c|}{ CodeComponent } & \multicolumn{9}{|c|}{ Medium Number } & \multirow{2}{*}{$\begin{array}{l}\text { Effect of } \\
\text { each } \\
\text { Component } \\
\end{array}$} & \multirow{2}{*}{$\begin{array}{l}\text { Optimum } \\
\text { Medium } \\
\text { Composition }\end{array}$} \\
\hline & & 1 & 2 & 3 & 4 & 5 & 6 & 7 & 8 & 0 & & \\
\hline A1 & Glutamate & + & & & + & & & + & & & $\begin{array}{l}1.982+1.753+ \\
0.289=4.024\end{array}$ & Glutamate \\
\hline $\mathrm{A} 2$ & Succinate & & + & & & + & & & + & & $\begin{array}{l}0.874+0.675+ \\
1.075=2.624\end{array}$ & \\
\hline A3 & Acetate & & & + & & & + & & & + & $\begin{array}{l}0.033+0.044+ \\
0.069=0.146\end{array}$ & \\
\hline B1 & $\begin{array}{l}150 \mathrm{mg} / \mathrm{L} \mathrm{bi} \\
1.5 \mathrm{mg} / \mathrm{L} \\
\text { thiamine }\end{array}$ & i) + & + & + & & & & & & & $\begin{array}{l}1.982+0.874+ \\
.033 \\
=2.702\end{array}$ & $\begin{array}{c}150 \mathrm{mg} \\
\text { biotin+1.5mg } \\
\text { thiamine) } / \mathrm{L}\end{array}$ \\
\hline B2 & $\begin{array}{l}100 \mathrm{mg} / \mathrm{L} \text { bi } \\
1.0 \mathrm{mg} / \mathrm{L} \\
\text { thiamine }\end{array}$ & & & & + & + & + & & & & $\begin{array}{l}1.753+0.675+ \\
.044 \\
=2.472\end{array}$ & \\
\hline B3 & none & & & & & & & + & + & + & $\begin{array}{l}0.289+1.075+ \\
.069=1.433\end{array}$ & \\
\hline $\mathrm{C} 1$ & $\begin{array}{l}2 \mathrm{~g} / \mathrm{L} \\
\text { casamino } \\
\text { acids }\end{array}$ & + & & & & & + & & + & & $\begin{array}{l}1.982+.044+1 \\
.075 \\
=3.101 \\
\end{array}$ & $\begin{array}{c}\text { Casamino acids } \\
(0.2 \%)\end{array}$ \\
\hline $\mathrm{C} 2$ & $\begin{array}{l}1 \mathrm{~g} / \mathrm{L} \\
\text { casamino } \\
\text { acids }\end{array}$ & & + & & + & & & & & + & $\begin{array}{l}0.874+1.753+ \\
0.069=2.696\end{array}$ & \\
\hline $\mathrm{C} 3$ & none & & & + & & + & & + & & & $\begin{array}{l}.033+0.675+0 \\
.289 \\
=0.997\end{array}$ & \\
\hline D1 & $\begin{array}{l}0.4 \mathrm{~g} / \mathrm{L} \\
\text { peptone }+ \\
0.2 \mathrm{~g} / \mathrm{L} \\
\text { yeast }\end{array}$ & + & & & & + & & & & + & $\begin{array}{l}1.982+.675+. \\
069 \\
=2.726\end{array}$ & \\
\hline D2 & $\begin{array}{l}0.2 \mathrm{~g} / \mathrm{L} \\
\text { peptone }+ \\
0.1 \mathrm{~g} / \mathrm{L} \\
\text { yeast }\end{array}$ & & & + & + & & & & + & & $\begin{array}{l}0.033+1.753+ \\
1.075=2.861\end{array} \mid$ & $\begin{array}{l}0.2 \mathrm{~g} / \mathrm{L} \text { peptone }+ \\
0.1 \mathrm{~g} / \mathrm{L} \text { yeast }\end{array}$ \\
\hline D3 & $\begin{array}{l}\text { No peptone } \\
\& \text { yeast }\end{array}$ & & + & & & & + & + & & & $\begin{array}{l}.874+.044+.2 \\
89 \\
=1.207\end{array}$ & \\
\hline & $\begin{array}{l}\text { Medium } \\
\text { Code }\end{array}$ & $\begin{array}{l}\text { A1B } \\
\text { C1D }\end{array}$ & $\begin{array}{l}\mathrm{A} 2 \mathrm{~B} \\
\mathrm{C} 2 \mathrm{D}\end{array}$ & $\begin{array}{l}\mathrm{ABB} \\
\mathrm{C} 3 \mathrm{D} \\
\end{array}$ & & $\begin{array}{l}\mathrm{A} 2 \mathrm{~B} \\
\mathrm{C} 3 \mathrm{D}\end{array}$ & $\begin{array}{l}\text { A3B } \\
\text { C1D }\end{array}$ & $\begin{array}{l}\text { A1B: } \\
\text { C3D }\end{array}$ & $\begin{array}{l}\mathrm{A} 2 \mathrm{~B} 3 \\
\mathrm{C} 1 \mathrm{D} 2\end{array}$ & $\begin{array}{l}\mathrm{A} 3 \mathrm{~B} 3 \\
\mathrm{C} 2 \mathrm{D} 1\end{array}$ & & \\
\hline & $\begin{array}{l}\text { Abs } \\
\text { @ } 600 \mathrm{~nm}\end{array}$ & 1.982 & 0.87 & 0.03. & 1.75 & 0.67 & 0.04 & 0.289 & 1.075 & 0.069 & & \\
\hline
\end{tabular}


Table 12: Graeco Latin Square Matrix for T. thermophilus Growth in Minimal Media

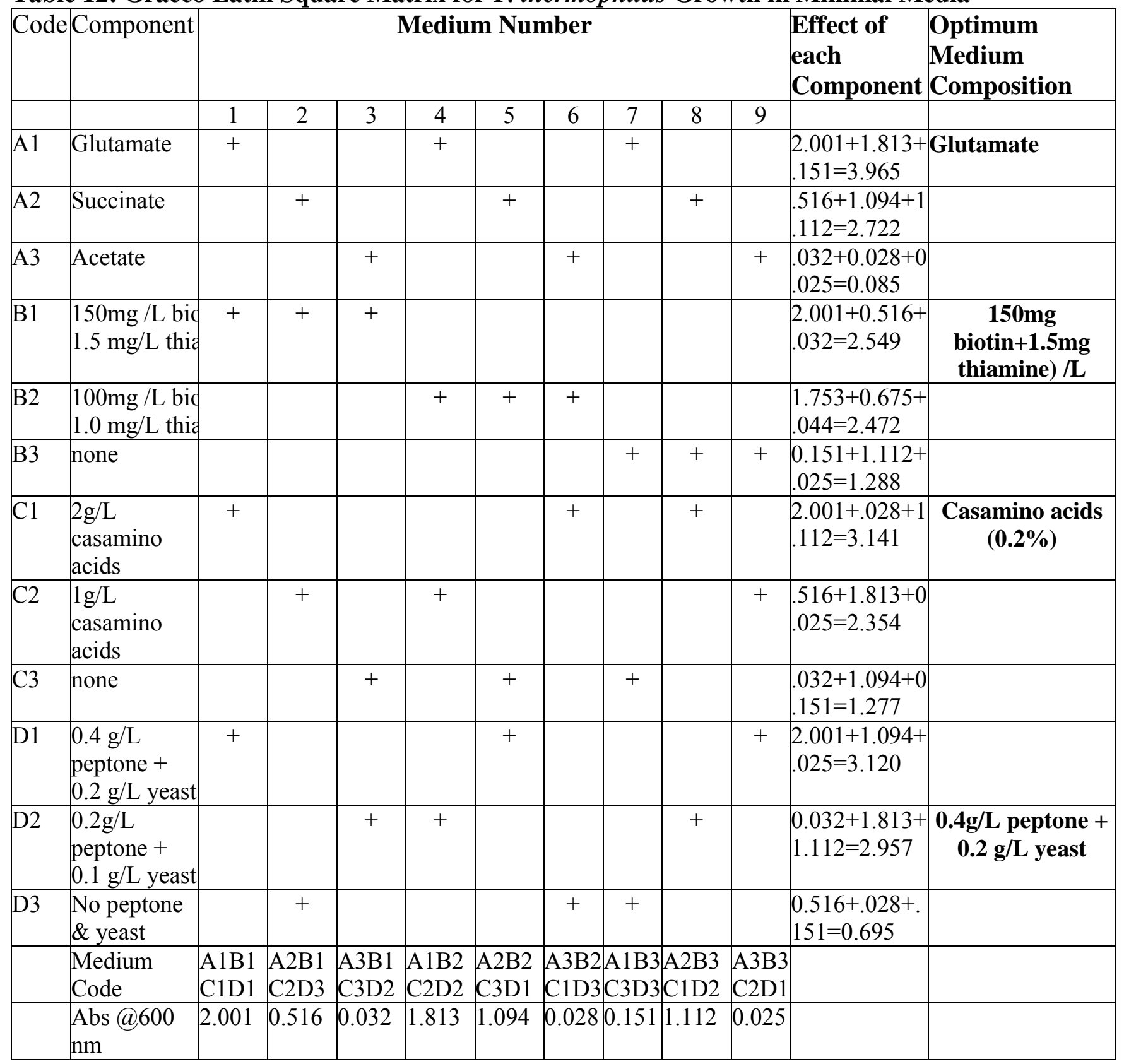

In the above experiments, the carbon requirement of the microorganism based on its carbon content was $0.3 \mathrm{M}$. The carbon source concentration in $\mathrm{g} / \mathrm{L}$ corresponded to this molarity of carbon.

Graeco Latin Square experiments consist of nine shake flasks/reactors in which various combinations of ingredients are tested according to a specific design illustrated in Tables 11 and 
12. The growth of T. flavus was studied in the results reported in Table 11, while the growth of T. thermophilus HB27 was studied in the experiment reported in Table 12. There are four main variables designated $\mathrm{A}, \mathrm{B}, \mathrm{C}$ and $\mathrm{D}$ and each main variable has three conditions/sub-variables designated A1, A2, A3, B1, B2, B3, etc. The main variables in the experiment described in Tables 11 and 12 are $\mathrm{A}=$ carbon source, $\mathrm{B}=$ Biotin (bio) plus thiamine, $\mathrm{C}=$ casamino acids, and $\mathrm{D}=$ peptone plus yeast extract. The three conditions for each main variable can be different carbon sources as shown in A1, A2, and A3 or different concentrations of compounds as shown in B1, B2, and B3. This experiment is scored based on the total amount of growth achieved during a 5-day incubation at $65^{\circ} \mathrm{C}$ and growth is measured by absorbance at $600 \mathrm{~nm}$ using a spectrophotometer. The last row in the bottom of Tables 11 and 12 indicates the amount of growth obtained in each of the nine shake flasks. The design of the experiment places each variable in three different shake flasks. For example variable A1 is present in shake flasks 1, 4, and 7 while $\mathrm{A} 2$ is present in flasks 2, 5, and 8 and so on. To assess the effect of each variable the growth obtained from each of the three shake flasks that contained that variable are summed and that is recorded in Tables 11 and 12 in the column labeled "Effect of each Component". These sums are then compared for all of the variables which in the case for T. thermophilus in Table 12 as $\mathrm{A} 1($ glutamate $)=3.965, \mathrm{~A} 2($ succinate $)=2.722$, and $\mathrm{A} 3$ (acetate) $=0.085$. These results indicate that the A category variable that yielded the best result was A1 or glutamate. Similarly the results in Table 12 indicate that the best results in the other categories were obtained with B1 (150 mg/L biotin plus $1.5 \mathrm{mg} / \mathrm{L}$ thiamine), C1 (2g/L casamino acids), and D2 (0.4 g/L peptone plus $0.2 \mathrm{~g} / \mathrm{L}$ yeast extract).

Moreover it can be seen that while B1 C1, and D2 yielded the best results decreasing the concentration of these compounds as in conditions B2, and C2 yielded nearly the same result, but that some amount of these compounds was required for good growth as evidenced by the low values obtained in conditions B3, C3, and D3.

Low substrate utilization is claimed to be characteristic feature of thermophiles. We performed experiments to find the best carbon source for $T$. thermophilus. These experiments include a much smaller concentration (1-2 g/L glucose as compared to $10 \mathrm{~g} / \mathrm{L}$ used earlier). We have observed good growth with 1 and $4 \mathrm{~g} / \mathrm{L}$ glucose $\left(\mathrm{A}_{600 \mathrm{~nm}}\right.$ upto 1$)$. This has led to our hypothesis that like E. coli, T. thermophilus might a threshold concentration above which acidogenesis (Crabtree effect) occurs. The Crabtree effect is the formation of acetate, which is 
toxic to the cells, in the presence of excess glucose. Results from these experiments will lead to a carbon source that gives best growth and has the highest utilization efficiency. These experiments included $1 \mathrm{~g} / \mathrm{L}$ proline, which is a nutritional requirement of $T$. thermophilus.

In our quest to obtain a minimal media composition that gives optimum growth results, we also worked on finding a mutant of $T$. thermophilus (HB27) that would not have any specific nutritional requirements like proline. We obtained such a prototroph by mutagenesis of HB27 and is designated as HB28.

Table 13: Growth of Prototroph HB28 in Minimal Media

\begin{tabular}{|c|c|}
\hline $\begin{array}{l}\text { Carbon } \\
\text { Source }\end{array}$ & Observations \\
\hline Glycerol & 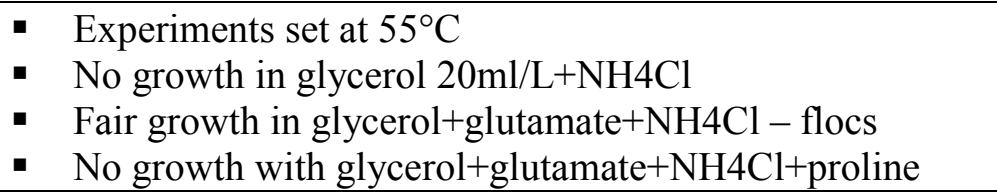 \\
\hline Glutamate & $\begin{array}{l}\text { - } \text { Experiments set at } 55^{\circ} \mathrm{C} \\
\text { - } \text { Growth in all compositions tested } \\
\text { - } \text { Glutamate } 4 \mathrm{~g} / \mathrm{L}+\mathrm{NH} 4 \mathrm{Cl}-\text { flocs } \\
\text { - } \text { Glutamate } 4 \mathrm{~g} / \mathrm{L}+\mathrm{NH} 4 \mathrm{Cl}+\text { Proline }- \text { no flocs } \\
\text { - } \text { Glutamate } 16 \mathrm{~g} / \mathrm{L}-\text { flocs } \\
\text { - Glutamate } 16 \mathrm{~g} / \mathrm{L}+\text { Proline - flocs } \\
\text { - } \text { Growth apparent after long incubation of }>10 \text { days. }\end{array}$ \\
\hline Glucose & $\begin{array}{l}\text { - Experiments set at } 55^{\circ} \mathrm{C} \\
\text { - Good growth (OD } 0.6 / 0.4)- \text { no flocs in Glucose } 1 \mathrm{~g} / \mathrm{L}+/- \\
\text { Proline in } 3 / 5 \text { days. }\end{array}$ \\
\hline
\end{tabular}

The next round of experiments confirmed the growth of HB28 in minimal media. It showed good growth in pyruvate and slight growth in glucose. A similar experiment was set up in parallel in a microtiter plate reader that has the advantageous of automated readings and replicate growth curves. Six replicates each for the six carbon sources (2 concentrations for each carbon source) were set up in microtiter plate. Mechanical problems and varied evaporation in the wells did not yield quantitative results. But qualitative observations indicate pyruvate, succinate, fumarate could be candidates in the next round of experiments. The carbon sources used in the flask and microtiter experiments were glucose, glutamate, malate, pyruvate, succinate, and fumarate.

\section{Reactor Studies}


In addition to optimizing the minimal media composition for Thermus cultures in shake flasks, experiments to study and optimize growth in reactors were performed. A goal was to obtain an understanding and expertise in optimization of the culture conditions and process parameters for the production of recombinant DNA products in Thermus thermophilus.

The literature regarding $T$. thermophilus is rather sparse, particularly as regards growth under conditions suitable for a bioprocess. A fair amount of research in this project has been directed at the study of the growth of $T$. thermophilus. A manuscript has been prepared and submitted to the Journal of Biosciences and Bioengineering that summarizes the results of experiments to characterize the effect of aeration and agitation conditions on the growth of $T$. thermophilus HB27 in a bench-scale fermenter using rich growth medium. Those experiments resulted in the highest cell yields of any Thermus culture reported in the literature.

Additionally, experiments were performed to evaluate the level of malate dehydrogenase enzyme activity that can be detected in various $T$. thermophilus cultures available in our laboratory. In order to demonstrate the use of $T$. thermophilus as a host in a bioprocess it may be reasonable to use malate dehydrogenase as a model of a biotechnology product. This enzyme can be accurately quantified using a spectrophotometric assay and in our laboratory we have several Thermus cultures available that contain deletions of the $m d h$ gene, or that contain the $m d h$ gene cloned in various expression vectors. Additionally, the medium and growth conditions employed can effect the level of MDH activity detected. An evaluation of the MDH levels that can be obtained using various Thermus cultures grown in shake flasks or fermentors, and using complex or minimal medium was performed. This survey serves as a starting point to indicate the baseline of MDH activity that can be obtained in Thermus and to indicate what conditions might yield higher activity. The results of this preliminary survey of MDH activity are summarized in Figure 20 where it can be seen that the results are highly variable. Cells grown in the same medium do not always produce the same level of MDH activity. This survey was performed by obtaining samples of bacterial cultures that were available in the lab and not from cultures that were specifically grown for the purpose of optimizing the expression of $\mathrm{MDH}$ activity. That is to say that the majority of these cultures were grown for purposes other than the optimum expression of MDH activity. Accordingly, the phase of growth of each culture when the sample was obtained was not standardized and this alone is probably the biggest source of variability in the data. Nonetheless Figure 20 illustrates that the best results are obtained in 
minimal medium rather than rich (TT) medium. Moreover cultures that contain a cloned $m d h$ gene (pKII-mdh), don't appear to have any better activity than those cultures that have only a chromosomally encoded $m d h$ gene. The plasmid pKII-mdh has the $m d h$ gene under the control of the native promoter and it is likely that placing the $m d h$ under the control of other Thermus promoters will result in higher levels of expression, as well as independence from the effects of the composition of the growth medium. Future experiments are required to examine these and other possibilities to demonstrate the use of T. thermophilus as a host for the high level production of $\mathrm{MDH}$ or some other biotechnology product.

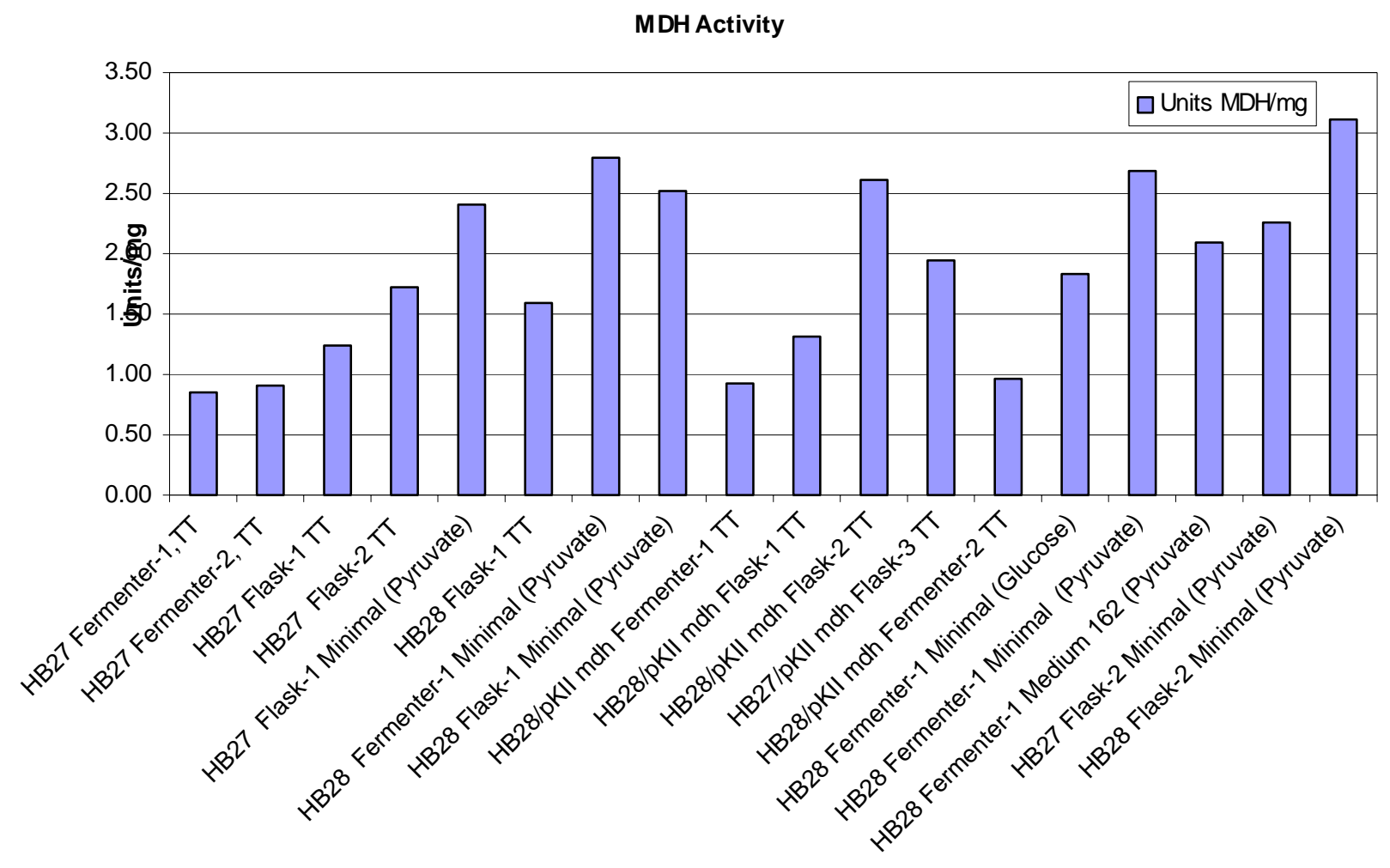

FIGURE 20. MALATE DEHYDROGENASE LEVELS OF VARIOUS T. THERMOPHILUS STRAINS. 
Most bioprocesses use Escherichia coli as a production host because genetic tools and fermentation technology are well developed for this microorganism. The application of thermophilic bacteria in biotechnological processes has several advantages such as, high metabolic activity, low contamination risk, little to no cooling, better solubility of nongaseous components, decreased viscosity, production of thermostable proteins and enzymes, good process stability and treatment performance. Thermus thermophilus grows at temperatures ranging from 48 to $85^{\circ} \mathrm{C}$ and is currently the best studied thermophile for which convenient genetic tools are available, making it the thermophilic host of choice for the production of recombinant DNA products. The potential advantages of using $T$. thermophilus, as a production host in commercial bioprocesses can be realized only after a thorough understanding of the interrelationships between its cell growth and process/environmental conditions is achieved.

Although suitable genetic tools are available for some thermophilic microorganisms, sparse literature is available on growth, interaction, and response of thermophilic microorganisms to environmental parameters. A more detailed investigation of these potentially useful microorganisms is critical for a clear understanding of the strategies developed by these microbes to survive under extreme conditions and to evaluate favorable conditions for optimal growth of these thermophilic microorganisms. The cultivation of microorganisms in high cell density systems can present oxygen limitations, which may be more pronounced when working with thermophiles due to low oxygen solubility at high temperatures. However, the oxygen transfer rate (OTR) from the gas phase into the broth does not change significantly from low to high temperatures, because OTR depends not only on the oxygen solubility but also on the oxygen mass transfer coefficient. Although $\mathrm{O}_{2}$ solubility is lower at higher temperatures than at lower temperatures, the diffusion coefficient for gases in liquid increases with temperature due to decreased viscosity of the medium leading to improved $\mathrm{K}_{\mathrm{L}}$ a values at higher temperatures.

The purpose of this study was to investigate the growth kinetics of Thermus thermophilus HB27 at different aeration and agitation rates at atmospheric pressure to improve cell productivity for the use of this bacterium as a production host in bioprocesses. Aeration is of prime importance in an aerobic fermentation process and the measurement of OTR and $\mathrm{K}_{\mathrm{L}} \mathrm{a}$ are important parameters of aerobic bioreactors. This study reports the effect of various aeration- 
agitation rate combinations on $\mathrm{K}_{\mathrm{L}} \mathrm{a}$ and $\mathrm{OTR}$ as a part of the ultimate goal of optimizing growth rate and cell yield for T. thermophilus.

Thermus thermophilus $\mathrm{HB} 27$ was grown at $65^{\circ} \mathrm{C}$ in 2 liters of TT medium in 3-liter bioreactors. Aeration and agitation rates varied from 0.5 to $2 \mathrm{vvm}$ and 200 to $500 \mathrm{rpm}$ respectively. The fermentor run conditions, volumetric mass transfer coefficients, oxygen transfer rates, and bacterial growth results are summarized in Table 14. The oxygen transfer rate (OTR) from the gas phase into the broth was calculated for each combination of aeration and agitation. Saturated solubility of oxygen at $65^{\circ} \mathrm{C}$ in broth was assumed to be equal to the saturation value of oxygen in water. The $\mathrm{C}^{*}$ values were not corrected for the presence of salt $(0.2 \% \mathrm{NaCl})$ since it is well below the $4 \%$ limit above which it can alter the $\mathrm{K}_{\mathrm{L}} \mathrm{a}$ values.

Table14. The oxygen transfer rate, maximum growth rate, doubling time, and maximum cell yields of $T$. thermophilus $\mathrm{HB} 27$ at different aeration and agitation rates

\begin{tabular}{|c|c|c|c|c|c|c|}
\hline $\begin{array}{l}\text { Aeration } \\
\text { (vvm) }\end{array}$ & $\begin{array}{l}\text { Agitation } \\
\text { (rev/min) }\end{array}$ & $\begin{array}{l}\mathrm{K}_{\mathrm{L}} \mathrm{a} \\
\left(\mathrm{h}^{-1}\right)\end{array}$ & $\begin{array}{l}\text { OTR } \\
(\mathrm{mol} \\
\left.\mathrm{m}^{-3} \mathrm{~h}^{-1}\right)\end{array}$ & $\begin{array}{l}\mu_{\max } \\
\left(\mathrm{hr}^{-1}\right)\end{array}$ & $\begin{array}{l}\mathrm{t}_{\mathrm{D}} \\
(\mathrm{hr})\end{array}$ & $\begin{array}{l}\text { Dry Cell } \\
\text { Weight } \\
(\mathrm{g} / \mathrm{L})\end{array}$ \\
\hline 0.5 & 200 & 15.9 & 2.9 & 0.276 & 2.52 & 1.35 \\
\hline 0.5 & 300 & 37.9 & 6.9 & 0.299 & 2.32 & 1.81 \\
\hline 0.75 & 200 & 22.9 & 4.1 & 0.302 & 2.30 & 1.64 \\
\hline 0.75 & 300 & 45.9 & 8.3 & 0.168 & 4.13 & 1.98 \\
\hline 1.0 & 200 & 27.0 & 4.9 & 0.342 & 2.03 & 1.79 \\
\hline 1.0 & 300 & 57.8 & 10.4 & 0.504 & 1.38 & 2.33 \\
\hline 2.0 & 500 & 175.4 & 31.7 & 0.265 & 2.62 & 3.0 \\
\hline
\end{tabular}


We have experimentally determined $\mathrm{K}_{\mathrm{L}}$ a values in bioreactors as a function of agitation rate and aeration rate. $\mathrm{K}_{\mathrm{L}} \mathrm{a}$, and hence $\mathrm{OTR}$, increases as the agitation and aeration rates increase. Our results confirm previous observations that agitation has a stronger effect on $\mathrm{K}_{\mathrm{L}} \mathrm{a}$ and hence OTR compared to aeration. At a given aeration rate, agitation had a pronounced and consistent effect on the oxygen uptake rate such that increasing the agitation speed from 200 to $300 \mathrm{rpm}$ resulted in increased OTR's of about 2-fold. $\mathrm{K}_{\mathrm{L}} \mathrm{a}$ and OTR values were also reported by Belo et al. 2000 for fermentation experiments involving thermophiles. They found that at 200 rpm and $1 \mathrm{vvm}$ aeration rate in a $2 \mathrm{~L}$ reactor under batch cultivation a $\mathrm{K}_{\mathrm{L}} \mathrm{a}$ of $26 \mathrm{~h}^{-1}$ and an OTR of $3 \mathrm{~mol} \mathrm{~m}^{-3} \mathrm{~h}^{-1}$ were observed. At the same conditions of agitation and aeration, we obtained a $\mathrm{K}_{\mathrm{L}} \mathrm{a}$ and an OTR of $27 \mathrm{~h}^{-1}$ and $4.9 \mathrm{~mol} \mathrm{~m}^{-3} \mathrm{~h}^{-1}$ respectively in our bioreactor setup.

The actual dissolved oxygen levels recorded during the course of these fermentations are illustrated in Figure 21 which makes it clear that oxygen limitation was experienced by each of these fermentation conditions with the exception of fermentations operated at $2 \mathrm{vvm}$ and 500 rpm. The growth rates, as reflected either by the maximum specific growth rate or minimum cell doubling time recorded in Table 14, show that cell growth rates generally increase with increased oxygen transfer rates. An $8 \%$ increase in maximum specific growth rate $\left(\mu_{\max }\right)$ was observed when agitation was increased from $200 \mathrm{rpm}$ to $300 \mathrm{rpm}$ at $0.5 \mathrm{vvm}$ aeration as compared to a $47 \%$ increase at $1 \mathrm{vvm}$ aeration and the same increase in agitation. A $24 \%$ improvement in $\mu_{\max }$ was observed when aeration was increased from 0.5 to $1 \mathrm{vvm}$ at a constant agitation of $200 \mathrm{rpm}$ while a $68 \%$ increase in $\mu_{\max }$ was observed at $300 \mathrm{rpm}$ when aeration was increased from 0.5 to 1 vvm. About $15 \%$ increase in $\mu_{\max }$ was observed when the aeration rate was changed from 0.75 vvm to $1 \mathrm{vvm}$ at 200 .

The fermentation performed at $0.75 \mathrm{vvm}-300 \mathrm{rpm}$ had a shorter lag phase than most of the other fermentations and grew faster initially, but never achieved a maximum growth rate as fast as the other fermentation runs. In fact the fermentation performed at $0.75 \mathrm{vvm}-300 \mathrm{rpm}$ yielded a minimum cell doubling time of 4.13 hours, whereas the minimum cell doubling times for most of the other fermentations ranged from 2 to 2.5 hours. A possible explanation for the slow growth rate of this culture may at least in part be due to a nutrient limitation inherent in these experiments. An inspection of Figure 22 indicates that growth limitations are observed in all fermentations within a few hours. The period during which logarithmic growth is observed in 
any of these fermentations is only a matter of about 4 hours. While the fermentor operated at $0.75 \mathrm{vvm}-300 \mathrm{rpm}$ had the slowest growth rate it resulted in one of the highest cell yields, suggesting that slower growth may be beneficial for obtaining high cell yields, as has been demonstrated for E. coli fermentations[22]. However, looking at the data in Table 1 and Figure 2 there is no clear trend indicating that slower maximum growth rates correlate with higher cell yields. A good correlation between OTR and cell yield is observed, although higher OTR did not always result in faster cell growth rates.

\section{FIGURE 21. DISSOLVED OXYGEN LEVELS OF T. THERMOPHILUS HB27 CULTURES AT VARIOUS AERATION AND AGITATION RATES}

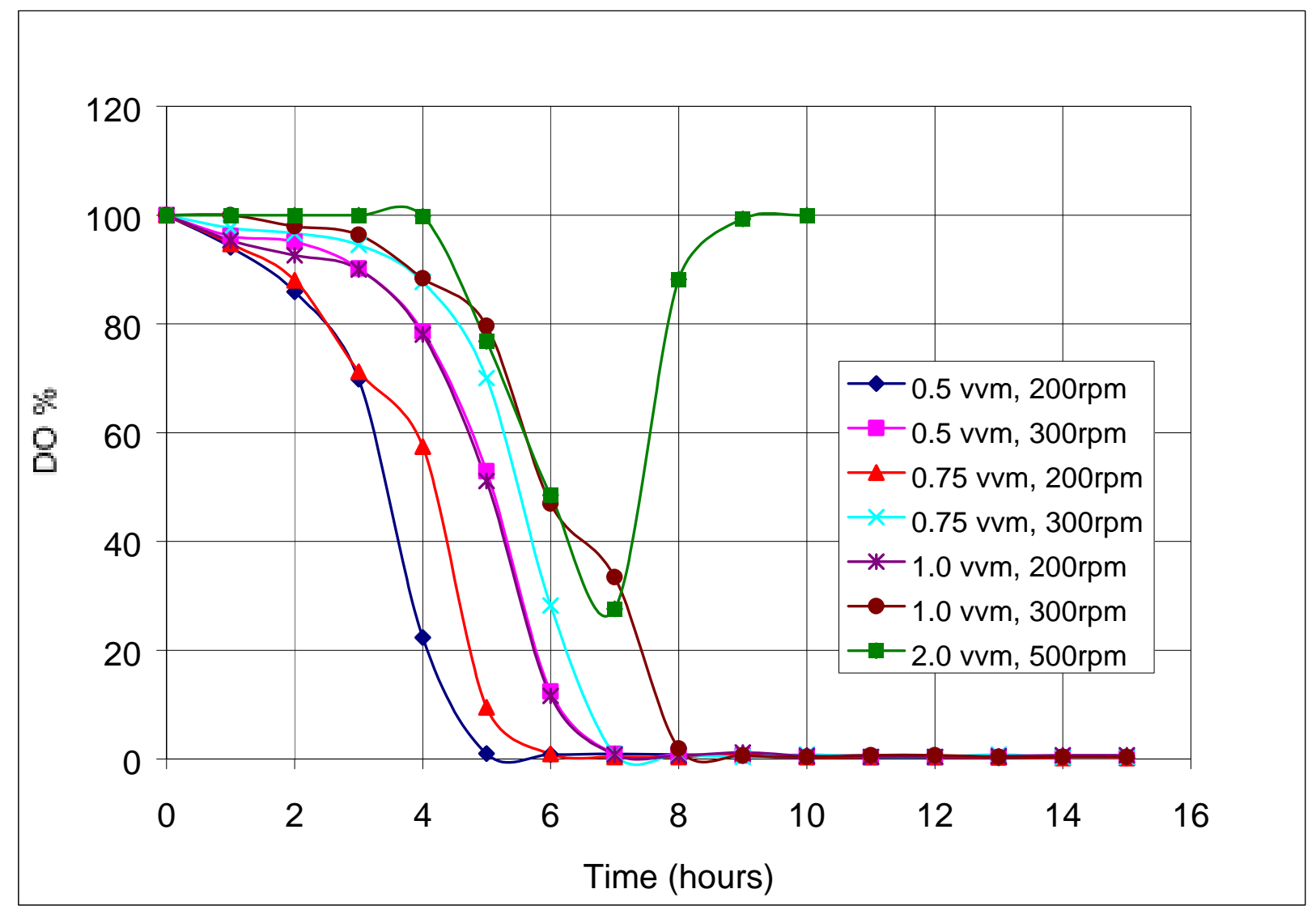




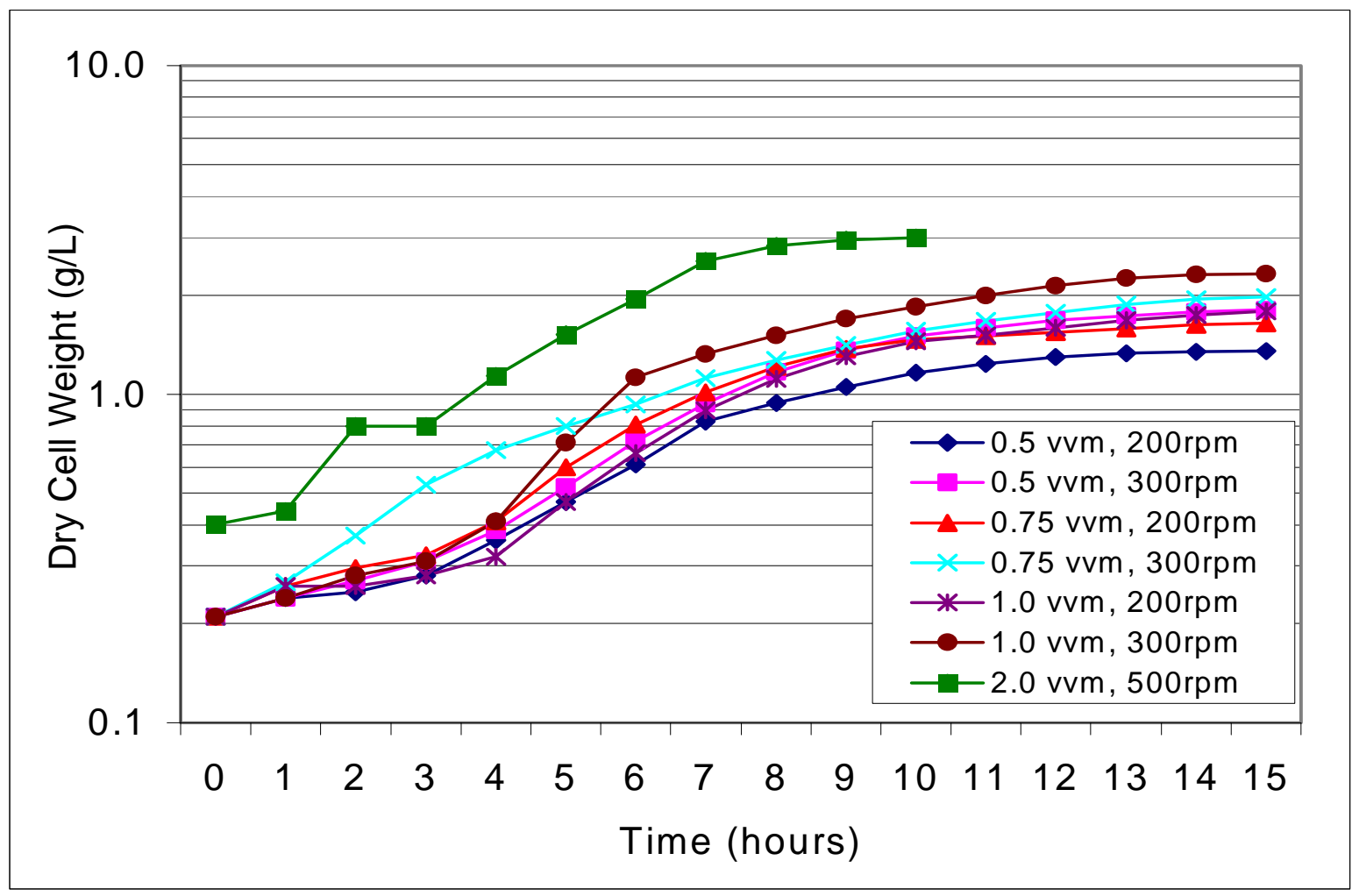

While the fermentation performed at $2 \mathrm{vvm}-500 \mathrm{rpm}$ yielded the highest OTR and the highest cell yield, this condition yielded the second slowest maximum cell growth rate observed. This slower cell growth rate could be due to oxygen toxicity. Oxygen is necessary for the growth of aerobic cultures, but high aeration rates, particularly employing pure oxygen as was the case here, can damage cells. Thermophiles, including T. thermophilus, possess oxygen inducible defense systems in the form of catalase, peroxidase, and superoxide dismutase activity to combat oxygen toxicity. Other investigators have observed that increased growth rates can be achieved by adapting a culture to high aeration conditions. Even though OTR correlates with cell yield, the highest cell yield was obtained from a fermentation that had a higher inoculum level than the other fermentations. Future experiments will be required to determine the specific effects of OTR versus inoculum size on cell yield of T. thermophilus. However, the results of 
shake flask experiments employing T. thermophilus HB27 in TT medium (data not shown) indicate that inoculum size from 0.1 to $10 \%$ does not effect the cell yeild.

Another alternative to obtain higher OTR is to increase the driving force for oxygen transfer, which is done by pressurizing the reactor. A two-fold increase in cell mass productivity from about 0.5 to $1.1 \mathrm{~g}$ dry weight/L was obtained with the use of hyperbaric air $(0.5 \mathrm{MPa})$ using Thermus sp. RQ-1 in batch cultures at $70^{\circ} \mathrm{C}$. In related studies Thermococcus peptonophilus showed maximal growth rates at elevated pressures (30 to $45 \mathrm{MPa})$ and the optimum temperature shifted from $85^{\circ} \mathrm{C}$ at $30 \mathrm{MPa}$ to $90-95^{\circ} \mathrm{C}$ at $45 \mathrm{MPa}$. In these high pressure-high temperature experiments the maximum cell yield of $T$. peptonophilus reached was less than $10^{9}$ cells $/ \mathrm{mL}$. The data presented here demonstrate that minimum cell doubling times of about $1.4 \mathrm{hr}$ and cell yields of $3 \mathrm{~g} / \mathrm{L}$ can be achieved using T. thermophilus HB27 in ATCC medium 697 at $65^{\circ} \mathrm{C}$. To our knowledge, this is higher than any cell yield previously reported for the batch fermentation of a Thermus species.

It is highly likely that further improvements in cell yield and growth rate can be obtained by using cultures adapted to high aeration conditions, higher carbon-nutrient levels, different inoculum levels, different temperatures, and combinations of these variables. The particular strain of bacteria used can also have a profound effect on growth rates and cell yields obtained with a given bacterial species under identical fermentation conditions. It should also be kept in mind that these experiments were performed under batch conditions using a non-optimized growth medium. Commercial fermentations typically employ fed-batch or other high cell density cultivation techniques and medium optimized for the growth of a particular culture.

The fastest possible growth rates and the highest cell and product yields will be needed if T. thermophilus is to be used as a production host in a bioprocess. Escherichia coli is currently the most commonly used production host for bioprocesses. While high cell density culture techniques can achieve over $150 \mathrm{~g}$ DCW/L in fed-batch mode, when E. coli was grown in batch cultures under conditions similar to the experiments reported here, yields of about 5-10 $\mathrm{g}$ DCW/L were obtained. This shows that further studies with process/culture conditions and reactor/feeding strategies can lead to a high-density culture system of $T$. thermophilus. 


\section{CONCLUSIONS}

The project was completed on schedule. Significant progress was made in three major research topics: isolation of biocatalysts to selectively cleave $\mathrm{C}-\mathrm{N}$ or $\mathrm{C}-\mathrm{S}$ bonds, genetic manipulation of $T$. thermophilus, and optimization of the growth of T. thermophilus. While several bacterial cultures were isolated that were capable of selectively cleaving C-N or C-S bonds, and removing nitrogen or sulfur from petroleum, improved biocatalysts are still needed. In particular, biocatalysts that possess a broader substrate range allowing the cleavage of $\mathrm{C}-\mathrm{N}$ or $\mathrm{C}-\mathrm{S}$ bonds in the wide variety of chemical structures present in petroleum are needed, as well as biocatalysts that have higher specific activity so that smaller amounts of biocatalysts are capable of treating greater quantities of petroleum. Sphingomonas strain GTIN11 is a unique carbazole degrading culture isolated in this project. The ability of Sphingomonas sp. GTIN11 to remove as much as $95 \%$ carbazole from oil was demonstrated. This is the first report of the removal of carbazole from an oil sample using a biocatalyst, and it demonstrates the appropriateness of this culture to aid in the development of a petroleum biorefining process. However, the lack of activity on a wider range of chemical structures indicates that improved cultures are needed. Similarly the thermophilic culture Mycobacterium phlei GTIS10 was isolated and shown to be capable of selectively cleaving C-S bonds in dibenzothiophene at temperatures as high as $57^{\circ} \mathrm{C}$. While Mycobacterium phlei GTIS10 displays higher levels of desulfurization activity at higher temperatures than previously reported desulfurization cultures improvements are still needed. In particular biodesulfurization biocatalysts that have high specific activities at temperatures of $65^{\circ} \mathrm{C}$ to $100^{\circ} \mathrm{C}$ would be preferred for the development of a biorefining process aimed at the treatment of heavy crude oil.

Genetic experiments succeeded in developing plasmid and integrative vectors for gene expression studies in $T$. thermophilus. Several convenient promoter probe and gene expression vectors were developed and used in this project demonstrating that one can now do genetic manipulation of T. thermophilus with almost the same convenience as for Escherichia coli. The $m d h$ gene of $T$. thermophilus was demonstrated to be a useful reporter gene for the quantitative study of gene expression in T. thermophilus. Additionally, the functional expression of the $d s z C$ gene from Mycobacterium phlei GTIS10 in T. thermophilus is the first demonstration of the 
expression of a cofactor-requiring heterologous gene in $T$. thermophilus. The genes encoding the carbazole-degradation trait of Sphingomonas sp. GTIN11 were cloned and sequenced. These data will allow a thorough comparison of the relatedness of carbazole-degradation genes from Sphingomonas sp. GTIN11 with all previously reported bacterial gene sequences, and will facilitate the further genetic manipulation of this metabolic pathway to achieve selective $\mathrm{C}-\mathrm{N}$ bond cleavage in a broad range of substrates.

Growth experiments with T. thermophilus succeeded in defining the composition of defined mineral salts medium and choice of carbon source that resulted in the best growth. Moreover, the effect of aeration and agitation were examined for $T$. thermophilus growing in rich medium in batch laboratory-scale fermentation experiments. These experiments resulting in biomass yields that were higher than any reported in the literature. Future research is recommended to explore the growth of $T$. thermophilus under fed-batch fermentation and to determine the optimum yield of cloned gene products that can be obtained in fermentations using T. thermophilus.

Taken altogether then, the results reported in this project significantly contributed to the development of future high temperature bioprocesses, particularly biorefining processes. Significant data obtained in this project has been used to prepare several publications in refereed journals.

"Isolation and Characterization of a Carbazole Degrading Bacterium Sphingomonas sp. GTIN11", J. J. Kilbane II, A. Daram, J. Abbasian, and K. J. Kayser, Submitted to Applied \& Environmental Microbiology.

"Effect of Aeration and Agitation on the Growth rate of Thermus thermophilus in Batch Mode," M. U. Demiritas, A. Kolhatkar, and J. J. Kilbane II, J. Biotechnology \& Bioengineering, In Press.

"Cloning and Expression of the Dibenzothiophene Monooxygenase Gene $(d s z C)$ in Thermus thermophilus HB27” Park, H.-S., K. J. Kayser and J. J. Kilbane II, submitted to J. Bacteriol.

"Isolation and Characterization of a Moderate Thermophile, Mycobacterium phlei GTIS10, Capable of Dibenzothiophene Desulfurization.” K. J. Kayser, L. Cleveland, H.-S. Park, J.-H. Kwak, A. Kolhatkar, and J. J. Kilbane II. Applied Microbiology \& Biotechnology, In Press. 
“A New Host/Vector System for Thermus sp. Based on the Malate Dehydrogenase Gene." Kayser, K. J., and J. J. Kilbane II, J. Bacteriology 183: 1792-1795 (2001).

"Inducible and Constitutive Expression Using New Plasmid and Integrative Expression Vectors for Thermus sp." Kayser, K. J., J. H. Kwak, H. S. Park, and J. J. Kilbane II. Letters in Applied Microbiology 32: 1-7 (2001).

"Selective Removal of Nitrogen from Quinoline and Petroleum by Pseudomonas ayucida IGTN9m," J. J. Kilbane, R. Ranganathan, K. J. Kayser, L. Cleveland, C. Ribiero and M. M. Linhares, Appl. Environ. Microbiol. 66: 688-693 (2000). 


\section{REFERENCES}

Wiegel, J., and Ljungdahl, L. G., The importance of thermophilic bacteria in biotechnology. Critical Reviews in Biotechnology. 3: 39-107 (1985).

Stover, E.L., Thermophilic treatment process is an alternative to mesophilic treatment for highstrength industrial waste residuals. Industrial Wastewater. 8(2): 31-34 (2000).

Kayser, K.J., Kwak, J.H., Park, H.S., and Kilbane II, J.J., Inducible and constitutive expression using new plasmid and integrative expression vectors for Thermus sp. Lett Appl Microbiol. 32(6): 412-8 (2001).

Kayser, K.J. and Kilbane II, J.J., New host-vector system for Thermus spp. based on the malate dehydrogenase gene. J Bacteriol. 183(5): 1792-5 (2001).

Koyama, Y., Hoshino, T., Tomizuka, N., and Furukawa, K., Genetic transformation of the extreme thermophile Thermus thermophilus and of other Thermus spp. J Bacteriol. 166(1): 338-40 (1986).

Mather, M.W. and Fee, J.A., Development of plasmid cloning vectors for Thermus thermophilus HB8: expression of a heterologous, plasmid-borne kanamycin nucleotidyltransferase gene. Appl Environ Microbiol. 58(1): 421-5 (1992).

Quandt, J. and Hynes, M.F., Versatile suicide vectors which allow direct selection for gene replacement in gram-negative bacteria. Gene. 127(1): 15-21 (1993).

Stanbury, P.E., and Whitaker, A., Principles of Fermentation Technology. Pergamon Press, Oxford. 181-182 (1984).

Belo, I., Pinheiro, R., and Mota, M., Response of the thermophile Thermus sp. RQ-1 to hyperbaric air in batch and fed-batch cultivation. Appl Microbiol Biotechnol. 53(5): 51724 (2000).

Boeck, B. and Schinzel, R., Growth dependence of alpha-glucan phosphorylase activity in Thermus thermophilus. Res Microbiol. 149(3): 171-6 (1998).

Heinen, W., Klein, H.P., and Volkmann, C.M., Fatty acid composition of Thermus aquaticus at different growth temperatures. Arch Mikrobiol. 72(2): 199-202 (1970).

Krahe, M., Antranikian, G., and Markl, H., Fermentation of extremophilic microorganisms. FEMS Microbiological Reviews. 18: 271-285 (1996).

Lechler, A., Keller, B., Hennecke, H., and Kreutzer, R., Overproduction of phenylalanyltRNA synthetase from Thermus thermophilus HB8 in Escherichia coli. Protein Expr Purif. 8(3): 347-57 (1996).

Loginova, L.G. and Khraptsova, G.I., [Influence of carbon sources on the development of Thermus ruber at different temperatures]. Mikrobiologiia. 46(1): 38-40 (1977).

MacMichael, G.J., Effects of oxygen and methyl viologen on Thermus aquaticus. J Bacteriol. 170(10): 4995-8 (1988).

Pham, P.L., Strehaiano, P. and Taillandier, P., Effect of aeration on xylanase production by Bacillus sp. I-1018. Bioprocess Engineering. 18: 41-43 (1998).

Stramer, S.L. and Starzyk, M.J., Improved growth of Thermus aquaticus on cellular lysates. Microbios. 23(93-94): 193-8 (1978).

Rainer, B.W., Oxygen transfer in bioreactors. Chemical and Biochemical Engineering. 4: 185196 (1990).

Bailey, J.E., and Ollis, D. F., Biochemical Engineering Fundamentals, 2nd edition. McGrawHill. pp. 463-472 (1986). 
Atkinson, B., and Mavituna, F., Biochemical Engineering and Biotechnology Handbook: 2nd edition, M. Stockton press (1991).

Gevantman, L.H., Solubility of Selected Gases in Water, in CRC Handbook of Chemistry and Physics, Lide, D.R., Editor. p. 86-87 (1999).

Eppstein, L., Shevitz, J., Yang, X.-M., and Weiss, S., Increased biomass production in a benchtop fermentor. Biotechnology. 7: 1178-1181 (1989).

Toma, M.K., Ruklisha, M. P., Vanags, J. J., Zeltina, M. O., Leite, M. P., Galonina, N. I., Viesturs, U. E., and Tendergy, R. P., Inhibition of microbial growth and metabolism by excess turbulence. Biotechnology and Bioengineering. 38: 552-556 (1991).

Canganella, F., Gonzalez, J.M., Yanagibayashi, M., Kato, C., and Horikoshi, K., Pressure and temperature effects on growth and viability of the hyperthermophilic archaeon Thermococcus peptonophilus. Arch Microbiol. 168(1): 1-7 (1997).

Janssen, P.H., Peek, K., and Morgan, H. W., Effect of culture conditions on the production of an extracellular proteinase by Thermus sp. Rt41A. Applied Microbiology and Biotechnology. 41: 400-406 (1994).

Cometta, S., Sonnleitner, B., and Fiechter, A., The growth behavior of Thermus aquaticus in continuous cultivation. Applied Microbiology and Biotechnology. 15: 69-74 (1982).

Altintas, M.M., and Ulgen, K. O., Growth of Thermus aquaticus and its Taq1 endonuclease production. Acta Biotechnology. 19: 45-56 (1999).

Tenreiro, S., Nobre, M.F., and da Costa, M.S., Thermus silvanus sp. nov. and Thermus chliarophilus sp. nov., two new species related to thermus ruber but with lower growth temperatures. Int J Syst Bacteriol. 45(4): 633-9 (1995).

Marteinsson, V.T., Birrien, J.L., Raguenes, G., da Costa, M.S., and Prieur, D., Isolation and characterization of Thermus thermophilus Gy1211 from a deep-sea hydrothermal vent. Extremophiles. 3(4): 247-51 (1999).

Lyon, P.F., Beffa, T., Blanc, M., Auling, G., and Aragno, M., Isolation and characterization of highly thermophilic xylanolytic Thermus thermophilus strains from hot composts. Can J Microbiol. 46(11): 1029-35 (2000).

Chung, A.P., Rainey, F.A., Valente, M., Nobre, M.F., and da Costa, M.S., Thermus igniterrae sp. nov. and Thermus antranikianii sp. nov., two new species from Iceland. Int J Syst Evol Microbiol. 50 Pt 1: 209-17 (2000).

Beffa, T., Blanc, M., Lyon, P.F., Vogt, G., Marchiani, M., Fischer, J.L., and Aragno, M., Isolation of Thermus strains from hot composts (60 to 80 degrees C). Appl Environ Microbiol. 62(5): 1723-7 (1996).

Lee, S.Y., High cell-density culture of Escherichia coli. Trends Biotechnol. 14(3): 98-105 (1996).

Kennedy, M., and Krouse, D., Strategies for improving fermentation medium performance: a review. Journal of Industrial Microbiology and Biotechnology. 23: 456-475 (1999).

Luli, G.W. and Strohl, W.R., Comparison of growth, acetate production, and acetate inhibition of Escherichia coli strains in batch and fed-batch fermentations. Appl Environ Microbiol. 56(4): 1004-11 (1990).

Sato, S. I., J. W. Nam, K. Kasuga, H. Nojiri, H. Yamane, and T. Omori. 1997. Identification and characterization of genes encoding carbazole 1,9a- dioxygenase in Pseudomonas sp. strain CA10. J Bacteriol 179(15):4850-8. 
Sato, S. I., N. Ouchiyama, T. Kimura, H. Nojiri, H. Yamane, and T. Omori. 1997. Cloning of genes involved in carbazole degradation of Pseudomonas sp. strain CA10: nucleotide sequences of genes and characterization of meta- cleavage enzymes and hydrolase. $\mathrm{J}$ Bacteriol 179(15):4841-9.

Shepard, J. M., and G. Lloyd-Jones. 1998. Novel carbazole degradation genes of Shingomonas CB3: Sequence analysis, transcription, and molecular ecology. Biochem. Biophys. Res. Com. 247:129-135.

Schneider, J., R. J. Grosser, K. Jayasimhulu, W. Xue, B. Kinkle, and D. Warshawsky. 2000. Biodegradation of carbazole by Ralstonia sp. RJGII.123 isolated from a hydrocarbon contaminated soil. Can J Microbiol 46(3):269-77.

Denis-Larose, C., Bergeron, H., Labbe, D., Greer, C.W., Hawari, J., Grossman, M.J., Sankey, B.M., and Lau, P.C., Characterization of the basic replicon of Rhodococcus plasmid pSOX and development of a Rhodococcus-Escherichia coli shuttle vector. Appl Environ Microbiol. 64(11): 4363-7 (1998).

Denome, S.A., Oldfield, C., Nash, L.J., and Young, K.D., Characterization of the desulfurization genes from Rhodococcus sp. strain IGTS8. J Bacteriol. 176(21): 6707-16 (1994).

Gray, K.A., Pogrebinsky, O.S., Mrachko, G.T., Xi, L., Monticello, D.J., and Squires, C.H., Molecular mechanisms of biocatalytic desulfurization of fossil fuels. Nat Biotechnol. 14(13): 1705-9 (1996).

Kayser, K., Cleveland, L., Park, H., Kwak, J., and Kilbane II, J., Isolation and characterization of a moderate thermophilic bacterium capable of dibenzothiophene desulfurization. Manuscript in preparation.: (2000).

Reichmuth, D.S., H., H., Blanch, H.W., and Keasling, J.D., Biodesulfurization of dibenzothiophene in Escherichia coli is enhanced by expression of a Vibrio harveyi oxidoreductase gene. Biotechnol. Bioeng. 67(1): 72-78 (2000).

Brock, T. D. and H. Freeze (1969). “Thermus aquaticus gen. n. and sp. n., a nonsporulating extreme thermophile." J Bacteriol 98(1): 289-97.

Hidaka, Y., M. Hasegawa, et al. (1994). "The entire population of Thermus thermophilus cells is always competent at any growth phase." Biosci Biotechnol Biochem 58(7): 1338-9.

Horinouchi, S., M. Nishiyama, et al. (1987). "Construction and characterization of multicopy expression-vectors in Streptomyces spp." Mol Gen Genet 210(3): 468-75.

Koyama, Y., Y. Arikawa, et al. (1990). "A plasmid vector for an extreme thermophile, Thermus thermophilus.” FEMS Microbiol Lett 60(1-2): 97-101.

Koyama, Y., S. Okamoto, et al. (1990). "Cloning of alpha- and beta-galactosidase genes from an extreme thermophile, Thermus strain T2, and their expression in Thermus thermophilus HB27." Appl Environ Microbiol 56(7): 2251-4. 
Lasa, I., M. de Grado, et al. (1992). "Development of Thermus-Escherichia shuttle vectors and their use for expression of the Clostridium thermocellum celA gene in Thermus thermophilus." J Bacteriol 174(20): 6424-31.

Maseda, H. and T. Hoshino (1995). "Screening and analysis of DNA fragments that show promoter activities in Thermus thermophilus.” FEMS Microbiol Lett 128(2): 127-34.

Mather, M. W. and J. A. Fee (1992). "Development of plasmid cloning vectors for Thermus thermophilus HB8: expression of a heterologous, plasmid-borne kanamycin nucleotidyltransferase gene.” Appl Environ Microbiol 58(1): 421-5.

Osipiuk, J. and A. Joachimiak (1997). "Cloning, sequencing, and expression of dnaK-operon proteins from the thermophilic bacterium Thermus thermophilus." Biochim Biophys Acta 1353(3): 253-65.

Raven, N. D. H. (1995). Genetics of Thermus. Thermus Species., Williams. New York, Plenum Press.

Tamakoshi, M., M. Uchida, et al. (1997). “A new Thermus-Escherichia coli shuttle integration vector system.” J Bacteriol 179(15): 4811-4.

Wayne, J. and S. Y. Xu (1997). "Identification of a thermophilic plasmid origin and its cloning within a new Thermus-E. coli shuttle vector.” Gene 195(2): 321-8.

Weber, J. M., S. P. Johnson, et al. (1995). "A chromosome integration system for stable gene transfer into Thermus flavus." Biotechnology (N Y) 13(3): 271-5. 